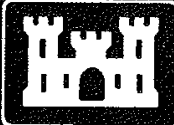

Technical Report HL-94-14

September 1994

US Army Corps

of Engineers

Waterways Experiment

Station

\title{
Claremont Terminal Channel, New York Harbor
}

by Randy A. McCollum, Barbara P. Donnell

Approved For Public Release; Distribution Is Unlimited 
The contents of this report are not to be used for advertising, publication, or promotional purposes. Citation of trade names does not constitute an official endorsement or approval of the use of such commercial products. 


\section{Claremont Terminal Channel, New York Harbor}

by Randy A. McCollum, Barbara P. Donnell

U.S. Army Corps of Engineers

Waterways Experiment Station

3909 Halls Ferry Road

Vicksburg, MS 39180-6199

Final report

Approved for public release; distribution is unlimited 


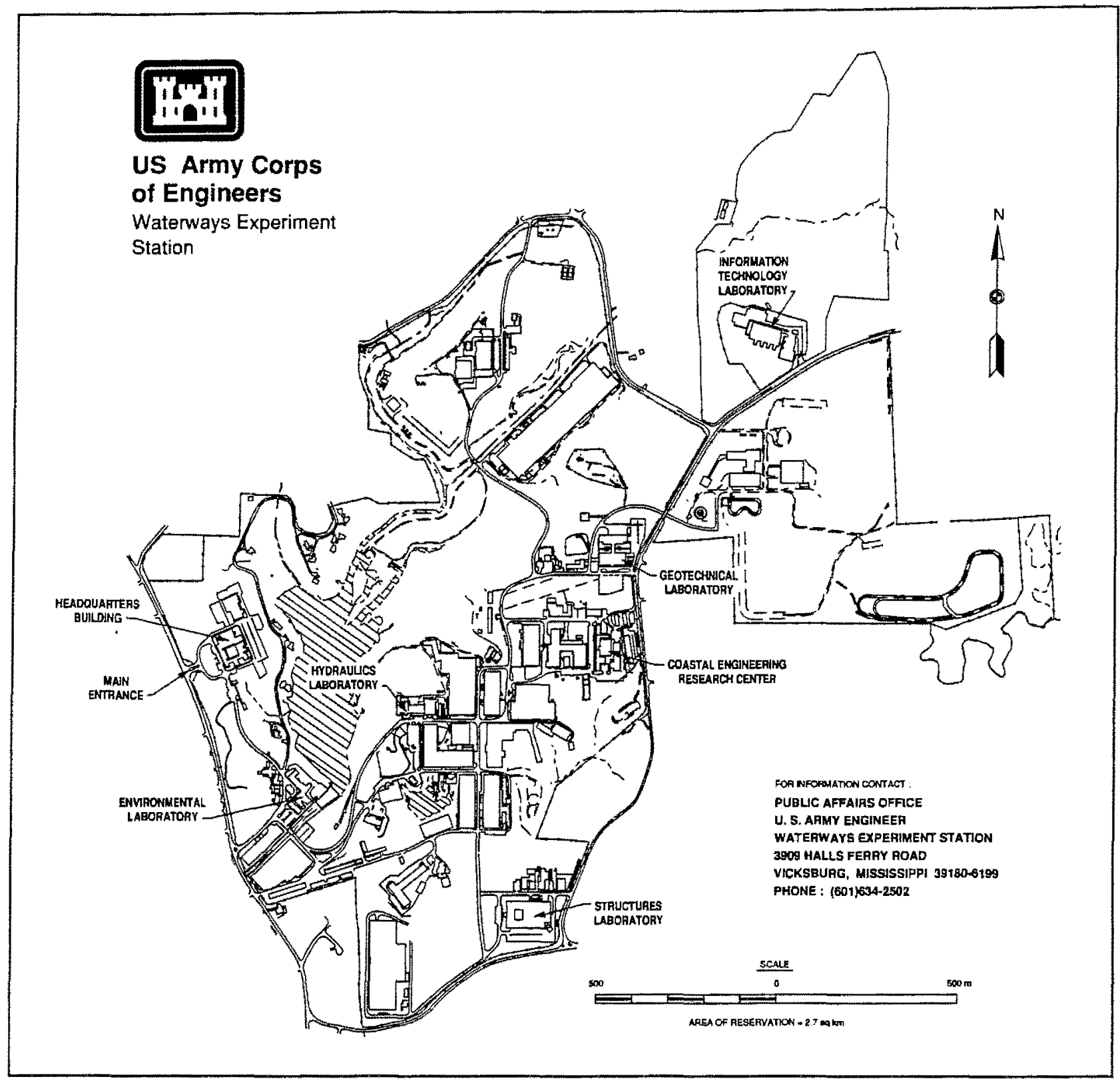

\section{Waterways Experiment Station Cataloging-in-Publication Data}

McCollum, Randy A.

Claremont Terminal Channel, New York Harbor / by Randy A.

McCollum, Barbara P. Donnell ; prepared for U.S. Army Engineer District, New York.

145 p. : ill. ; $28 \mathrm{~cm}$. - (Technical report ; HL-94-14)

Includes bibliographic references.

1. Navigation - Atlantic Coast (N.J.) - Simulation methods. 2. Channels (Hydraulic engineering) - New Jersey - Jersey City - Design and construction - Evaluation. 3. Claremont Terminal Channel (N.J.) - Design and construction - Evaluation. 4. Harbors - New York (N.Y.) - Hydro dynamics - Computer simulation. I. Donnell, Barbara P. II. United States. Army. Corps of Engineers. New York District. III. U.S. Army Engineer Waterways Experiment Station. IV. Hydraulics Laboratory (U.S.) V. Title. VI. Series: Technical report (U.S. Army Engineer Waterways Experiment Station); HL-94-14. 


\section{Contents}

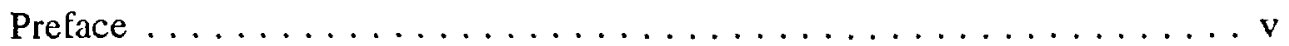

Conversion Factors, Non-SI to SI Units of Measurement $\ldots \ldots \ldots \ldots$ vi

1 -Introduction $\ldots \ldots \ldots \ldots \ldots \ldots \ldots \ldots \ldots \ldots \ldots \ldots$

Proposed Channel Improvements . . . . . . . . . . . . . . 1

Purpose and Scope of Investigation $\ldots \ldots \ldots \ldots \ldots \ldots \ldots$

2-Data Development $\ldots \ldots \ldots \ldots \ldots \ldots \ldots \ldots \ldots \ldots \ldots \ldots$

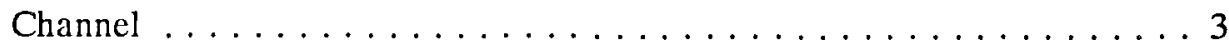

Visual Scene ........................ 4

Radar . . . . . . . . . . . . . . . . . . . . . . 5

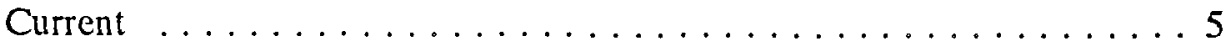

Test Ship . . .....................

Wind ......................... 6

Tug Boats $\ldots \ldots \ldots \ldots \ldots \ldots \ldots \ldots \ldots \ldots \ldots \ldots \ldots \ldots \ldots \ldots$

$3-$ Navigation Study $\ldots \ldots \ldots \ldots \ldots \ldots \ldots \ldots \ldots \ldots \ldots$

Validation $\ldots \ldots \ldots \ldots \ldots \ldots \ldots \ldots \ldots \ldots \ldots \ldots$

Test Conditions . . . . . . . . . . . . . . . 9

4 -Study Results . . . . . . . . . . . . . . . . . . 12

Pilot Evaluations . . . . . . . . . . . . . . . . . . 12

Inbound, flood tide . . . . . . . . . . . . . . . . . 12

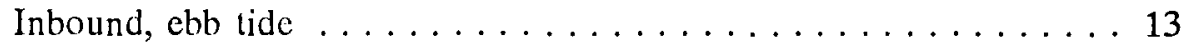

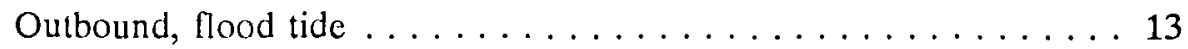

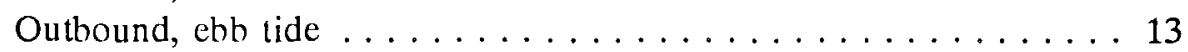

Summary ......................... 14

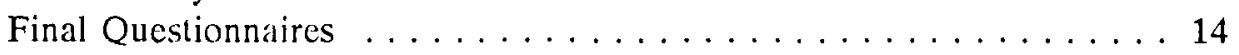

Navigation Parameter Plots . . . . . . . . . . . . . . 17

Ship speed and engine RPM $\ldots \ldots \ldots \ldots \ldots \ldots \ldots \ldots \ldots$

Minimum clearance distances and rudder position $\ldots \ldots \ldots \ldots 20$

Summary . . . . . . . . . . . . . . . . . . . . . 23

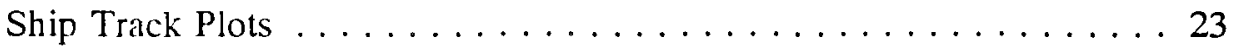

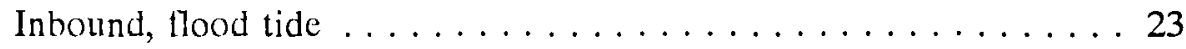

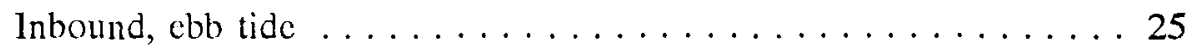




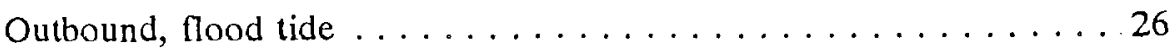

Outbound, ebb tide ...................... 27

5-Conclusions and Recommendations . . . . . . . . . . . . . . 29

Limitations of the Study . . . . . . . . . . . . . . . . . 29

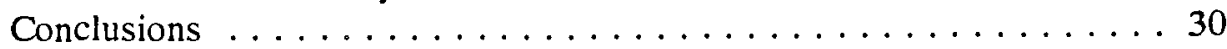

Recommendations ..................... 32

Appendix A: Claremont Channel Ship Simulator

Hydrodynamic Study . . . . . . . . . . . . . A1

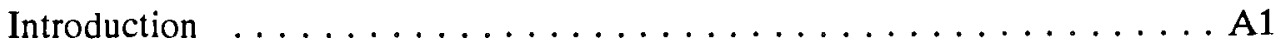

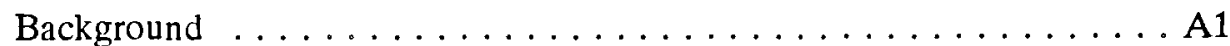

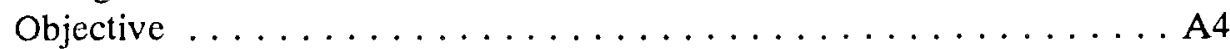

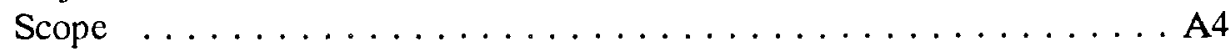

Technical Approach $\ldots \ldots \ldots \ldots \ldots \ldots \ldots \ldots \ldots \ldots$ A4

Hydrodynamic Numerical Modeling $\ldots \ldots \ldots \ldots \ldots \ldots \ldots$

The TABS-MD Modeling System . . . . . . . . . . . A5

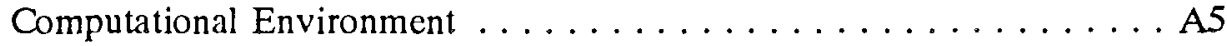

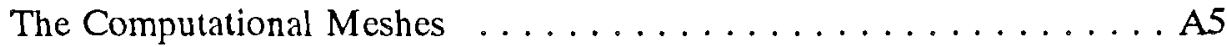

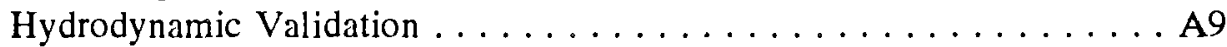

Test of Base Versus Plan Channel Designs . . . . . . . . . . A25

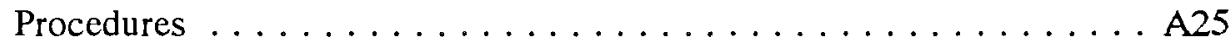

Hydrodynamic Comparisons . . . . . . . . . . . . . A25

Summary and Conclusions $\ldots \ldots \ldots \ldots \ldots \ldots \ldots \ldots \ldots \ldots$

Appendix B: The TABS-MD System $\ldots \ldots \ldots \ldots \ldots \ldots \ldots$ B1

Finite Element Modeling $\ldots \ldots \ldots \ldots \ldots \ldots \ldots \ldots \ldots$

The Hydrodynamic Model, RMA2 ............. B3

The Sediment Transport Model, STUDH . . . . . . . . . B B

The Water Quality Transport Model, RMA4 . . . . . . . . . B14

References . . . . . . . . . . . . . . B17

SF 298 


\section{Preface}

The ship simulator investigation and numerical modeling of hydrodynamic conditions for the Claremont Channel, New York Harbor, New York, Project, as documented in this report were performed for the U.S. Army Engineer District, New York (CENAN).

Mr. Frank Santangelo was the CENAN-PL-CE liaison during the study.

The ship simulator investigation was conducted in the Hydraulics Laboratory (HL) of the U.S. Army Engincer Waterways Experiment Station (WES) from October 1992 to March 1993 under the direction of Messrs. Frank A. Herrmann, Jr., Director, HL; Richard A. Sager, Assistant Director, HL; M. B. Boyd, Chief, Waterways Division (HR) (retired); and Dr. L. L. Daggett, Chief, Navigation Branch (HRN). The study was performed and the report prepared by Mr. R. A. McCollum, Navigation Branch.

Ms. D. C. Derrick (HRN) provided assistance in preparation of the visual scene database.

The hydrodynamic model study was conducted in the HL, WES, from June 1992 to May 1993 under the dircction of Messrs. Herrmann, Sager, William H. McAnally, Jr., Chicf, Estuaries Division (ED), and David R. Richards, Chief, Estuarine Simulation Branch (ESB), ED. The work was performed and the report was prepared by Ms. Barbara Park Donnell, ESB. Mr. Joseph V. Letter, Jr., ED, provided insights pertaining to previous numerical modeling work in New York Harbor. Mr. Ben Brown, Jr., ESB, served as the primary assistant for the mesh development.

At the time of publication of this report, Director of WES was Dr. Robert W. Whalin. Commander was COL Bruce K. Howard, EN.

The contents of this report are not to be used for advertising, publication, or promotional purposes. Citation of trade names does not constitule an official endorsement or approval of the use of such commercial products. 


\section{Conversion Factors, Non-SI to SI Units of Measurement}

Non-SI units of measurement used in this report can be converted to SI units as follows:

\begin{tabular}{||l|l|l|}
\hline Multiply & By & To Obtain \\
\hline \hline cubic feet & 0.02831685 & cubic meters \\
\hline cubic feet per second & 0.02831685 & cubic meters per second \\
\hline feet & 0.3048 & meters \\
\hline feet per second & 0.3048 & meters per second \\
\hline
\end{tabular}




\section{Introduction}

Claremont Terminal Channel is located on the eastern shoreline of the Upper Bay of New York Harbor at Jersey City, New Jersey (Plate 1). The existing deep-water channel varies in available width at a depth of from 25 to $27 \mathrm{ft}$ with a minimum width of approximately $150 \mathrm{ft}$ in some locations from the Claremont Terminal to the intersection with the federally maintained Anchorage Channel.

The typical ship using the port is a Panamax bulk carrier with lengths as great as $760 \mathrm{ft}$, beam of $106 \mathrm{ft}$, typically drafting $16 \mathrm{ft}$ at the bow, $20 \mathrm{ft}$ at the stern in ballast and $30 \mathrm{ft}$, even keel, loaded. The typical operation is to come into the port in ballast, turning off the end of the Caven Point (or sometimes referred to as Ocean Terminal) Pier, in the intersections of the Claremont and Pierhead Channels, with the assistance of two tugs, rated between 3000 and $4000 \mathrm{hp}$, and back into the dock. The ship is loaded to draft $30 \mathrm{ft}$, then the pilot waits for maximum flood tide (the tidal range is $4.7 \mathrm{ft}$ above mean low water, $\mathrm{mlw}$ ) to make their transit out. This allows from less than $1 \mathrm{ft}$ to $1.5 \mathrm{ft}$ underkeel clearance. The export material is mainly scrap metal.

The design draft of the vessel type used in this port is $41 \mathrm{ft}$. Vessels are normally loaded to $36 \mathrm{ft}$ before leaving for their destinations. Due to the channel depth restriction, the vessels loaded at Clarcmont are loaded only to $30 \mathrm{ft}$, then required to go to another port to "top off".

\section{Proposed Channel Improvements}

The proposed channel improvements are for the deep-water channel to become a federally maintained channel, deepened to 34-ft mlw and widened to $300 \mathrm{ft}$. The entrance transition width from the Anchorage Channel is designed to be $1,250 \mathrm{ft}$ with both north and south transitions tapering to the $300-\mathrm{ft}$ Claremont Channel width. The plan proposes to require ships to turn in the Anchorage Channel and back into the Claremont Channel. This requires that tugs of adequate capacity to handle the ballastcd design ship in maximum ebb and flood tide currents be available. 


\section{Purpose and Scope of Investigation}

The purpose of the ship simulator investigation is to develop a safe and optimal navigation channel, including a ship turning area which will accommodate the design vessel. This is accomplished by testing with the existing condition along with proposed channel improvements to determine the relative difficulty and safety of operation for each condition.

The study limits of the Claremont Terminal Channcl simulation were from the Claremont Terminal to the intersection with the Anchorage Channel, then approximately 2 miles of the Anchorage Channel south of the intersection with the Claremont Channel (Plate 1). Approximately 1,000 ft of the Anchorage Channel north of the intersection with the Claremont Channel was modeled to allow for turning maneuvers. The plans tested were:

a. Existing Condition (Platc 2)

b. $300 \mathrm{ft}$ by $34 \mathrm{ft}$, Plan A proposed in the Feasibility Report (Plate 3)

c. $300 \mathrm{ft}$ by $34 \mathrm{ft}$ from Anchorage Channel to Ocean Terminal Pier, $250 \mathrm{ft}$ by $34 \mathrm{ft}$ from Ocean Terminal Picr to Claremont Terminal, Plan B (Plate 4)

Turning maneuvers will be tested off the end of the Ocean Terminal Pier for Plan A and in the Anchorage Channel for Plan B since the plans are identical from the Anchorage Channel up to the end of the pier. 


\section{Data Development}

In order to properly simulate the study area, it is necessary to develop information relative to five types of input data:

a. Channel data base contains dimensions for the existing channel and the proposed channel modifications. It includes the channel cross-sections, bank slope angle, overbank depth, initial conditions, and autopilot trackline and speed definition.

b. Visual scene data base is composed of three-dimensional images of principal features of the simulated area, including the aids to navigation, docks, and buildings.

c. Radar data base contains the features for the plan view of the study area.

d. Ship data file contains characteristics and hydrodynamic coefficients for the test vessels.

e. Current pattern data in the channel including the magnitude and direction of the current and the water depth for each cross section defined in the channel data base.

\section{Channel}

Channel cross sections are used to define the ship simulator channel data base. The information used to develop the channel data base came from the District-furnished hydrographic survey charts dated July 1992. This was the latest information available concerning depths, dimensions, and bank lines of the existing channel. State planar coordinates as shown on the hydrographic survey were used for the definition of the data bases. Prototype survey ranges were generally used to locate the simulator cross sections. If the prototype survey ranges werc not spaced close enough or were not sufficiently oriented, a new range was interpolated.

The ship simulator model uses eight equally spaced points to define each cross section. At each of these points, a depth, current magnitude, and 
direction are required. For each cross section, the width, right and left bank slopes, and overbank depths are required. The channel depth, current magnitude, and direction for each of the eight points was provided by a TABS-2 model (Appendix A).

The channel side slope and overbank depth are used to calculate bank effects on the passing test vessel. The shallower the overbank and the steeper the side slope, the greater the computed bank effects. A small difference (1 to $2 \mathrm{ft}$ ) in channel and overbank depth produces negligible bank forces and moments.

\section{Visual Scene}

The visual scene data was created using information obtained from the National Oceanic and Atmospheric Administration (NOAA) chart number 12334, dated December 1984, the 1992 hydrographic survey, and photographs of the area. As in the devclopment of the channel data base, the state planar coordinate system was used. Comments by local pilots and Corps of Engineer personnel constituted other sources of information for the scene. These allowed inclusion of the significant features and also helped determine which, if any, features the pilots use for informal ranges and location sightings. All aids-to-navigation such as buoys, buildings, docks, towers, and tanks were included in the visual scene.

The visual scene is gencrated in three dimensions: north-south, east-west, and vertical clevation. As the ship progresses through the channel, the threedimensional picture is constantly transformed into a two-dimensional perspective graphic image representing the relative size of the objects in the scene as a function of the vessel's position and orientation and the relative direction and position on the ship bridge for vicwing. The graphics hardware used for this project was a stand-alone computer (Silicon Graphics-Iris 4D/35). This computer performs all the visual scene generation as well as the hydrodynamic interactions of ship, current, wind, and pilot command. Information which includes parameters such as vessel heading, rate of turn, forward and lateral velocity, and position are displayed on the precision navigation parameter screen. The ficld of view is approximately 40 degrees. The viewing angle, which normally is straight ahead, can be changed to any angle by a lookaround feature. This leature simulates the pilot's ability to see any object with a turn of his head. The pilot's position on the bridge can also be changed from the center of the bridge to any position wing to wing to simulate the pilot walking across the bridge to obtain a better view, c.g., along the edge of the ship from the bridge wing. 


\section{Radar}

The radar data base is used by the radar software to create a simulated radar for use by the test pilots. The radar data base contains $\mathrm{X}$ - and $\mathrm{Y}$ coordinates that define the border between land and water. The file also contains coordinates for any structure on the bank or extending into the water such as bridges, docks, piers, and aids to navigation. In short, these data basically define what a pilot would see on a shipboard radar. The radar image is a continuously updated plan view of the vessel's position relative to the surrounding area. Three different ranges of 0.5 mile, 0.75 mile, and 1.5 miles were programmed to enable the pilot to chose the scale needed.

\section{Current}

A current data base contains current magnitude, direction, and channel bottom depths at eight points across the channel at each of the cross sections defined in the channel. Interpolation of the data between cross sections provides continuous and smooth current patterns during testing.

Accurate simulation of ship handling in the Claremont and Anchorage Channels required detailed modeling of the currents in New York Harbor. A TABS-2 model study was performed to provide these currents (Appendix A). Current data bases were developed lor the existing, Plan A, and Plan B channels. Verification of the currents for the existing channel was by comparison to physical model results. Maintained channel depths are referenced to mean low water for New York Harbor. Currents were provided for the maximum ebb and flood tides during spring tide where both the highest current magnitudes and maximum tide advantage was present. This was determined to be at 39.25 hours (flood tide) and 44.00 hours (ebb tide) during the tidal cycle used with the TABS model. Vector plots showing the magnitude and direction of the currents generated by the TABS model are shown in Plates 5-10. Currents for the simulator are interpolated from the current fields provide by the TABS model to eight points along each cross-section of the channels. Vector plots showing the magnitude and direction of the interpolated currents used for simulator testing are presented in Plates 11-16.

\section{Test Ship}

One design ship was used for pilot testing. The vessel required a ship data base consisting of the ship characteristics and coefficients used in the ship hydrodynamic model for calculating forces and moments acling upon the vessel.

The vessel used in the simulation was based on the design ship which is $760 \mathrm{ft}$ long, has a 106-ft beam, 41-ft design draft and 50,000 DWT 
displacement. This vessel was to be tested in ballast with 16-ft draft at the bow and 20-ft draft at the stern, 30-ft even keel draft for the loaded, existing condition, and 36-ft even kecl for the load plan conditions. The ship model was developed under a contract with DESIGN AND PLANNERS, INC., Arlington, VA. (report in preparation).

\section{Wind}

Based on conversations with local pilots, the prevalent wind direction was determined to be from the southwest. The highest sustained wind in which they would navigate the channel was determined to be about 25 miles per hour $(\mathrm{mph})$. Winds coming from that direction and at the magnitude specified occur frequently. The simulator models wind as gusting plus or minus 70 percent about the specified 25 -mph average. The direction of the wind also randomly varies, with southwest being the predominant direction. Wind effect was spatially uniform and was not diminished by natural windbreaks such as land topography or man-made objects, such as buildings or docks.

\section{Tug Boats}

Based on conversations with local pilots, two tug boats, each rated at $4000 \mathrm{hp}$ were available to the pilot. The tugs could be placed on either side at the bow or stern and could be directed to either push or pull. Magnitudes of power could be entered in 25 pereent increments from 0 to 100 percent. A radar image screen with a range of approximatcly .25 mile was used to indicate magnitude and direction of thrust. A vector from the bow or stern of the vessel indicated position and direction of thrust and the length indicated relative magnitude. As vessel speed increased, the length of the vector decreased as the tug effectiveness was reduced. 


\section{Navigation Study}

Formal pilot testing was conducted with 6 pilots who were familiar with and licensed to operated in the Claremont Terminal Channel. Involving local professional pilots incorporated their experience and familiarity with handling ships in the study area into the navigation project evaluation. The tests were conducted using the WES ship simulator.

The WES ship simulator provides the pilot with a helm control, visual references, radar images, and precision navigation parameters such as heading, speed across the bottom, speed through the water, lateral speeds for the bow and stern, wind direction and magnitude, engine rpm setting, and rate of turn; these are information that he would normally have on the bridge of a ship. In this study, WES personnel served as helmsmen, manning the controls for ship rudder, engine, and tug boat operation, at the command of the pilot.

\section{Validation}

The simulation was validated over a 5-day period with the assistance of two pilots familiar with operation in the Claremont Channel. The following information was verified and fine tuned during validation:

a. Ship models

b. The channcl definition.

(1) Bank conditions.

(2) Currents.

c. Wind forces.

d. The radar image and visual scene of the study area.

(1) Location of all aids to navigation.

(2) Land/water edge 
(3) Landmarks such as buildings, loading facilities, etc.

To validate the ship models, the pilots were allowed to make both inbound and outbound runs with no wind or current effects, then asked to evaluate the reaction of the ship. The validation pilots both agreed that the ship was extremcly sluggish in response to enginc commands, did not back as strongly as they would expect, and did not twist (torque) as expected when backing. The engine response was improved so that engine rpm responded more quickly to engine command. The torquing expected during backing (the stern of the ship should move to the port, or left, during backing) was improved by increasing the torquing coefficients. The design of the ship model did not allow the engine to produce the same number of engine rpm astern as it does ahead, which the pilots said was normal in diesel-powered ships. To compensate for this, the WES helmsman ignored the one-quarter astern engine setting. When the pilot requested slow astern, one-half astern was used. For half-astern commands, three-quarters was used and any command above onehalf got full astern. The pilots agreed that this yielded much better response. After the ship models were adjusted, the pilots were allowed to run with currents and winds to see if the ship still responded as they expected. The pilots both agreed that the ship model was still somewhat sluggish as compared to what they were familiar with, but not unreasonably so.

To validate the reaction of the vessel to bank forces, several simulation runs were made with the vessel transiting the entire study area. Special attention was given by the pilots to the response of the ship to the bank forces. If any problems were noted, the areas were isolated, and the prototype data for these areas was examined. The values for the overbank depth, the side slope, or the bank force coefficient would then be adjusted. Additional simulation runs would be undertaken through the problem areas, and if necessary, further adjustment was made. This process would be repeated until the pilot was satisfied that the simulated vessel response to the bank force was similar to that of an actual vessel passing through the same reach in the prototype. The pilots noted no problems with the bank forces and no adjustments were made.

The reaction of the vessel to current forces was verificd by conducting several simulation runs over the entire study area without wind effect. The pilots were instructed to pay particular attention to current effects. The pilots were told that the model was set up to have the maximum ebb and flood tide currents that corresponded with the peak of tidal stage advantage. Both pilots agreed the currents were as strong as they would expect for such conditions and requested no changes.

To validate the wind effect on the vessel, the pilots were allowed to perform transits inbound and outbound with wind but no current effect, then asked to evaluate if the wind was eflecting the ship as they would expect. The pilots both agreed the wind effect was as strong as they would expect and, if the wind were of any greater sustained magnitude, that they would not attempt to make passage through the Claremont Channel. 
The pilots were allowed to make inbound and outbound runs with both the wind and current effect. The pilots stated that the greatest effect and highest difficulty would be when the wind and current were both moving in the same direction. The wind was initially set to come from the southwest. At the pilots' request, the wind was turned to come from the northeast with the ebb tide currents. The pilots agreed that the winds and currents were as strong as they expected and no further adjustments were made.

To validate the radar and visual scenes, the pilots were allowed to run through the channel and asked to point out anything in either the radar or visual image that needed to be added, deleted, or modified. The pilots asked that an apartment or condominium complex be added to the visual scene. A column of windows in this building complex is used as a range marker when coming into the Claremont Terminal. The pilots asked that a marker buoy near the end of the Occan Terminal Picr be moved to the northwest to mark a shoal area. The pilots also asked that some of the moored barges be removed or relocated. One building was added approximatcly mid-length of the Ocean Terminal picr. It is uscd as a reference to mark a slight "dog-leg" in the existing channel.

The pilots also requested that the horsepower available for the tugs be reduced from 4,000 to 3,000. According to the pilots, tugs as large as 4,000 hp are not commonly available at this port, and 3,000-hp tugs are more typical of what would normally be available.

\section{Test Conditions}

The validation pilots stated that outbound traffic only went out with the peak flood tide in the existing channel. This is done to take advantage of the maximum tide differential of $4.5 \mathrm{ft}$ so that the ships can be loaded as much as possible. Maximum chb tide has 2.5-ft stage advantage over mean low water $(\mathrm{mlw})$, so if the present channel is $25-27 \mathrm{ft}$ below $\mathrm{mlw}$, there is not enough depth to go out with a ship drafting $30 \mathrm{ft}$. Theoretically, Plan A and Plan B channels with a $34 \mathrm{ft}$ depth below mlw would have opportunity to start outbound with peak cbb tide with a ship loaded to $36 \mathrm{ft}$ since there would be a minimum of $36.5 \mathrm{ft}$ ol depth, providing approximately 0.5 -ft underkeel, which is similar to the underkeel clearance for the existing channel with peak flood tide. Testing was conducted outbound with ebb tide for the plan channels to determine the viability of this procedure. For testing comparison of the existing condition versus the plan conditions, outbound tests with a ship drafting 30 feet was performed with cbb tide and the water depth available was adjusted to provide an underkeel clearance of about .5 feet, as does the Plan A and B channels. The environmental impact statement for Claremont, dated September 1986, states that the bottom of the channel has a layer of from 1 to 2 feet of soft silt. The validation pilots stated that at times, especially when the channel has silted in, that they "skim over" or "drive through" the soft bottom material, "feeling" their way through the channel. 
The testing schedule as implemented on the WES ship simulator for the Claremont Terminal Channel is summarized in the following tabulation:

\begin{tabular}{|l|l|l|l|l|l|}
\hline Plan & Direction & Tide & $\begin{array}{l}\text { Ship } \\
\text { Draft, ft }\end{array}$ & $\begin{array}{l}\text { Channel } \\
\text { Depth, ft }\end{array}$ & $\begin{array}{l}\text { Tidal } \\
\text { Stage, ft }\end{array}$ \\
\hline \hline Existing & Inbound & Flood & 16,20 & 27 & 4.7 \\
\hline$"$ & $"$ & Ebb & $"$ & 27 & 2.5 \\
\hline$"$ & Outbound & Flood & 30 & 27 & 4.7 \\
\hline$"$ & $"$ & Ebb & $"$ & $28{ }^{\prime}$ & 2.5 \\
\hline Plan A & Inbound & Flood & 16,20 & 34 & 4.7 \\
\hline$"$ & $"$ & Ebb & $"$ & 34 & 2.5 \\
\hline$"$ & Outbound & Flood & 36 & 34 & 4.7 \\
\hline$"$ & $"$ & Ebb & $"$ & 34 & 2.5 \\
\hline Plan B & Inbound & Flood & 16,20 & 34 & 4.7 \\
\hline$"$ & $"$ & Ebb & $"$ & 34 & 2.5 \\
\hline$"$ & Outbound & Flood & 36 & 34 & 4.7 \\
\hline " & "Channel depth was increased one foot to allow comparison testing of the Existing & \\
\hline \hline
\end{tabular}

The current is the maximum current for flood and ebb tide and the corresponding tidal stage.

Turning maneuvers were performed with all inbound runs. For the existing channel, the turning maneuvers were performed in the intersection of the Claremont and Picrhead channels. Since the channel designs for Plans A and $B$ were identical from the Ocean Terminal Pier out to the Anchorage Channel, inbound runs for Plan $A$ were turned at the Claremont-Pierhead intersection and for Plan B, at the Anchorage-Claremont intersection. Through an oversight, the proposed turning basin ofl the end of the pier was not tested. The proposed turning basin will be superimposed on tracks of the turns made during the Plan A inbound runs which turned off the end of the pier to determine how the enlarged basin would have affected the results. Since the ship movement in the turning area is slow and under control of the tugs, the movement of the ship will not be significantly affected by the change in geometry of the bottom in this area except to allow additional mancuvering room.

Tests were chosen and conducted in a random order. The chosen test was performed and then removed from the list of conditions to be tested. This was done to prevent prejudicing the results as could happen if, for example, all existing conditions were run prior to running the plan conditions. The skill gained by familiarization with any one test condition could show the plans to be easier than they really were. 
During each run, the characteristic parameters of the ship were automatically recorded every 5 seconds. These parameters included the position of the ship's center of gravity, speed, revolutions per minute (rpm) of the engine, heading, drift angle, rate of turn, rudder angle, port and starboard clearances, and tug forces.

The findings of the simulator study are based on pilot evaluations of individual runs, final questionnaires, ship control parameter plots, and ship track plots. The following section will present the evaluations of individual run ratings, final questionnaires, ship control parameter plots (speed, engine rpm, rudder angle, and port and starboard clearance distances) and ship track plots. 


\section{Study Results}

\section{Pilot Evaluations}

After completing each test run, the pilot was asked to complete an evaluation of the run, rating the bank effects, current, wind, and ship handling. The ratings for each question for each test condition was averaged and these averages were plotted in the form of a bar chart to directly rate the same question for plan condition and operation mode. A higher rating value will usually indicate more difficulty or a more adverse condition than a lower rating. In addition, the plots for inbound runs rate the difficulty of the turning basin maneuver. An individual run evaluation is presented as Plate 17. The plots of the averaged pilots' ratings are presented in Plates 18-21.

\section{Inbound, flood tide}

The pilots rated the existing channel the same or lower than the plan channels for most questions (Plate 18). The rating differences were mostly small and insignificant. The rating dilferences for run difficulty, grounding (or striking an object) danger, and turn difficulty were among the largest. For the existing channcl, the buoys are set well back from the channel edge. For the Plan A and B channels, the buoys were moved in to mark the exact edge of the deep water channel, so the buoys were only 300 fect apart, much closer to each other than with the existing channel. For all inbound runs, the ship was in ballast, drafting $16 \mathrm{ft}$ at the bow and $20 \mathrm{ft}$ at the stern. The vessels had much more maneuvering room than was indicated by the buoys marking the $34 \mathrm{ft}$ mlw channel. The buoys being set much closer to each other tended to make the inbound runs more difficult to avoid striking a buoy. This is reflected in the higher ratings for total run difficulty and danger of striking an object for Plans $\mathrm{A}$ and $\mathrm{B}$ and turning maneuver difficulty for Plan $\mathrm{A}$. The pilots also had difliculty with the limited field of view. As they looked out to the port or starboard, they could not see the ship, and therefore lost their perspective on where they were at and at what angle they were looking out relative to the ship direction. The pilots said that they relied almost exclusively on visual cues and rarely used radar. This probably contributed to the difficulty ratings, especially for the plan channels with unfamiliar buoy arrangements. The increase in turning mancuver difficulty of Plan B over 
Plan A is due to the turn for Plan B being performed out in the Anchorage Channel in the stronger currents.

\section{Inbound, ebb tide}

Almost all questions were rated the same or lower for the existing channel than the plan channcls (Plate 19). Again, most differences were relatively small. As with the flood tide runs, the run difficulty, attention required, danger of striking an object, and turning maneuver difficulty were higher with the plan channels than with the existing channel. This again is probably due to the positioning of the buoys with the plan channels being closer than with the existing channel and the limited ficld of vision. Turning out in the Anchorage Channel for Plan B was rated slightly less difficult than turning off the end of the pier with Plan A, but the Plan A rating is probably higher than the existing channel due to the placement of the buoys. The turning maneuver for the existing channel and Plan A channels should be almost identical, except for the placement of the buoys near the intersections of the Claremont and Pierhead Channels. The overall run difficulty ratings for the ebb tide condition were significantly less than for the flood tide conditions.

\section{Outbound, flood tide}

The existing channel rated the same or lower than the plan channels for all questions, except for danger of grounding or striking an object, where the plan channels were rated lower (Plate 20). Overall run difficulty was rated slightly higher for Plan A than the existing channel and slightly higher for Plan B than Plan A. Run difficulty and grounding danger are much less than with the inbound runs, reflecting the pilots verbal comments that the outbound runs are usually much easier than inbound runs. Most of the rating differences again are relatively small.

\section{Outbound, ebb tide}

Plan A was rated lower than the existing channel for all but danger of grounding or striking an object and Plan B nearly the same or lower than the existing channel for all questions except for run difficulty (Plate 21). Run difficulty and grounding danger were slightly higher when compared to the flood tide condition. This is probably due to the smaller underkecl clearances with the ebb tide condition, since the wind effect was rated almost the same for both tidal conditions and the current effect was rated higher for the flood tide than the ebb tide. 


\section{Summary}

The pilots tended to rate the plan channels as being more difficult than the existing channel and Plan B as being slightly more difficult than Plan A. For the inbound runs, the placement of the buoys near the deep-water channel edge for the plan channels increased the perception of difficulty and danger.

Although the plan channels were rated as more difficult, the differential of the ratings as compared to the existing channel were relatively small. Placing the buoys marking the plan channels away from the edge of the deep water channel would likely improve the pilots perception of the difficulty of the runs and the danger of striking one of the buoys. A large field of view would tend to improve the pilots' perception of the level of difficulty.

The pilots rated the turning maneuver in the Anchorage Channel to be more difficult than in the Claremont-Pierhead Channels for the flood tide condition and slightly less difficult with the ebb tide condition. The greater difficulty of the turning maneuver with Plan A than that of the existing channel condition is likely due to the placement of the buoys at the Claremont-Pierhead Channel intersection since the current and wind conditions are almost identical and the ballasted ship is basically unaffected by the increased width and depth of Plan A. Assuming that the ratings for the turning maneuver for the existing channel and Plan A would be almost identical if the buoys were moved away from the deep-water channcl edge (and possibly lower for Plan A if the proposed turning basin had been tested), the turning mancuver in the Anchorage Channel would be rated significantly more difficult for both the flood and ebb tide conditions.

\section{Final Questionnaires}

After finishing all test runs, the pilots completed a final questionnaire to give their opinions on the project as well as the simulation. Some of the comments made by the pilots on the project follow:

\section{Which of the channel designs did you prefer and why?}

"I would prefer Channel (Plan) A because it gives an added element of safety with the greater width."

"Plan A. It oflers the most room, 300 ft., all the way to (the) berth."

"Plan B is sufficient. Most ships will be turned inside off the (pier) where current is usually weaker. $250 \mathrm{ft}$ with tug assistance and dead slow steerage is wide enough."

"I preferred the $300 \mathrm{ft}$ (Plan A) as it gave greater safety for ship movement." "300 ft channel (Plan A), because it gave more room to maneuver in and it gives you a better approach in making the outbound turn." 
"300 ft width (Plan A) was preferable since maximum wind and current make approaches to entrances extremely difliculty and require as much room as possible."

\section{Will any of the proposed channel designs improve passage during peak tides?}

"Yes. Outbound much easier and allows greater drafts. Inbound will always remain difficult under adverse conditions (i.e. high winds and peak currents)."

"It will make it easier to exit the terminal and have little effect on inbound approaches to the terminal."

"Yes. Any channel improvements will greatly improve the safety of ships using this channel. At the present time, ship movements during peak tides can be very difficult."

"The widening of the main channcl entrance will help on the strong flood tide and southeast wind."

"Yes, a wider channel will be an improvement and make for easier passage."

"Plan A and B will both improve passages during peak tides, Plan A more than B..."

\section{What is your opinion of turning in the Anchorage Channel as opposed to turning off the end of the Ocean Terminal pier?}

"Turning in the Anchorage Channel is a valid option when coming in with flood current and southerly wind. It seems that turning at the end of the pier on flood current was extraordinarily diflicult and turning outside somewhat less difficult. Generally though, turning at the end of the pier was preferable."

"I consider turning in (the) Anchorage Channel the most difficult and prefer to turn vessel off end of picr. The Anchorage Channel has the strongest crosscurrents. Also, when turning in Anchorage channel you must back a much longer distance."

"Can be done (turn in Anchorage Channel) and have in the past when only one tug was available but prefer turning off pier."

"In the last 20 years I've only turned in the Anchorage Channel 6-7 times. I feel the current (except at slack) is too strong to consistently turn out in the Anchorage Channcl."

"As a matter of practice, 1 preler to turn off the picr. With a $760 \mathrm{ft}$ ship, it will probably be necessary to strongly consider turning the ship in the Anchorage Channel for safety rcasons." 
"Prefer to turn off pier to minimize effects of current. If allowed to time turns to reduced current periods, turning in Anchorage Channel is a viable option."

\section{Do you have any suggestions to improve navigation of the proposed channels (alignment, channel width, navigation aids, etc.)?}

"At the present time when I have a ship going into Claremont that is under $580 \mathrm{ft}$ and light draft on the bow (8-12 ft), I turn the ship off Dock 5. I think you should look at the idea of digging a little of the mud out near the Corps Pier and creating a turning basin to turn the $760^{\prime}$ ships inside. This would mean we could turn where the wind and current had the least effect on a ship."

"I think that a red buoy placed near the pumphouse (mid-length of the Ocean Terminal Pier) would holp to line-up an outbound vessel in the channel. It would act as a range with the first set of buoys."

"Perhaps 3 or 4 spar buoys could be put in between red and black nun off south corner of Caven Pt. pier and beginning of concrete dock at Claremont Terminal."

"The inner channel should be marked on both sides by buoys. The south side was marked years ago by spar buoys."

"I found it particularly difficult to navigate inbound when the buoys were placed on the edges of both the 250 and $300 \mathrm{ft}$ channels. The wind and current effects made it almost impossible to safely navigate."

\section{Do you have any suggestions for improving the simulation?}

"The single screen leaves much to be desired. I found I was working with the radar more than the screen. Going to a real bridge layout and 3-5 screens would be a tremendous improvement."

"Perhaps adding tugs alongside when they are in usc, wavelets caused by wind, water flowing around buoys, sound eflects of wind and ships engine, perhaps using some sort of mouse to allow the pilot to look around as he would by turning his head."

"If possible try to improve depth pereeption especially when looking ahead and ship running ahead. With existing simulator, I find mysclf constantly checking radar for distance to buoys."

"It would help if the pilots had a more panoramic view so one could observe how the ship was maneuvering in relation to all of the buoys around it."

\section{On a scale of 0 to 10 (10 being excellent), what is your overall opinion} of the simulator and of the Claremont Terminal simulation? 
"Given its present limitations, the simulation was very good and should give excellent results... "8"."

"9"
"8"
"8"
"8"
"8/9"

7. COMMENTS:

"I think perhaps the effect of wind was exaggerated and the tugs' power was underrated. In my opinion, a pair of $3000 \mathrm{HP}$ tugs should be able to easily cope with the wind of 25 or so knots..."

"I consider outbound transits much easier than inbound. Backing a vessel with strong wind and current conditions is the most difficult. I prefer to turn off end of Caven Point pier when inbound..."

"When possible, channels should be wide and deep enough to allow for dead slow speed; use of half and full will cause the ship to squat. We presently use half and full so as to keep moving should the ship slow or rub bottom outbound."

"It would be helpful if a wider field of vicw was available so the pilots could react in a more timely fashion to changing situations."

"...I felt the simulation from inception to completion was professionally done and I felt comfortable performing the tasks required."

\section{Navigation Parameter Plots}

During operation of each test condition by each pilot, the navigation parameters of the ship which include speed, engine rpm, rudder position, rate of turn, drift angle, minimum clearance distance to the defined edge of the channel, both port and starboard, ship position, and tug forces were recorded every 5 seconds. All of the pilots' runs for the same test condition were combined and avcraged to provide the data used for the plots. The ship parameters are plotted against the distance along track. Distance along track is the distance along a line beginning near the origin point (for inbound runs) and running near the centerline of the Anchorage and Claremont Channels into the terminal. All plots, whether inbound or outbound, are plotted versus this distance, with the outbound runs being plotted from right to left as they come outbound. Reference for the distance along track is provided in Plate 22. The 
parameters that will be examined are ship speed, engine rpm, port and starboard clearances, and rudder position. Maximum engine rpm for the ship's used for this study was 100 , so commands for one-quarter ahead would be 25 $\mathrm{rpm}$ and half-ahead would be $50 \mathrm{rpm}$.

\section{Ship speed and engine RPM}

Inbound, flood tide. The initial starting speed for the inbound runs was set at 5 knots. For the existing channel and Plan A channel, the pilots tended to maintain that speed as they approached the Claremont Channel and make the turn into Claremont (Plate 23). The pilots all tended to use about onequarter ahead to maintain their speed up to the turn. For the existing channel, engine rpm was increased, indicating that several pilots used at least one-half ahead to help them make the turn. For Plan A, at lcast one pilot went to full ahead near the entrance of the Claremont Channel, an indication he was having difficulty making the turn. This probably led to more difficulty near the end of the pier, since the speed as they approached the end of the pier was approximately two knots greater than for the existing channel. For both conditions as they got near the end of the pier, the pilots backed the engine from half-astern to full astern in order to stop the ship and perform the turn. As they made the turn and started backing along the pier, they gradually reduced the engine rpm astern till the got near the dock, then they went to nearly halfahead to stop the ship.

For Plan B, the pilots were required to turn in the Anchorage Channel. Speed and engine rpm were dropped earlier than with the existing or Plan A channels. As they approached the Claremont channcl flare, the engine was stopped, then backed at near half-astern to bring the ship to a stop. At one point, at approximately 7000 feet along track, the rpm came to almost zero. At least one pilot had to come ahead with the engine to gain control and avoid striking the outer buoys marking the llare. This averaged in with most pilots going slowly astern yiclded the near zero rpm. This pilot probably came ahead with one-half or full ahcad, but only used it bricfly, since the plot for speed at this point doesn't show any aberration. The engine was backed at near one-quarter astern for most of the transit through the Claremont Channel, occasionally being reduced to slow the backing speed of the ship. From the end of the pier to the dock, all plans had almost the exact same speed and very similar engine usage.

Inbound, ebb tide. Speed for the entire length of the run was almost identical for the existing channcl and Plan A (Plate 24). Engine rpm for the existing and Plan A channels was very similar, both requiring much less engine power to make the turn than with the flood tide, indicating much less difficulty.

Plan B shows that the pilots started slowing almost immediately after starting their runs, using only slow to onc-half ahead up to about $5,000 \mathrm{ft}$ along track, then reducing rpm to near zero. As they reached the southern edge of 
the channcl flare, they started backing the engine slowly to reduce speed, then as they completed their turn, they backed more strongly to build up speed astern, then reduced the rpm to maintain a constant speed. The pilots backed from the Anchorage Channel to the end of the pier at about the same speed as they backed from the end of the pier into the terminal, approximately 4 knots. As they passed the end of the pier, they tended to run with nearly the same speed and engine rpm as with the existing and Plan A channels.

Outbound, flood tide. For all the outbound runs, the initial starting speed was $1 \mathrm{knot}$ and the engine at dead stop. The pilots for all the test channels came to half ahead immediatcly (Plate 25), some using full ahead briefly to get their speed up more quickly. After pulling away from the dock they tended to run at about one-half ahead until they passed all the moored barges at approximatcly $12,000 \mathrm{ft}$ along track. At this point with the existing channel, some of the pilots increased engine rpm. For Plan $A$, they tended to hold about one-half ahead and for Plan B, one or two pilots increase engine rpm. As the pilots reached the end of the pier, near $10,000 \mathrm{ft}$ along track, five pilots went to full ahead for the existing channel, four pilots for Plan B and three for Plan A. By the time they reached the end of the Claremont Channel, all pilots for all channel conditions had gone to full ahead and remained that way through the completion of the runs, except for one pilot during a Plan B run that pulled back the engine bricfly as he completed his turn into the Anchorage Channel.

Speed for all the channel conditions increased steadily from the beginning of the run to the end of the run. The Plan A and B runs are somewhat slower than the existing channel due to the larger draft (36 ft) of the ship used for the Plan A and B channcls. Plan B had greater spced than Plan A due to more pilots going to full ahead earlier than with Plan A.

Outbound, ebb tide. As the pilots started the runs for each channel condition, they came almost immediately to onc-hall ahead (Plate 26). The southerly set due to the wind and the increased bank forces due to deepening the channel tended to make getting away from the dock more difficult than for the Plan A and B Channels. The pilots for Plan A used a large engine rpm briefly to help them pull away from the dock. As they pulled away from the dock, the rpm for Plan A tended to average 10 or $15 \mathrm{rpm}$ higher than the existing or Plan B channels. Engine rpm for the existing and Plan B channel was approximately the same until the pilots reached the end of the pier. As the runs passed the end of the picr, Plan A rpm increased only slightly, but the existing and Plan B engine rpms increased to exceed that of the Plan A channel. As they approached the start of the turn at 8,000 ft along track, almost all of the pilots for the existing and Plan B channels went to full ahead, but the Plan A channel only had four pilots to go to full ahead. As they completed the turn near 6,000 ft along track, the Plan A pilots all went to full ahead, one pilot from the existing channel came back to onc-half ahead and two pilots for Plan B came back to one-half ahead till near the end of the runs. 
Speed for all the channel conditions steadily increased throughout the runs. Again the existing channel was run somcwhat faster, due to smaller draft of the vessel used with the existing channel. Plan A was faster than Plan B from the start of the runs to near the start of the turn, due to more engine rpm being used early for Plan A. As they came through the turn, Plan A and B were almost exactly the same speed, then Plan $A$ was faster to the end of the run due to two pilots pulling back to one-half ahead for Plan B after completing the turn.

\section{Minimum clearance distances and rudder position}

Clearance distance is not plottcd up to $7500 \mathrm{ft}$ along track. This is due to the relative width of the Anchorage Channel as compared with the Claremont Channel. Distance is measured from the ship to the edge of the defined channel. With the ship in the Anchorage Channel, clearances in excess of $1,000 \mathrm{ft}$ were shown. To reduce the clearance plots to a more meaningful scale, the clearance distances in the Anchoragc Channcl were removed and only the clearance distances in the Claremont Channcl, starting at the channel flare were plotled.

Clearance distances for inbound and outbound runs will be discussed using different channel limit critcria for each condition. For all the outbound runs, clearances are defined to the limits of the deep-water channel. For the inbound runs, the clearances are defined to the 20-ft contour line which approximately represents the available channel for the ballasted vesscls. Normally clearances are defined as port or starboard clearance (clearance from the port or starboard side of the ship). When the ships are performing turning basin maneuvers off the end of Caven Point Pier, port clearance to the southern channel edge as the ship is coming in bow lirst becomes port clearance to the northern channel limit as the ship rotates and begins backing into the terminal. To avoid confusion, clearances for this study will be defined to the north or south channel limits.

Inbound, flood tide. Clearances for the existing channcl and Plan A were similar as the vessels entered the Claremont Channel and approached the turning basin (Plate 27). The large values of north clcarance and relatively small values of south clearance for the existing and Plan A channels in the turning basin area are somewhat deceiving since some of the pilots turned the ship in a counterclockwise direction instead of the more routine clockwise direction. The pilots who turned counterclockwise went much further south into the Picrhead Channel than did the other pilots and their clearance distances, averaged with the other pilots clearances, would yicld a large north clearance and a smaller south clearance. The average negative south clearance opposite the end of the Caven Point Pier for the existing channel is due to one pilot who turned counterclockwise and went well outside the south channel limit at the southwest comer of the Claremont-Pierhead Channel intersection. The near zero north clearance for Plan A near the end of Caven Point Pier is due to one pilot who went well up onto the pier. Plan B shows adequate 
clearance on both sides up to the end of the pier with the pilots tending to stay slightly closer to the southern channcl edge. As the ships backed into the terminal from the end of the pier, all of the plans are very similar. With all plans, there was a tendency to get very close to the south edge of the channel near mid-length of the pier, then work over to be near to or slightly outside the north channel limit near the completion of the runs. The values of rudder used vary widely by plan. For the existing and Plan A channels, the pilots let the current and wind turn them into the Claremont Channel, then used starboard rudder to hold up as they passed to the turning basin. With the cxisting channel, most pilots used hard right rudder to turn into the turning basin. With Plan A, the pilots averaged first using port rudder then going back to starboard rudder as the started their turns. This is again likely due to the pilots who turned opposite the direction of the other pilots. Once turned, rudder was occasionally used to help correct position in the channel. For Plan B, the pilots used little rudder after getting up to the channel flare, using mostly the tugs to turn and hold their position within the channel.

Inbound, ebb tide. Clcarances for the existing condition and Plan $\mathrm{A}$ are similar from the channel flare up to the turning basin (Plate 28). For the existing condition, all the pilots turned the vessel clockwise with most turning well off the end of the pier. The large average of north clearance (up to about $700 \mathrm{ft}$ at 10,000 $\mathrm{ft}$ along track) is likely an anomaly associated with the recording and averaging of a large number of clearance values while the ships were rotating in the turning basin. This is also the likely case for the very low south clearances from about 9,500 to $10,000 \mathrm{ft}$ along track. For Plan A, all the pilots turned clockwise in the basin. The turns tended to be made further into the basin, as reflected by the smaller north clearances as compared to the existing channel. As the turns were completed with the existing and Plan A channels, the current and wind tended to set the vessel down to the south and hold it there. For Plan B, the pilots tended to back into the Claremont Channel along the southern edge and remain there. With all plans, as they backed along the length of the pier, they set outside the south channel limit at about $13,000 \mathrm{ft}$ along track, then as they worked back in to the channel, they tended to go near to or slightly out of the north edge of the channel near the completion of the runs. Rudder usige for all plans was similar until they approached the channel llare. With the existing condition, the pilots used a long gradual application of port rudder to turn into the Claremont Channel, then maintained port rudder to hold up against the set of the wind and current until they reached the turning basin where they used starboard rudder to initiate their turn. With Plan A, the pilots applied a larger port rudder for a shorter duration than with the existing channel. This is duc to the placement of the channcl buoys being set in to mark the edge of the deep-water channel for Plan A, oflering a smaller clcarance between the buoys than with the existing channel. As they approached the basin, little rudder was used until they got into the basin where some port rudder was used. The turns were made mostly under tug control. The use of port rudder to make a clockwise turn is not readily explainable. It would seem likely that one or more pilots applied a large valuc of port rudder (or did not cancel an earlier command for port rudder) for an extended period while in the basin. This, if averaged in 
with other pilots using little or no rudder would yield the average as plotted. For Plan B, the pilots used starboard rudder for a extended period as they approached the flare to turn the vessels to prepare to back into the Claremont Channel. As they started backing into the channel, rudder was brought to midships. For all plans, rudder was occasionally used as the ships backed along the length of the picr, along with engine ahead, to reestablish position within the channel.

Outbound, flood tide. The existing condition maintains a negative south clearance for almost the entire length of the Claremont Channel (Plate 29). This was probably due to the pilots holding up against the northerly set of the currents and wind. The negative north clearance from approximately 14,000 to 12,000 feet along track is due to the angle that the ship is holding to compensate for the wind and current set, actually causing negative clearance on both sides of the channcl for a short span near 12,000 feet along track. The plots for both Plan A and B show that the pilots were able to stay within the defined channcls. The south clearances show that the pilots tended to use a similar path for both channels which would be near mid-channel for Plan A and slightly favoring the north side for Plan B. The reduction in channel width is along the north side for the outbound runs, which is clearly indicated in the north clearances.

Rudder usage for all three of the channel plans was very similar. The plots indicate that the pilots maintained more starboard rudder for a longer period of time with the plan channels versus the existing channel as they turned into the Anchorage Channel (5,000 to 8,000 feet along track), but this is probably due to the draft of the loaded vessel for the plan channels being 36 feet versus 30 feet for the existing channel and less maneuverable.

Outlound, eblo tide. The plots for north and south clearances for the existing channel are almost identical to those with the flood tide (Plate 30). The pilots averaged a ncgative south clearance for almost the entire length of the Claremont Channel and were out along the north side as they passed the moored barges. For Plan A and B, there were no problems with clearance, except at the very beginning of the runs where they start near the dock and slightly outside the defined channel. For the cbb tide runs, the pilots all tended to run toward the northern side of the channel to compensate for the southerly set.

The rudder usage plots for all the channel conditions are very similar. The pilots tended to vary on how they turned out into the Anchorage Channel. With the existing condition, they started the turn at the beginning of the flare and maintained fairly constant rudder until they completed the turn. With Plan A, they again started the turn at the beginning of the flare, but used less rudder than with the existing condition until they got well out into the Anchorage Channel where they applied more rudder and then used the large rudder setling longer than with the existing condition. For the Plan B Channel, the pilots started their turn a few hundred feet before reaching the beginning of the flare, then gradually increased the rudder till they got well out into the Anchorage 
Channel, then gradually reduced it. The reasons for these differences are not clear, but all of the turns were made successfully and none of the pilots indicated any problems associated with the turn.

\section{Summary}

The parameter plots indicate that inbound or outbound runs with the Plan A and $\mathrm{B}$ channels can be performed with no significant increase of engine power or rudder usage over that used for the existing condition runs. Both of the plan channels show major improvement in clearance distances for the outbound runs as compared with the existing condition. Adequate clearances were maintained while backing the entire length of the Claremont Channel after turning in the Anchorage Channcl.

\section{Ship Track Plots}

A complete set of combined ship track plots for the channel test conditions is presented in Plates 31-42. A tabulation of the individual piloted runs and their results is presented in Table 1 . For the inbound runs, with the ship in ballast at $16-\mathrm{ft}$ bow and 20 -ft stern, a 20 -ft and $16-\mathrm{ft}$ decp channel limit will be used for channel limits. As stated previously, the enlarged turning basin proposal was not tested directly. The proposed turning basin limits are superimposed on the track plots of the inbound runs for Plan A to determine how the enlarged turning basin would have allected the test results that were performed without the basin. For outbound runs, only the deep water channel is shown and used for channel limits.

\section{Inbound, flood tide}

Existing Channcl. The pilots split on how they chose to enter the Claremont Channel (Plate $31 \mathrm{~A}$ and $31 \mathrm{~B}$ ). Four came in along the southern edge of the flare and the other two allowed themselves to be set toward the northern edge of the llare, then drove back against the current and wind to come into the Channel. All of the pilots tended to be set toward the northern side of the Claremont Channel with two pilots going slightly outside the $20-\mathrm{ft}$ draft limit. Most of the pilots chose to turn the ship by going bow first off the end of the pier and turn clockwise. One pilot, due to the set he had as he entered the Claremont-Picrhad intersection, chose to put the bow to the south and turn in a counter-clockwise dircetion. According to verbal comments made by this pilot, he occasionally performed this maneuver when he is having difficulty getting the stern of the ship to come up into the strong wind and/or current from the south. This pilot went outside the 20-lt and 16-ft channel limits with the bow of the ship, so grounding would probably have occurred. As all the pilots backed into the terminal, they tended to follow a nearly uniform path, centering the deep water channel. One pilot allowed his ship to 
drift near the pier before coming back to mid-channel. This pilot went outside the 20 -ft channel limit briefly at approximately mid-length of the pier.

Plan A Channel. As with the existing channel condition, four of the pilots came in along the southern edge of the llare and the other two drifted to the northern edge, then drove into the currents and wind to come into the channel (Plate 32A and 32B). All the runs were set to the northern edge of the Claremont Channel with three pilots going slightly outside the 20 ft channel limit. Threc of the pilots turned clockwise off the end of the pier and the other three turned counterclockwise. One pilot ran over the northern buoy at the Claremont Channel llare, another over the northern buoy marking the Claremont-Pierhead Channel intersection and another edged the southern buoy opposite the end of the pier. One pilot struck the picr approximately 250 feet from the end of the pier. This was likcly due to excessive speed as the ship entered the turning area. Backing into the terminal was performed very similar to that of the existing channel with all pilots running toward the northern side of the channcl and one pilot going well outside the $20 \mathrm{ft}$ channel limit near mid-length of the pier, as was the casc during the existing condition. With the proposed turning basin in place, the pilots would have additional room along the northern edge of the channel to allow their ship to set to the north with the wind and current. Since the tendency was for the stern to set north, turning counterclockwise would likely be easicr than turning clockwise with the flood current. This additional room would have eliminated the groundings or near groundings to the south in the Pierhead Channel and also striking the pier since the pilots could have turned further out off the pier.

Plan B Channel. The pilots were required to turn in the Anchorage Channel and back into the Claremont Channel (Plate 33A and 33B). Most of the pilots tended to go to the northern side of the flare, hold up, let the stern come up to the north clockwise, then back into the channcl with the assistance of two tugs. One of these pilots approached with hard left rudder and actually performed a 270 -degree turn, going well north before driving to the southern edge of the flare near the buoy, then backing into the channel, striking the buoy as he backed. This pilot also went well beyond the 20 -ft channel limit and edged outside the 16-ft channel with the bow along the northern edge of the channel and struck the northern buoy marking the Claremont-Pierhead intersection. One other pilot also went out of the 20-lit channcl limit, but only with the bow and then only brielly. One pilot chose to start his turn well south of the channel thare and let the current and wind push his ship laterally to the north as he backed. All the pilots stayed near the northern channel edge till they reached the end of the picr. As they passed the pier, the pilots tended to have better control and completed their runs into the terminal near midchannel, except for one pilot who went slightly out of the 20-ft channel limit near mid-length of the picr, as was the case for both the existing channel and Plan A. The buoy marking the transition from the 250-ft to 300-ft channel was struck by one pilot. 


\section{Inbound, ebb tide}

Existing Channel. Most of the pilots chose to drive directly into the Claremont Channel, starting out near the right side of the channel at the outer northern buoy, anticipating the set from the current and wind from the north (Plate 34A and 34B). One of these pilots went well north of the channel flare, either expecting the set to start earlier than it did or expecting a greater set than he got, and struck the northern buoy marking the flare. The other pilot came to a stop in the Anchorage Channcl, used the tugs, wind, and current to rotate the ship into alignment with the Claremont Channel, then proceeded into the channel. One pilot skirted the edge of the 20 -ft channel limit along the northern side of the channel. All the pilots appeared to make the turning maneuver off the end of the picr with little difficulty. All the pilots turned clockwise, putting the bow up into the channel off the end of the pier. One pilot went slightly outside the 20 -ft channel limit to the north, but was well within the $16 \mathrm{ft}$ limit, so he probably would not have grounded. One of the tracks shows the bow coming near the southern edge of the 20-ft channel. This was due to the pilot completing his turn too far south and almost striking the southern buoy opposite the end of the pier with the stern of his ship. To avoid this, he put the rudder hard right and came ahead with the engine. This pushed the bow of the ship well down into the Pierhead Channel, south of the Claremont Channcl. He then backed and used the tugs to bring him into alignment with the Claremont Channcl. Backing from the end of the pier into the terminal appears to be similar in difliculty as with the flood tide condition. Near the completion of the run at the terminal, one pilot went wcll outside the 20-ft channel limit. Prior to reaching the end of the dock, he was backing along the southern edge of the channel. To avoid the barges moored at the end of the dock, he had the tug push the stern well up to the north. He may have been expecting the wind from the north to slow the northward motion. When it became apparent that the ship would not stop in time, he had the tug push the stern of the ship toward the south. This caused the bow to accelerate toward the north. As the stern of the ship moved out of danger, the pilot applied hard right rudder and engine ahead to brake the counterclockwise rotation of the ship. As the ship came back toward parallel with the dock, the run was ended.

Plan A Channcl. Four of the pilots started at the southern edge of the flare and made wide sweeping turns into the Claremont Channel, completing the turns near the northern edge of the channcl at the buoy (Plate 35A and 35B). Two pilots chose to go further north, then make sharper turns into the Claremont Channel. One of these pilots did not anticipate the wind and current set correctly and ran over the northern buoy at the llare. One other pilot hit this buoy, but only a glancing blow. All of the pilots completed the turning maneuver without excessive difficulty, except for avoiding the buoys along the southern edge of the Claremont Channel. The buoy marking the flare was struck once, the buoy marking the intersection of the Claremont and Pierhead Channels three times, and the buoy opposite the end of the pier once. There were several instances where the ship went outside the 20-ft channel limit, but all were out brielly and most of them were out with the bow which was 
drafting less than 20 feet. Backing in to the terminal was completed mostly without incident. Onc pilot did allow his ship to come very near the two moored barges just outside the terminal, but did not strike either of them. One pilot allowed the ship to strike the dock at the completion of his run. With the proposed basin in place, the pilots could "drive " into the basin along the northern edge of the channel to compensate for the current and wind set to the south, then with tug assist, began turning the vessel. This would likely eliminate the groundings along the southern edge of the channel between the channel flare and the Picrhead Channel.

Plan B Channel. Five of the six pilots turned in or near the flare. Most came up near the northern edge of the flare, stopped, then let the tugs, current, and wind turn the bow clockwise, then backed into the channcl (Plate 36A and 36B). One pilot went well north of the llare and let the ship drilt south as he performed his turn. The sixth pilot started his turn out in the Anchorage Channel south of the llare then backed against the current up into the channel. One pilot struck the southern buoy marking the Claremont-Pierhead intersection. The pilots all backed past the end of the pier with little apparent difficulty. As they approached the terminal, one pilot allowed his ship to set down near the outermost moored barges, but did not strike them. Near the end of the run, one pilot was coming in along the southern edge of the channel. As he neared the moored barges, he had the tug push the stern toward the north. He apparently had the tug push too long or hard or was expecting a stronger southerly set due to the wind. He allowed the ship to come near the northern limits of the 20 -ft draft channel, briclly going outside the 20 -ft channel opposite the dock.

\section{Outbound, flood tide}

Existing Channel. Most of the pilots tended to set to the northern edge of the channel as they came past the end of the dock and the moored barges (Plate 37). As they reached mid-length of the picr, they started getting their set for the wind and current and tended to run nearer the southern edge of the channel. As they passed the end of the pier, they still tended to run near or outside the defined channel limits out to the flare. Most of the pilots were running well south of the defined channel as they reached the flare, with two pilots being completely outside the channcl. The channel, especially near the flare, is only two or three fect deeper than the surrounding bottom elevations, so bank forces are not very strong. The pilots all turned into the Anchorage Channel with little difficulty, finishing their run near the center of the Anchorage Channel.

Plan A Channel. As the pilots began their runs, they mostly tended to stay near the center to southern edge of the channel (Plate 38). Only one pilot went up near the northern edge of the channel opposite the moored barges. As they approached the end of the pier, all the pilots tended to run from the center of channel to near the northern edge. As they passed the end of the pier, all pilots pushed down near the southern edge of the channel to prepare for the 
northerly set from the currents and wind. One pilot ran slightly outside the defined southerly edge of the channel between the inner and outer buoys. As the pilots passed the outer buoys they made their turns into the Anchorage Channel, completing their runs near the center of the Anchorage Channel.

Plan B Channcl. As the pilots started their runs, all but one tended to stay near the center of the channcl as they passed the moored barges (Plate 39). One pilot went up along the northern channel edge and went slightly outside the channel for about two ship lengths. As they approached the transition from the 250-ft to the 300-ft width channel, all the pilots tended to come north to come closely by the northern marker buoy. One pilot slipped out of the channel briefly just before reaching the buoy. As they passed the end of the pier, they all went down along the southern edge of the channel to hold against the wind and current set, as they did with Plan A. One pilot came alongside the southern channel limit as he approached the outer buoys, but did not go outside the channel. All the pilots started their turns as thcy passed through the outer buoys and completed their runs near the center of the Anchorage Channel.

\section{Outbound, ebb tide}

Existing Channel. All of the pilots tended to stay near the center of the channel from the start of the run to mid-length of the pier, but all went out on the northern or southern limit of the channel between these points (Plate 40). Further out along the pier, all the pilots tended to group along the southern edge of the channel, most going out of the channel limit. As they passed the end of the pier, most continued along the southern edge of the channel, mostly centering the southern channel limit. One pilot went up along the northern channel limit, going slightly out of the channel and remaining that way until reaching the flare. As the pilots passed through the outer buoys, they all started their turns and completed their runs near the center of the Anchorage Channel.

Plan A Channel. At the start of most of the runs, the pilots remained very close along the southern channel limit (Plate 41). The combination of the strong southerly wind and the increased bank suction with the deeper channel made pulling away from the south side more difficult than with the flood tide condition. One pilot pulled away from the dock more forcefully than the others and actually went out of the channel along the northern cdge as he passed the moored barges outside the terminal. After passing mid-length of the pier, all the pilots tended to stay from mid-channel to near the northern channel limit. One pilot grazed the northern inner buoy marking the Claremont-Picrhead intersection. As the pilots approached the flare, they all returned to near mid-channel. The pilots started their turn into the Anchorage Channel as they passed through the outer buoys or immediately after passing through them and completed their runs near mid-channel of the Anchorage Channel. 
Plan B Channel. As with Plan A, the pilots started their runs from center of channel to near the right channel edge (Plate 42). As they approached the buoy marking the transition from the 250-ft to the 300-ft channel, they grouped near mid-channel, then after passing the end of the pier, they moved to mid-channel of the 300-ft channel. Most of the pilots remained near midchannel till they passed through the outcr buoys and into the flare. One pilot moved toward the northern channel edge, starting at the inner buoys, ran along the northern channel edge, coming near the northern buoy marking the flare, then turned. The pilots varied from left-center to right-center of the Anchorage Channcl at the completion of their runs. 


\section{Conclusions and Recommendations}

\section{Limitations of the Study}

There are several limiting factors in determining test results and conclusions that can be reached. The simulator only provided one viewing screen, showing about a 40-degree ficld of view. Most pilots said that they rarely used the radar to make the transits either inbound or outbound, but relied on visual references and cues. Although the objects that they normally use were present in the visual scene, the restricted field of view limited their usefulness since it required that the look around feature be used constantly to provide them the field of view that they normally would have from the ship's bridge. All the pilots tended to rely more heavily on the radar image rather than moving the viewing angle which probably effected their operational technique. The ship model used for testing was derived from design characteristics of a steam turbine vessel. The pilots stated that there are almost none of this type vessel that use this port. They said that almost all the vessels that call on this port are diesel, which have a much quicker engine response and better backing characteristics than stcam lurbine vessels. The numerical ship model engine response and handling characteristics were modified to improve response and handling, but the ship was still described as being sluggish when compared with most vessels that they have piloted.

Testing was performed going outbound at the strength of ebb tide (as a worst case scenario), which is not normal practice for the existing channel. The proposed channcl deepening to $34 \mathrm{ft}$ mlw would provide a larger "window" of opcration than at present. The cbb tide condition tested for the plan channels is the latest point of the "window" that a vessel loaded to $36 \mathrm{ft}$ could leave the port and also the strongest ebb tide current. With the tidal stage advantage of $2.5 \mathrm{ft}$, the vessel would be going out with less than one $\mathrm{ft}$ of underkeel clearance, but according to pilots' comments, this is not unusual for present operations with flood tide. Testing with cbb tide was performed to determine if there were any adverse conditions that would be associated with this tidal condition. In practice, if the vessel was going out later than at peak flood tide, it would probably be taken out earlier than at maximum ebb tide current (during the declining flood tide or early in the ebb tide) when there 
was more water available and less current, but for testing, the strongest current that the pilots would be expected to opcrate in is more desirable. Therefore, the highest cbb tide current at the latest point of the "window of opportunity" was used. Comparative testing of the plan channels with the existing channel for this condition is not directly possible since there is not enough underkeel clearance during peak cbb tide for the existing channcl with the vessel drafting $30 \mathrm{ft}$. To make a comparison possible, the channel depth was increased one $\mathrm{ft}$ to $28 \mathrm{ft}$ and with the tidal stage of $2.5 \mathrm{ft}$, this would give an underkeel clearance of $0.5 \mathrm{ft}$, the same as that used for the plan channels. Again, operation during this portion of the tidal cycle would not normally be expected, but this represents the extreme limits of operation, as does the current and wind, that a pilot would attempt to navigate the channel. If the channel can be navigated successfully in the extremc conditions, the channel should be adequatc for navigation in normal operating conditions.

As previously mentioned, the proposed turning basin along the northern edge of the channel between the channel llare and the Pierhead Channel was not tested. The outline of the turning basin limits was superimposed on the track plots of the inbound runs for Plan A to help determine how the basin would have improved their passage through the outer Claremont Channel and their turns off the end of the picr. The availability of the extra area would likely have influenced how the pilots chose to enter the channel and turn. Taking the strategies that the pilots used to perform the turns for Plan A, the current conditions, and the wind conditions, an extrapolation of how the basin would have affected their operation can be made.

Although the previously described limitations made the operation for the pilots more difficult, they also will tend to make the results of the study more conservative. The wind and current conditions are set to be those which would be the most difficult the pilots would expect to navigate in. The pilots' ability to successfully navigate the test channels with the extreme current and wind conditions, along with the restrictions of visual field of view and ship handling would tend to confirm that the channels could be transited in the prototype under more favorable conditions with aceeptable levels of difficulty and safety.

\section{Conclusions}

Some of the pilots commented that coming inbound with a ballasted ship would be basically unaffected by whatever changes are made in the depth and width of the Claremont Channel. This is a logical and valid assumption. The currents run almost perpendicular to the alignment of the channel and were negligibly different from the existing channel to either of the plan channels. The amount of navigable channel available for the pilots to use will be unaffected, since in the ballast condition, they are only restricted by the limits of 20-ft depth. The only changes that would allect inbound traflic is placement of the buoys, whether the ship will turn off the end of the pier, as they 
do now, or out in the Anchorage Channel, and whether the proposed turning basin is constructed.

The pilots tended to rate the Plan A channel as more difficult than the existing channcl and Plan B slightly more difficult than Plan A. As discussed in the pilot evaluations, the buoys were set along the edge of the channel for Plan A, much closer together than the existing buoys are. For Plan B, an additional buoy was added to mark the transition from the 250- to 300-ft channel, also along the channel edge. For the existing channel conditions, there were no buoys struck during the inbound flood tide runs and one during the ebb tide. For the Plan A channel, there were four buoy strikes during the flood tide and seven during the ebb tide. Using the assumption stated in the previous paragraph, it becomes apparent that the increase of the handling difficulty rating with inbound ships in ballast with Plan A over the existing condition was a function of buoy placement. This is supported by a statement made by one pilot in his final questionnaire that the buoys should be placed further away from the channel edge. It appears that the buoy placement for the existing channcl tends to mark the 20 -it contour for inbound, light-loaded (or ballasted) vessels and the decper navigation channel for the loaded outbound vessels is unmarked. If the buoys had been placed away from the channel edge for Plan A and B as they were for the existing condition, the difficulty of the inbound runs with Plan A and B should be almost the same as for the existing channel, if not less. The buoy placement likcly increased the turning basin maneuver rating for Plan $\mathrm{A}$ also. The turning basin maneuver in the Anchorage Channel for Plan B is rated higher than the turning maneuver off the end of the pier for the existing condition for both ebb and flood tide and higher than Plan $\mathrm{A}$ for the flood tide. If the proposed turning basin had been availablc to the pilots for Plan $A$, the rating for Plan A would probably be much lower and the differentials to Plan B much greater. Although the averaged clearance distance indicated that turning in the Anchorage Channel could be done, examination of parameter plots, track plots, and pilots' comments indicate that turning in the Anchorage Channel during peak ebb and flood tide currents can be performed but is likely too difficult to be performed safely on a routine basis.

The outbound runs were rated by the pilots to be slightly more difficult for Plan A than the existing channel and slightly more difficult for Plan B than Plan A. The track plots for both Plan A and Plan B show much better runs with regard to staying within the defined channel than the existing channel. Plan A had only one pilot going outside the channel limit during an ebb tide run and Plan $\mathrm{B}$ had only one pilot going outside the channel limit during a flood tide run whereas the existing condition runs had many incidences of going out of the defined channel both to the north and south. None of the track plots clearly indicate why the pilots perceived the plan channels to be more difficult. The higher difficulty ratings for the plan channels may again be due to the placement of the buoys.

Based on the real-time pilot runs, the pilots' individual run evaluations, and 
comments made on their final questionnaires, the following preliminary conclusions were reached:

a. Inbound ships in ballast will be mostly unaffected by channel deepening or widening, except for positioning of the channel buoys and the proposed turning basin.

$b$. Plan A appears to provide adequate maneuvering room for the outbound transits with either the flood or ebb tide condition based on clearance distances and track plots.

c. Plan B appears to provide adequate maneuvering room for the outbound transits with either the flood or ebb tide condition, but provides less maneuvering room from the terminal to the end of Caven Point Pier than Plan A.

d. The design of the flare from the Claremont Channel to the Anchorage Channel is adequate.

e. Turning in the Anchorage Channel can be performed but is more difficult than turning off the end of the pier and increases the difficulty of the inbound transit due to backing a greater distance in strong cross currents and wind.

f. The proposed turning basin would improve inbound passage and turning during either ebb or flood tide.

\section{Recommendations}

Based on the pilot test results, comments, and conclusions reached, WES proposes the following:

a. Adopt either the Plan A or Plan B channel design. Both channel designs appear adequate for safe navigation, but Plan A provides slightly more clearance. If possible, remove the slight "dog-leg" in the channel so only one set of range markers would be needed.

b. Set the buoys to mark the 20 -ft channel contour for inbound traffic and install ranges to mark the $34-\mathrm{ft}$ navigation channel for outbound traffic.

c. Adopt the proposed turning basin, dredged to $-20 \mathrm{ft} \mathrm{mlw}$ if turning is to be performed off the end of the pier. Suggested modifications to the turning basin design and suggested marking of the basin are in Plate 43.

d. Restrict turning in the Anchorage Channel to slack or near slack tide conditions or provide additional channel by dredging to $-20 \mathrm{ft} \mathrm{mlw}$ along 
the northern edge of the channel as shown in Plate 44.

e. Dredge the southwest corner of the Claremont-Picrhead Channel intersection to provide additional area for turning counterclockwise off the end of the pier as shown in Plate 44. 


\begin{tabular}{|c|c|c|c|c|c|}
\hline \multicolumn{6}{|c|}{$\begin{array}{l}\text { Table } 1 \\
\text { Tabulation of Individual Pilot Runs }\end{array}$} \\
\hline \multicolumn{5}{|c|}{ TABULATION OF INDIVIDUAL PILOT RUNS } & PAGE 1 \\
\hline PILOT & PLAN & TIDE & DIRECTION & FIGURE NO. & \\
\hline C & EXISTING & EBB & INBOUND & 1 & Bow elightly outside $20^{\circ}$ contour near entrence \\
\hline 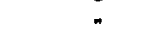 & $n$ & 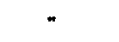 & OUTBOUND & 2 & Out along southern odge of channal \\
\hline - & $\cdot$ & FLOOD & INBOUND & 3 & OK \\
\hline - & " & n & OUTBOUND & 4 & Out to north near terminal, well out on eourth from ond of pler to flare \\
\hline " & PLAN A & EBB & INBOUND & 5 & Struck northern outer buoy and buoy opposito and of pior \\
\hline " & - & $\cdot$ & OUTBOUND & 6 & oK \\
\hline - & - & FLOOD & INBOUND & 7 & ok \\
\hline - & " & 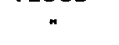 & OUTBOUND & 8 & Out elightly to eouth between Inner and outer buove \\
\hline - & PLAN B & EBB & INBOUND & 9 & Struck southern buoy at flare \\
\hline - & 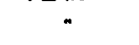 & - & OUTBOUND & 10 & OK \\
\hline " & $*$ & FLOOD & INBOUND & 11 & Struck southern inner buoy, out to north near mid-length of pler \\
\hline$n$ & * & $\cdot$ & OUTBOUND & 12 & Out to north near mid-longth of pler \\
\hline D & EXISTING & EBB & INBOUND & 13 & Struck northern buoy marking flaro, bow out over $20^{\circ}$ contour \\
\hline - & $n$ & - & OUTBOUND & 14 & Out to south near ond of pier, out to north juat before the flare \\
\hline$\cdot$ & " & FLOOD & INBOUND & 15 & ok \\
\hline " & n & $\cdot$ & OUTBOUND & 16 & Out to north near terminal, wall out to eouth from ond of piar to flare \\
\hline " & PLAN A & EBB & INBOUND & 17 & Struck northern outer buoy and eouthern inner buoy, out to south inner buoy \\
\hline - & 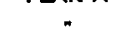 & - & OUTBOUND & 18 & Out to north near mid-length of pler and near north inner buoy, etruck north inner buoy \\
\hline " & " & FLOOD & INBOUND & 19 & Struck outer northorn buoy, struck pier \\
\hline " & " & $\sim$ & OUTBOUND & 20 & OK \\
\hline " & PLAN B & EBB & INBOUND & 21 & OK \\
\hline " & " & " & OUTBOUND & 22 & Out very elightly $\left(<10^{\prime}\right)$ to north near outer buoy \\
\hline " & " & FLOOD & INBOUND & 23 & Struck eouthern outer buoy, out to north near inner buoy \\
\hline " & " & - & OUTBOUND & 24 & Slightly out to north near buoy marking channel width change, near south odge at outer buoy \\
\hline $\mathbf{E}$ & EXISTING & EBB & INBOUND & 25 & Stern out slightiy to south near eouthern inner buoy \\
\hline " & - & $\cdot$ & OUTBOUND & 26 & Out to north near terminal, out to south from ond of pier to flere \\
\hline$"$ & * & FLOOD & INBOUND & 27 & Stern out to north of $20^{\circ}$ contour between buoye, bow out ellightiy in baein, out to north neer mid-length of pier \\
\hline * & " & $n$ & OUTBOUND & 28 & Out to north opposite of terminal, out to south from mid-length of pior to flare \\
\hline " & PLAN A & EBB & INBOUND & 29 & Struck southern inner buoy, stern out to south at eame buoy \\
\hline " & $\cdots$ & $\cdots$ & OUTBOUND & 30 & oK \\
\hline " & " & FLOOD & INBOUND & 31 & Out to north between buoys and to north at mid-tength of pior \\
\hline " & - & - & OUTBOUND & 32 & ok \\
\hline " & PLAN B & EBB & INBOUND & 33 & Struck southern inner buoy, bow out slightly to south over $\mathbf{2 0}$ contour near mid-length of pier \\
\hline " & 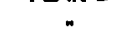 & 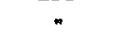 & OUTBOUND & 34 & OK. \\
\hline - & - & FLOOD & INBOUND & 35 & Struck northern inner buoy, etuck buoy marklng channel width chango \\
\hline " & $*$ & 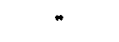 & OUTBOUND & 36 & oK \\
\hline
\end{tabular}




\begin{tabular}{|c|c|c|c|c|c|}
\hline \multicolumn{6}{|c|}{ Table 1 (Concluded) } \\
\hline \multicolumn{5}{|c|}{ TABULATION OF INDIVIDUAL PILOT RUNS } & \multirow{2}{*}{$\begin{array}{l}\text { PAGE } 2 \\
\text { RESULTS } \\
\end{array}$} \\
\hline PILOT & PLAN & TIOE & DIRECTION & FIGURE NO. & \\
\hline $\mathbf{F}$ & EXISTING & EBB & INBOUND & 37 & OK \\
\hline " & $\cdots$ & 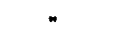 & OUTBOUND & 38 & Out to south for most of Claremont Channel \\
\hline " & . & FLOOD & INBOUND & 39 & OK \\
\hline " & . & - & OUTBOUND & 40 & Out alightly to north near terminal, out slightly to south near flare \\
\hline " & PLAN A & EBB & INBOUND & 41 & Struck northern outer buoy \\
\hline " & $\cdot$ & 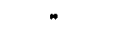 & OUTBOUND & 42 & oK \\
\hline - & - & FLOOD & INBOUND & 43 & OK \\
\hline " & " & 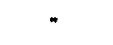 & OUTBOUND & 44 & OK \\
\hline " & PLAN B & EBB & INBOUND & 45 & OK \\
\hline - & $\cdot$ & $\cdot$ & OUTBOUND & 46 & OK \\
\hline - & " & FLOOD & INBOUND & 47 & OK \\
\hline " & " & " & OUTBOUND & 48 & oK \\
\hline G & EXISTING & EBB & INBOUND & 49 & Out to north opposite of torminal \\
\hline 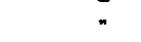 & - & 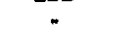 & OUTBOUND & 50 & Out to wouth from ond of pior to flare \\
\hline$\cdot$ & " & FLOOD & INBOUND & 51 & Out to north betwoen buove, woll ourt to eouth opposite end of pior \\
\hline 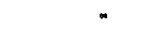 & " & " & OUTBOUND & 52 & Vory near edge of channol to south \\
\hline$\cdot$ & PLAN A & EBB & INBOUND & 53 & Struck southern inner buoy \\
\hline * & 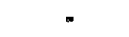 & - & OUTBOUND & 54 & ok \\
\hline * & " & FLOOD & INBOUND & 55 & Out to north near Inner buoy, struck same buoy, out to eouth opposite end of pier, out to north opposite terminal \\
\hline * & * & $\cdot$ & OUTBOUND & 56 & ok \\
\hline " & PLAN B & EBB & INBOUND & 57 & Out to north opposite terminal \\
\hline - & - & - & OUTBOUND & 58 & ok \\
\hline " & - & FLOOD & INBOUND & 59 & OK \\
\hline " & " & * & OUTBOUND & 60 & OK \\
\hline H & EXISTING & EBB & INBOUND & 61 & OK \\
\hline " & - & $\cdot$ & OUTBOUND & 62 & Out to south for most of Ciaremont Channel \\
\hline$"$ & " & FLOOD & INBOUND & 63 & ok \\
\hline - & * & $\cdot$ & OUTBOUND & 64 & Out to north noar torminal, out to south noar flare \\
\hline " & PLAN A & EBB & INBOUND & 65 & OK \\
\hline$\cdot$ & - & " & OUTBOUND & 66 & Slightly out to outh from terminal to mid-longth of pler \\
\hline " & - & FLOOD & INBOUND & 67 & Out to north at innor buoy, struck same buyoy, out to south opposite ond of pier \\
\hline " & " & $\cdot$ & OUTBOUND & 68 & OK \\
\hline " & PLAN B & EBB & INBOUND & 69 & ok \\
\hline " & " & $\cdot$ & OUTBOUND & 70 & Very near to south edge of channel near mid-longth of pler \\
\hline * & " & FLOOD & INBOUND & 71 & Struck northern inner buoy \\
\hline " & - & 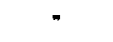 & OUTBOUND & 72 & OK \\
\hline
\end{tabular}




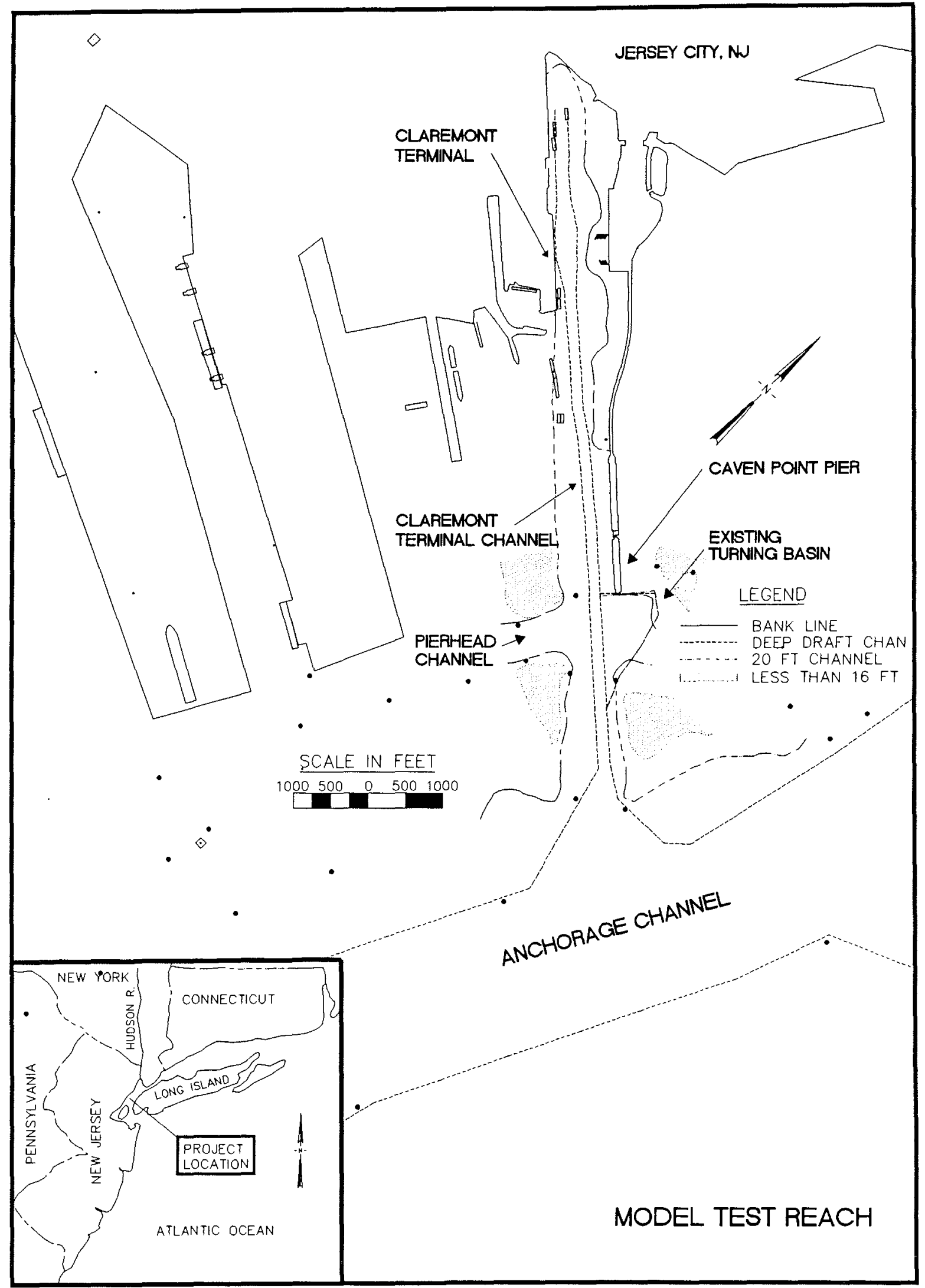

Plate 1 


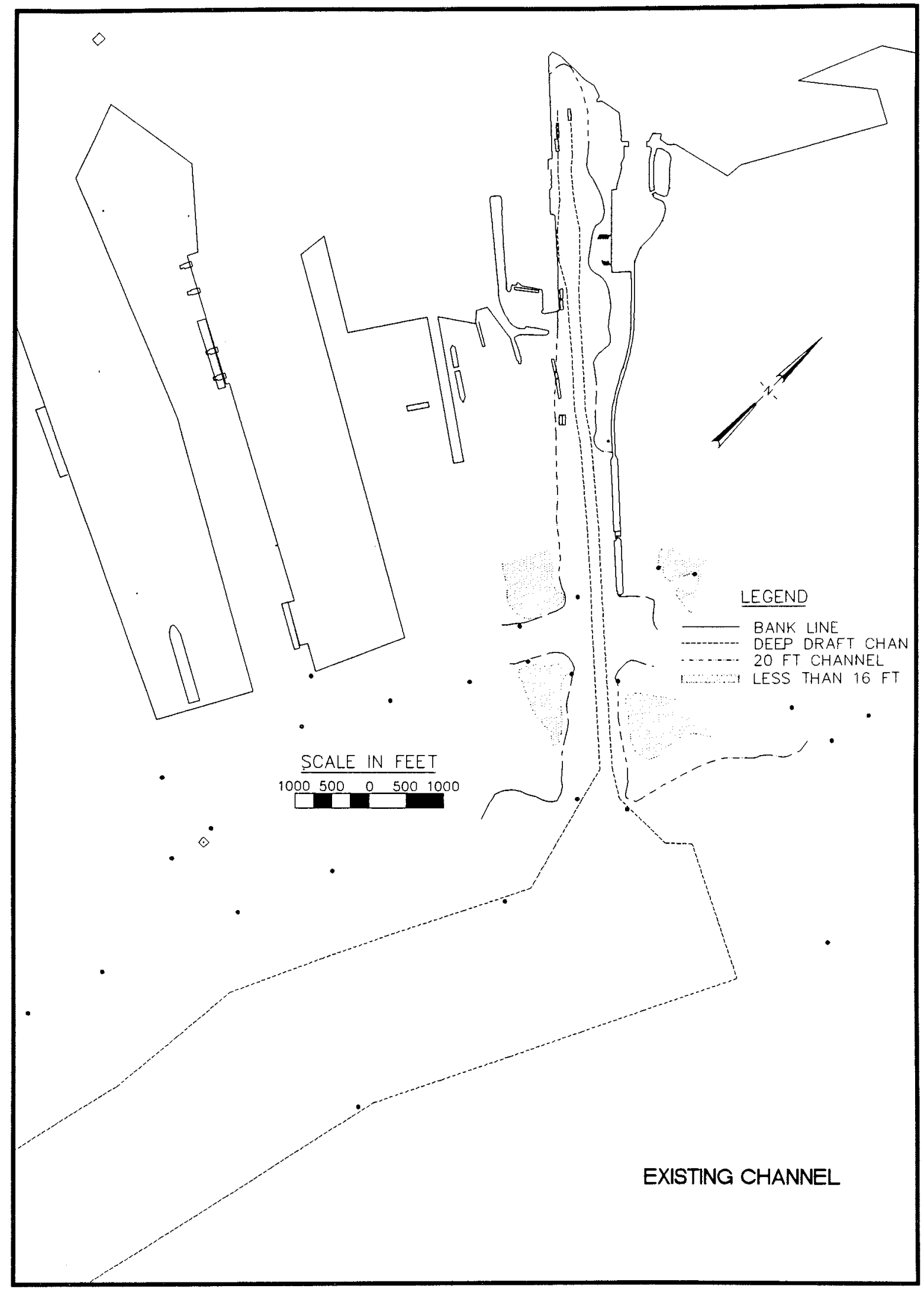

Plate 2 


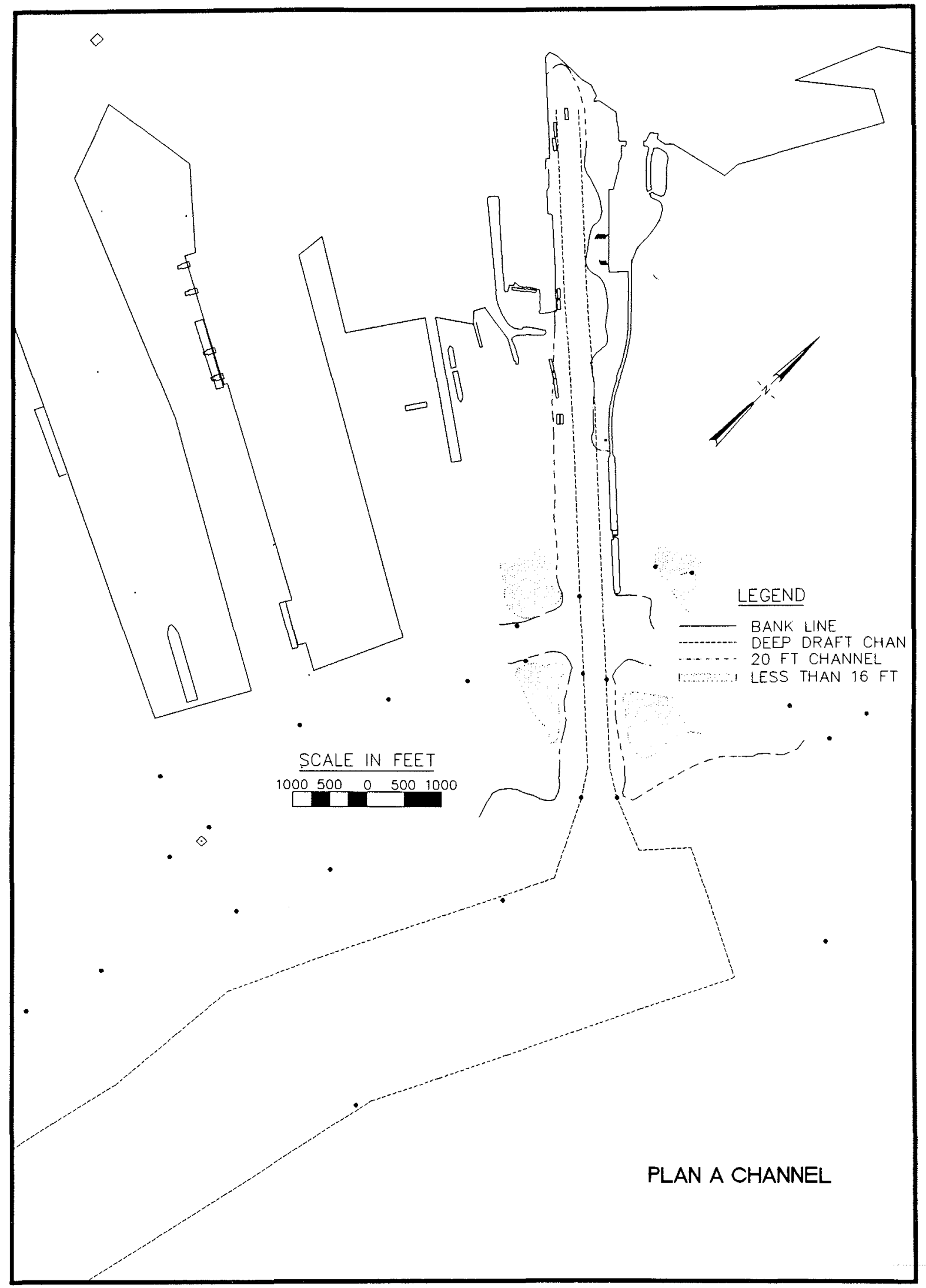

Plate 3 


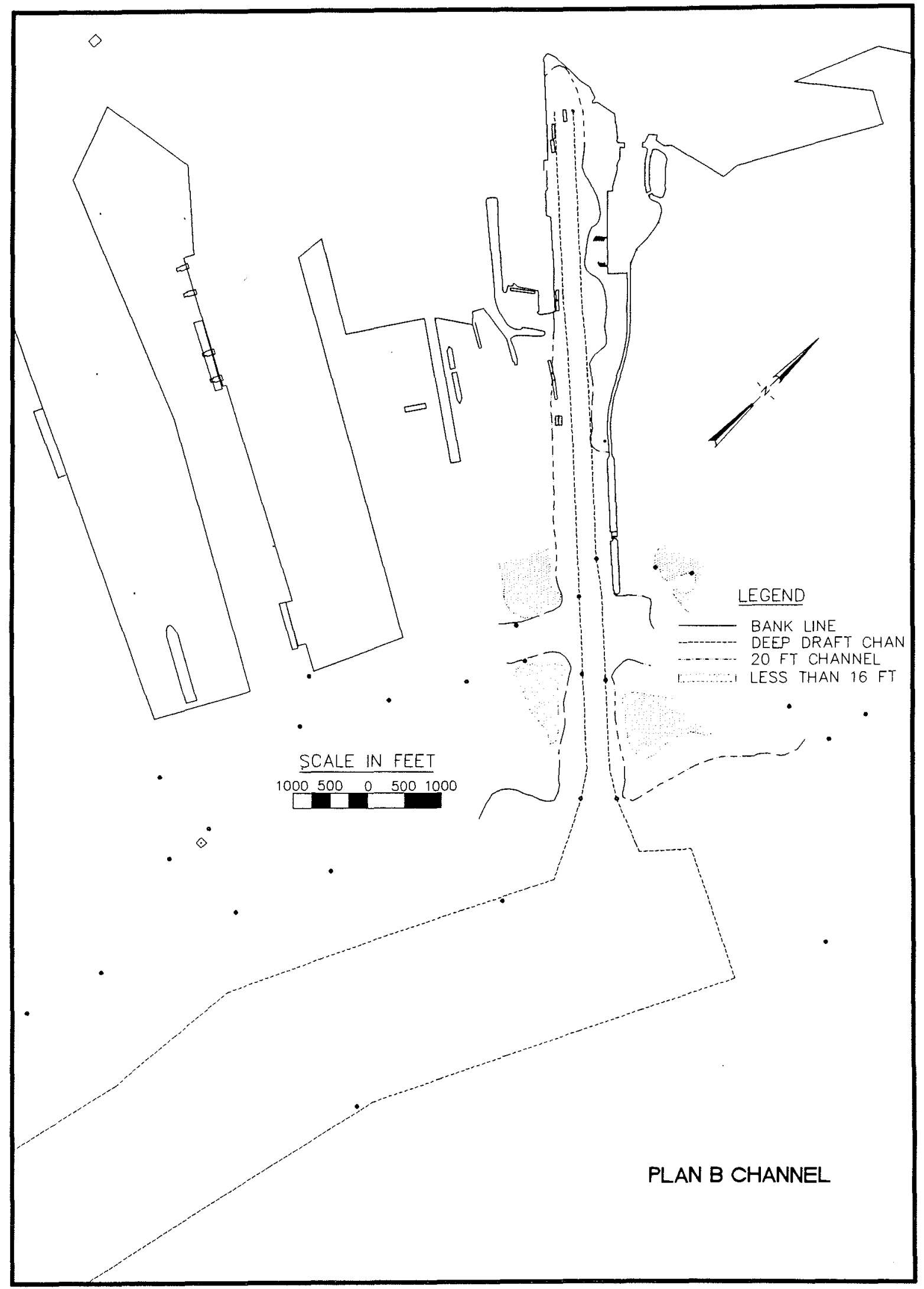

Plate 4 


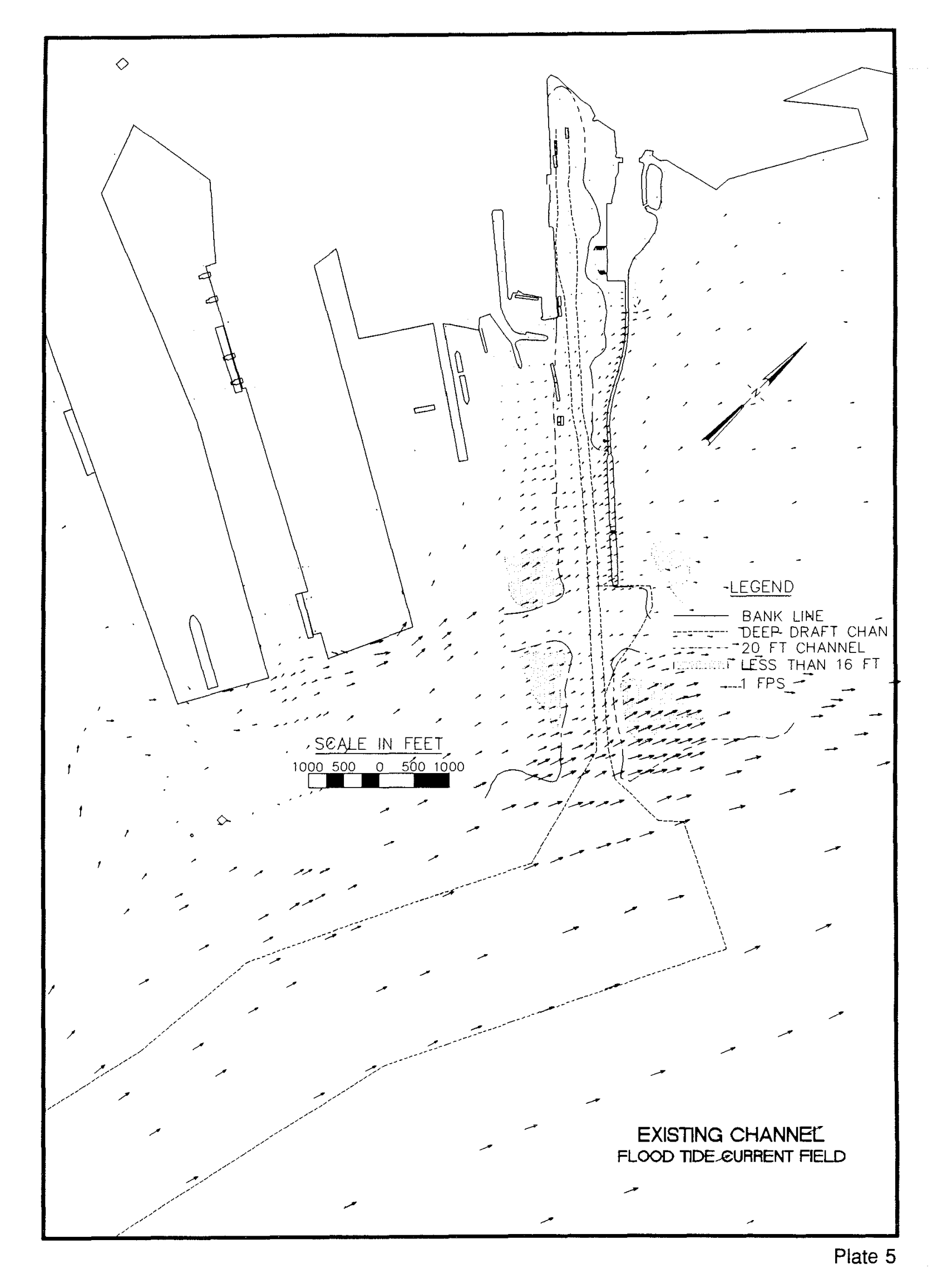




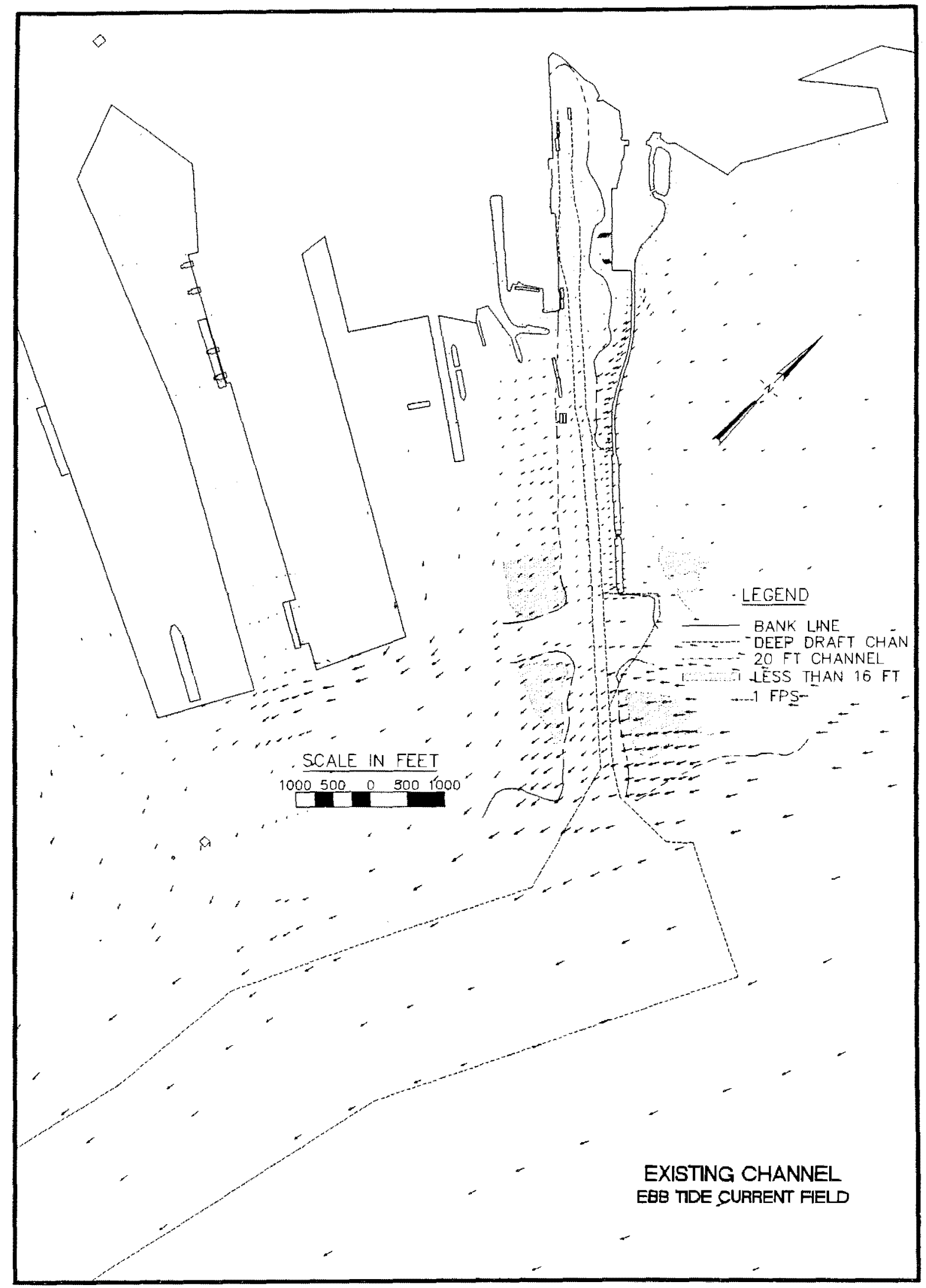

Plate 6 


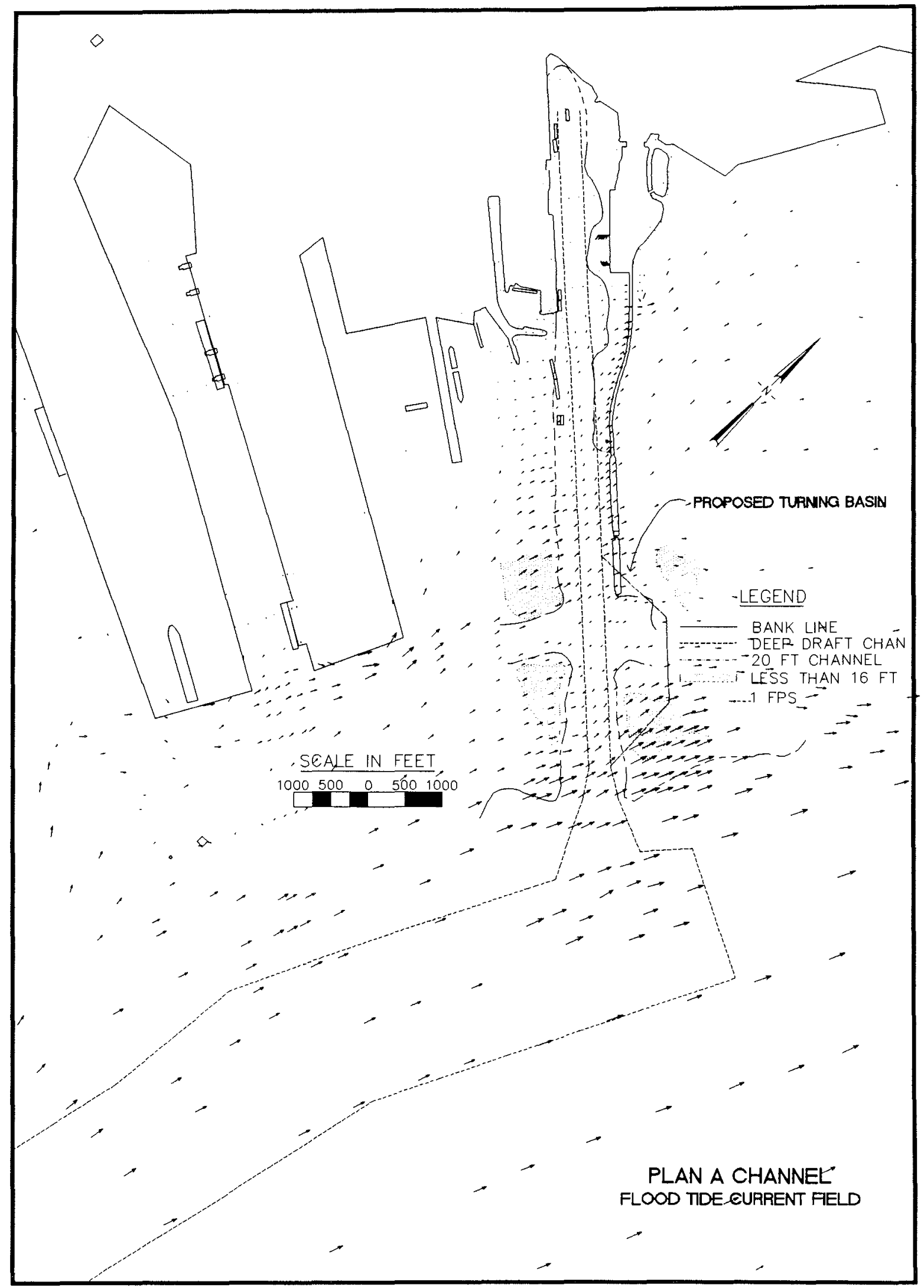

Plate 7 


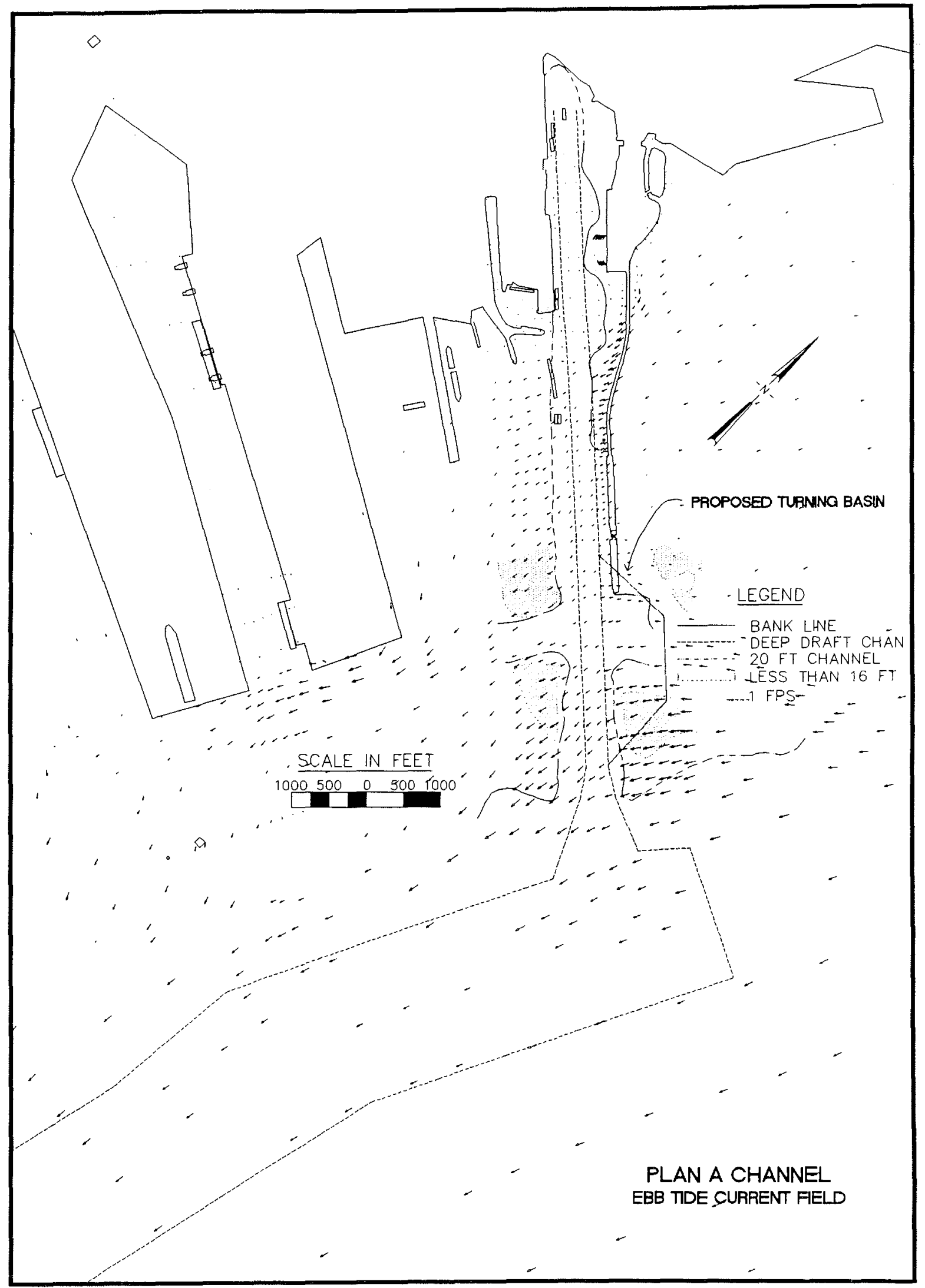

Plate 8 


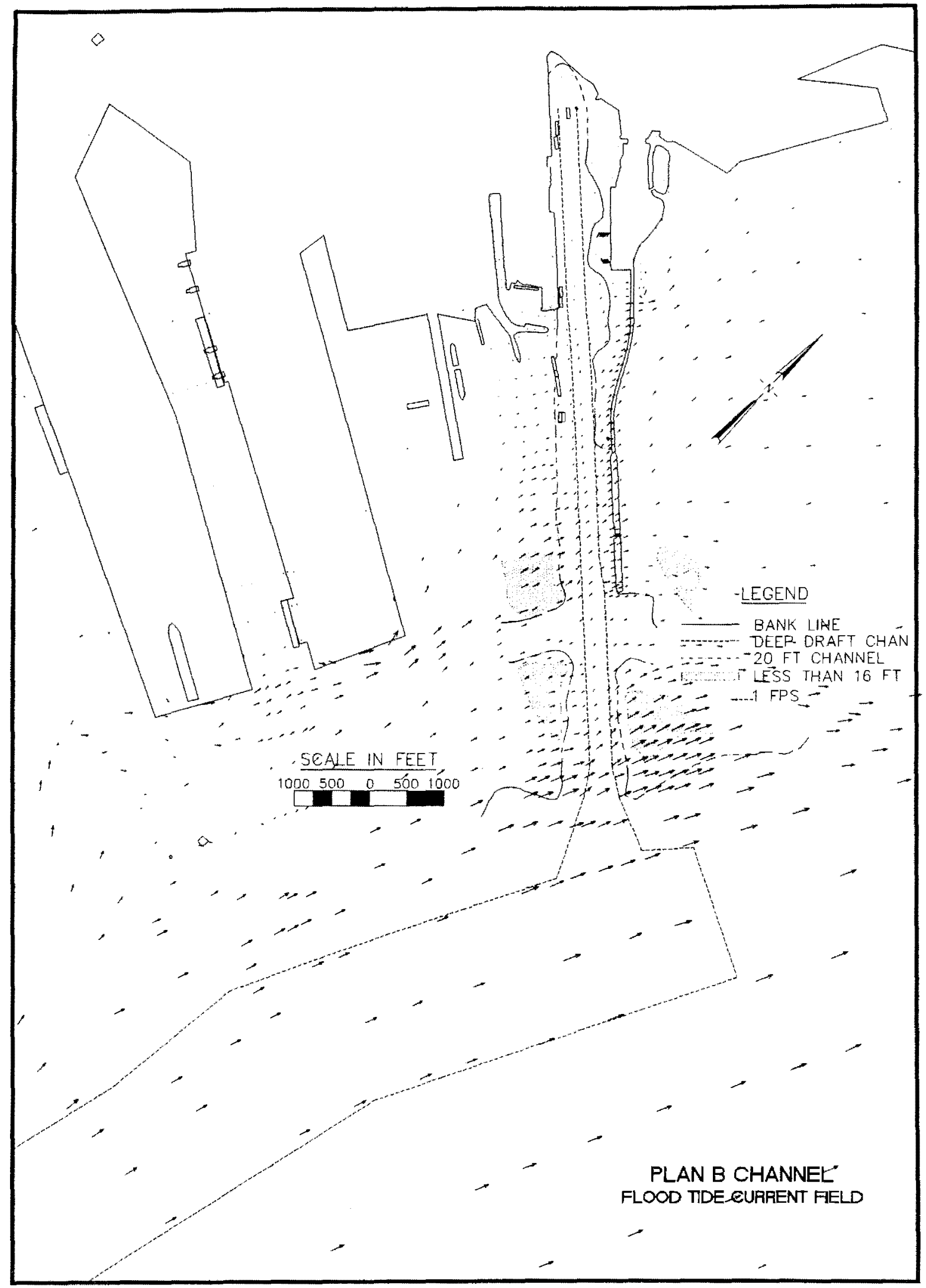

Plate 9 


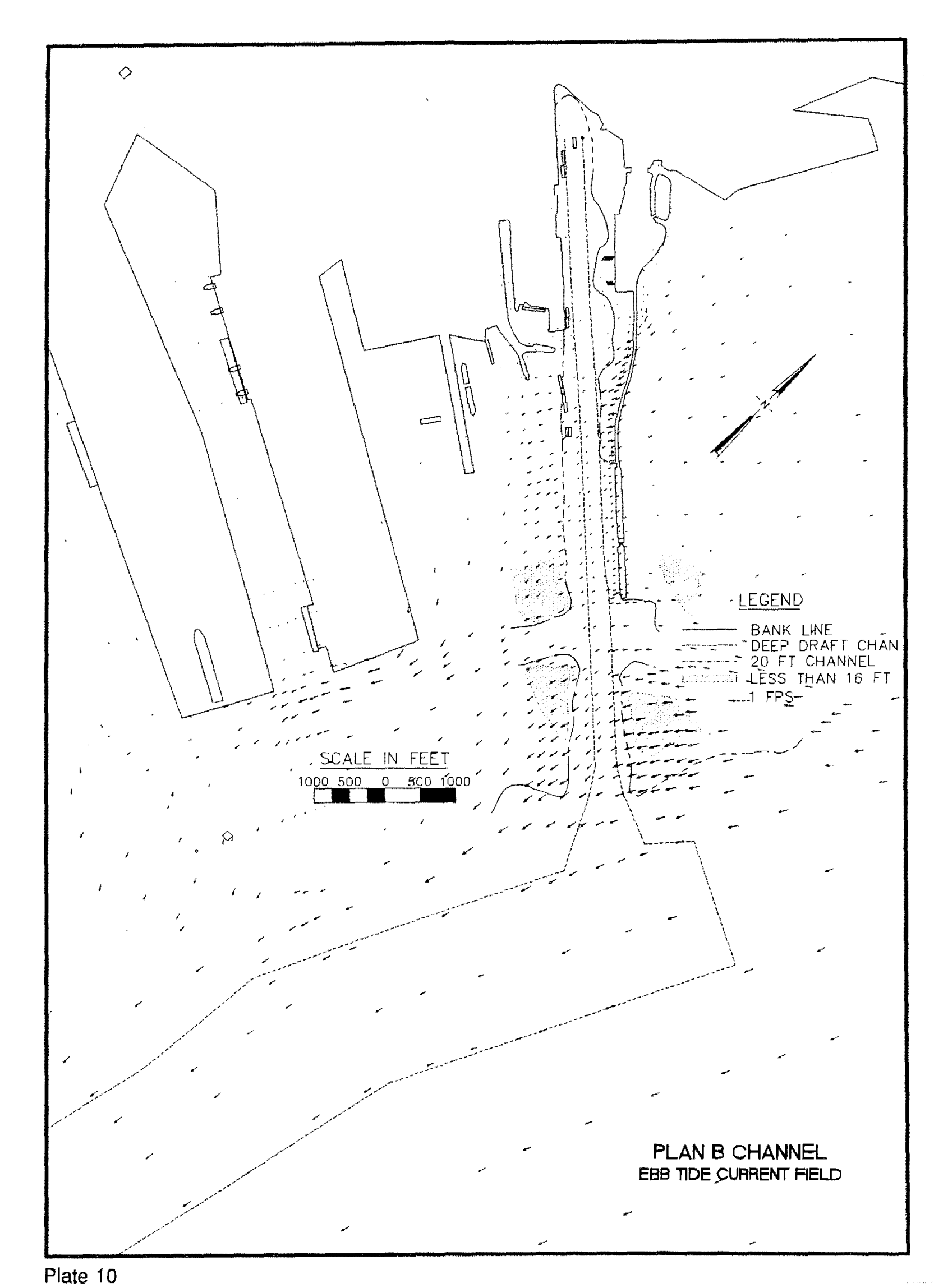




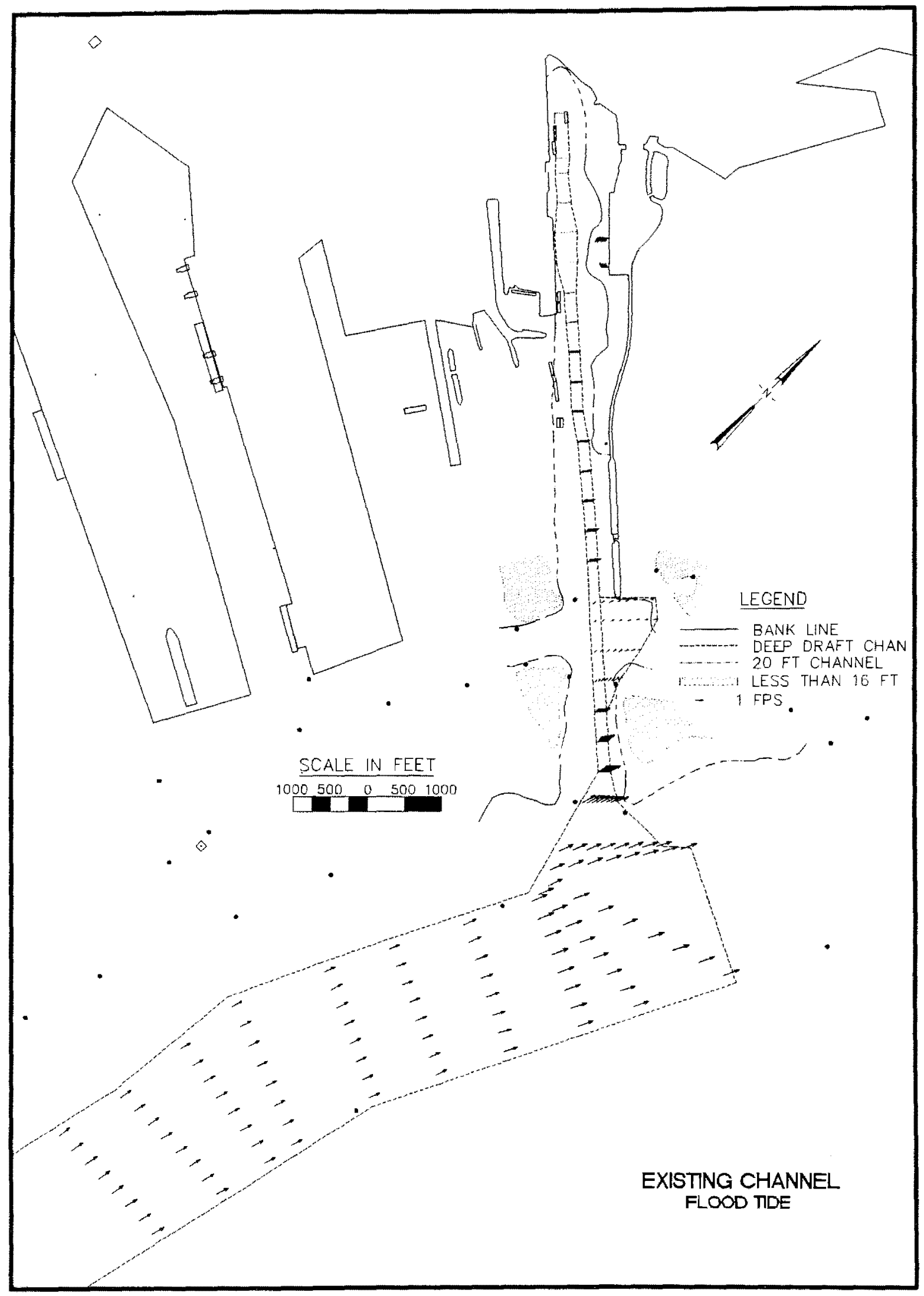

Plate 11 


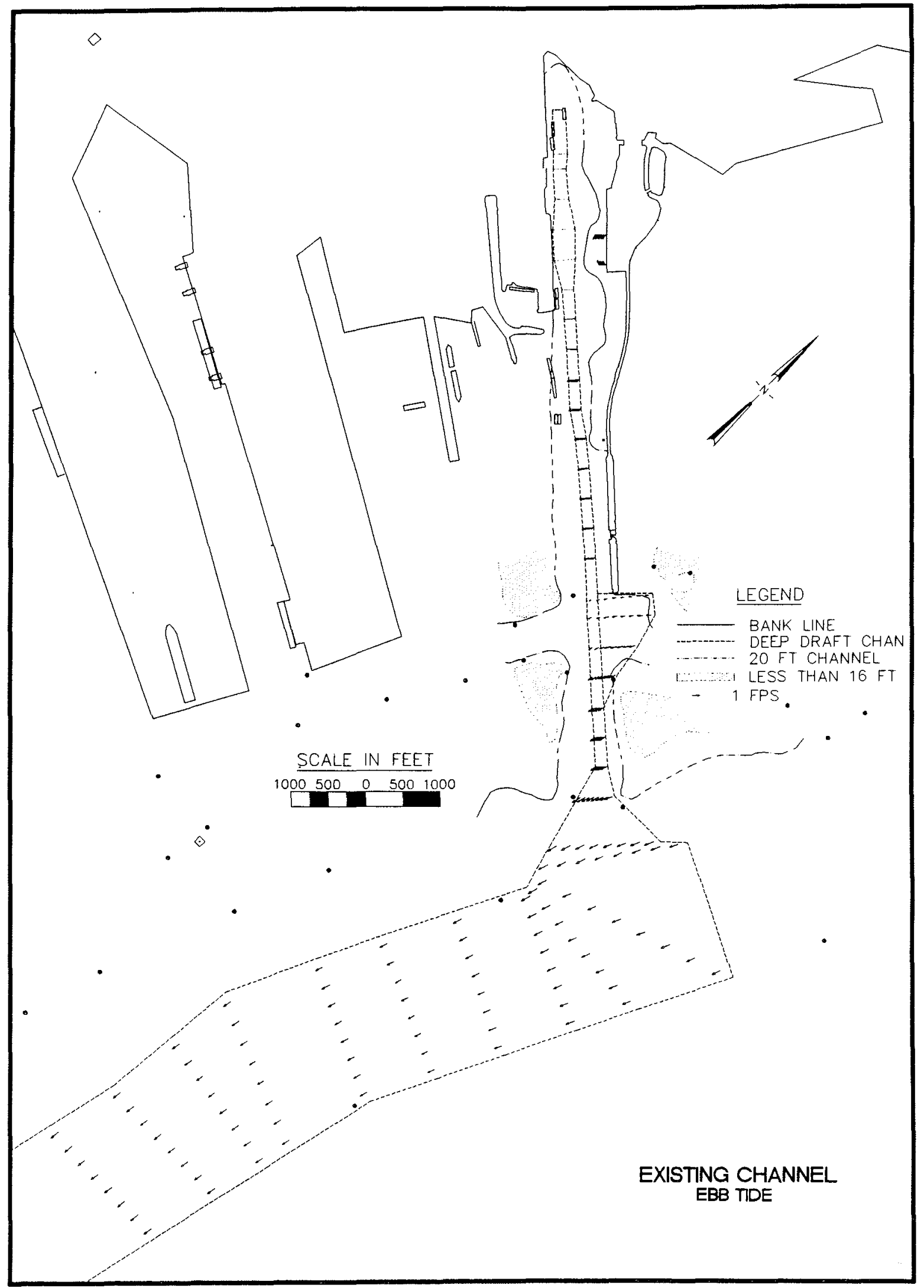

Plate 12 


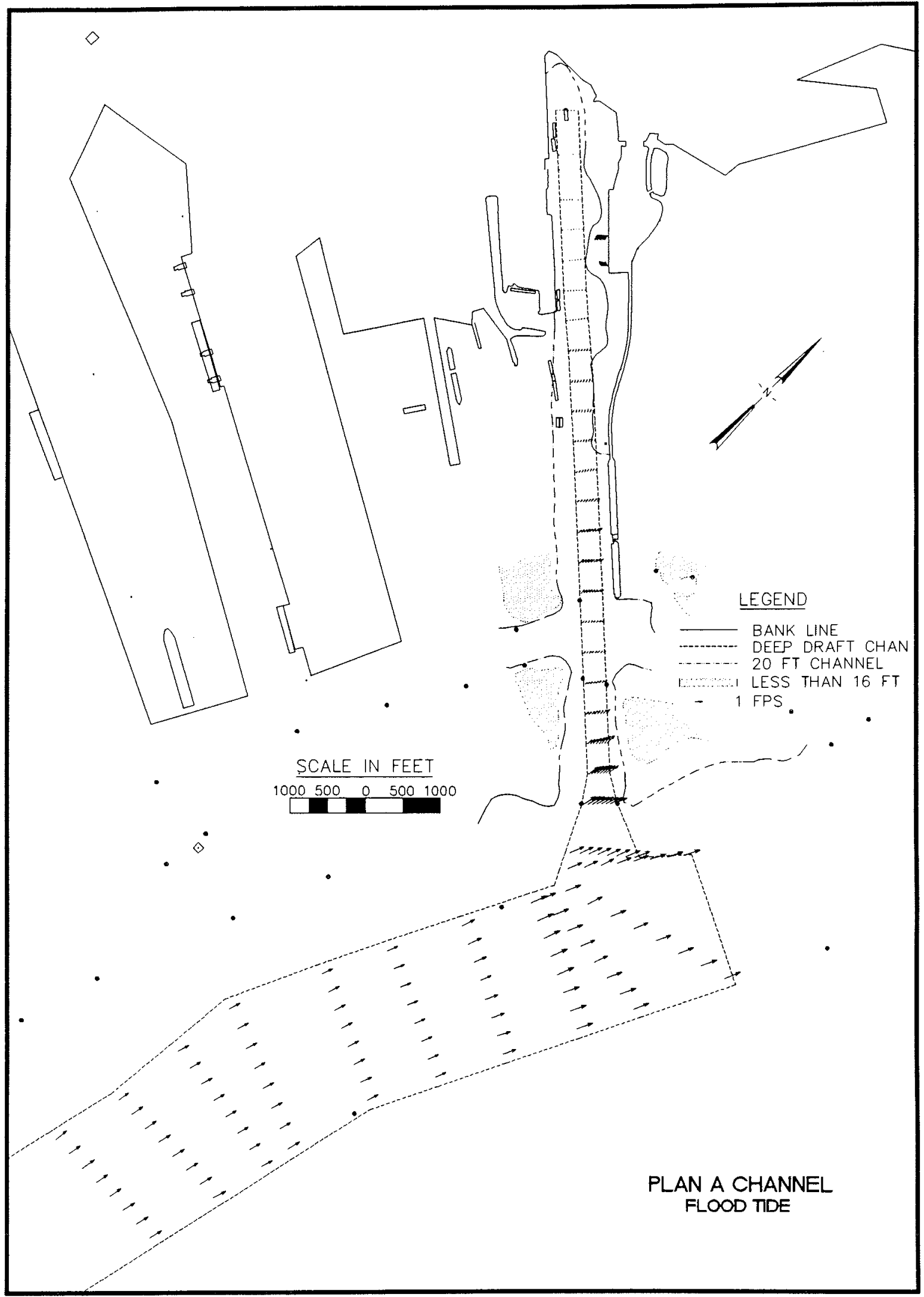

Plate 13 


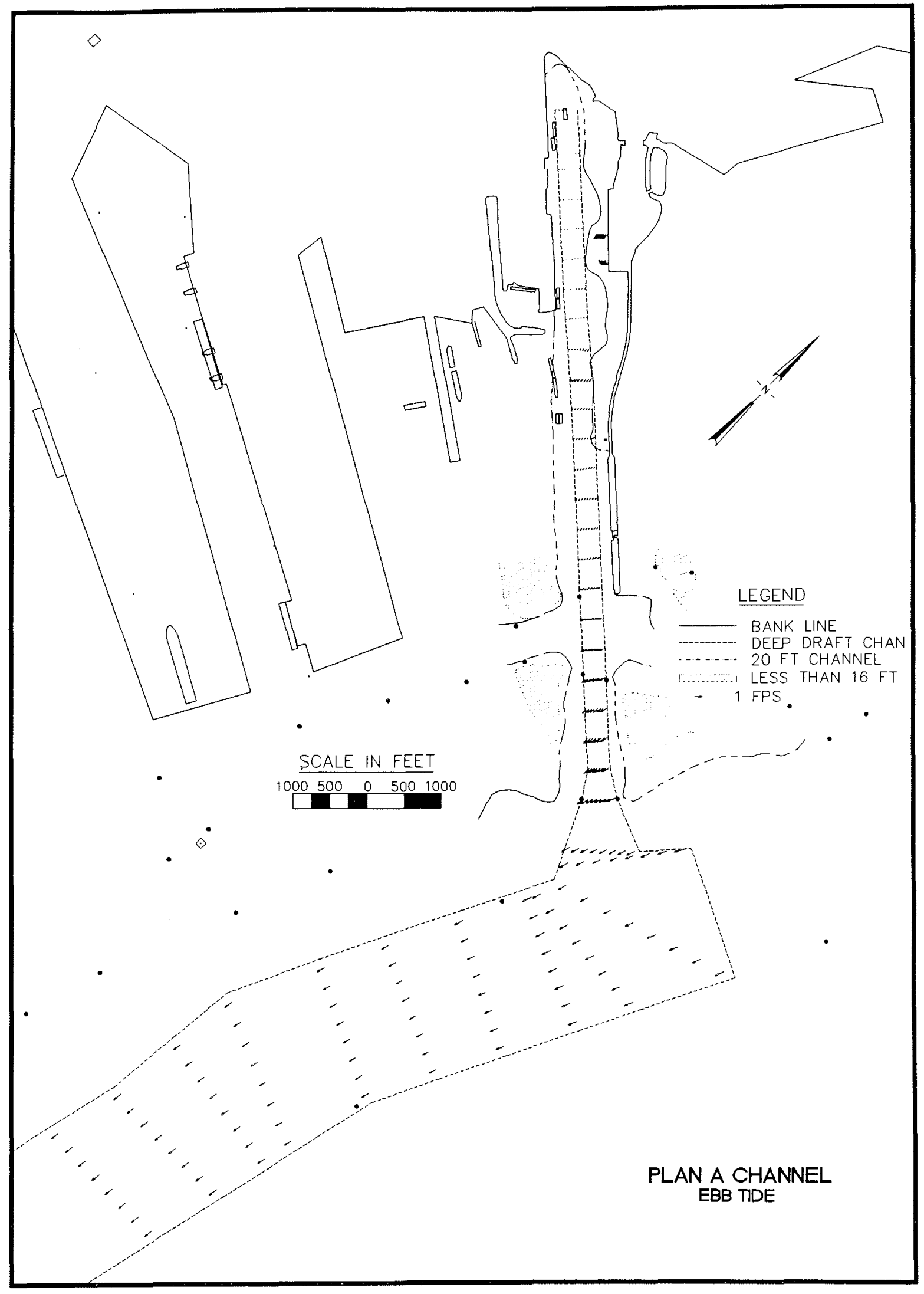

Plate 14 


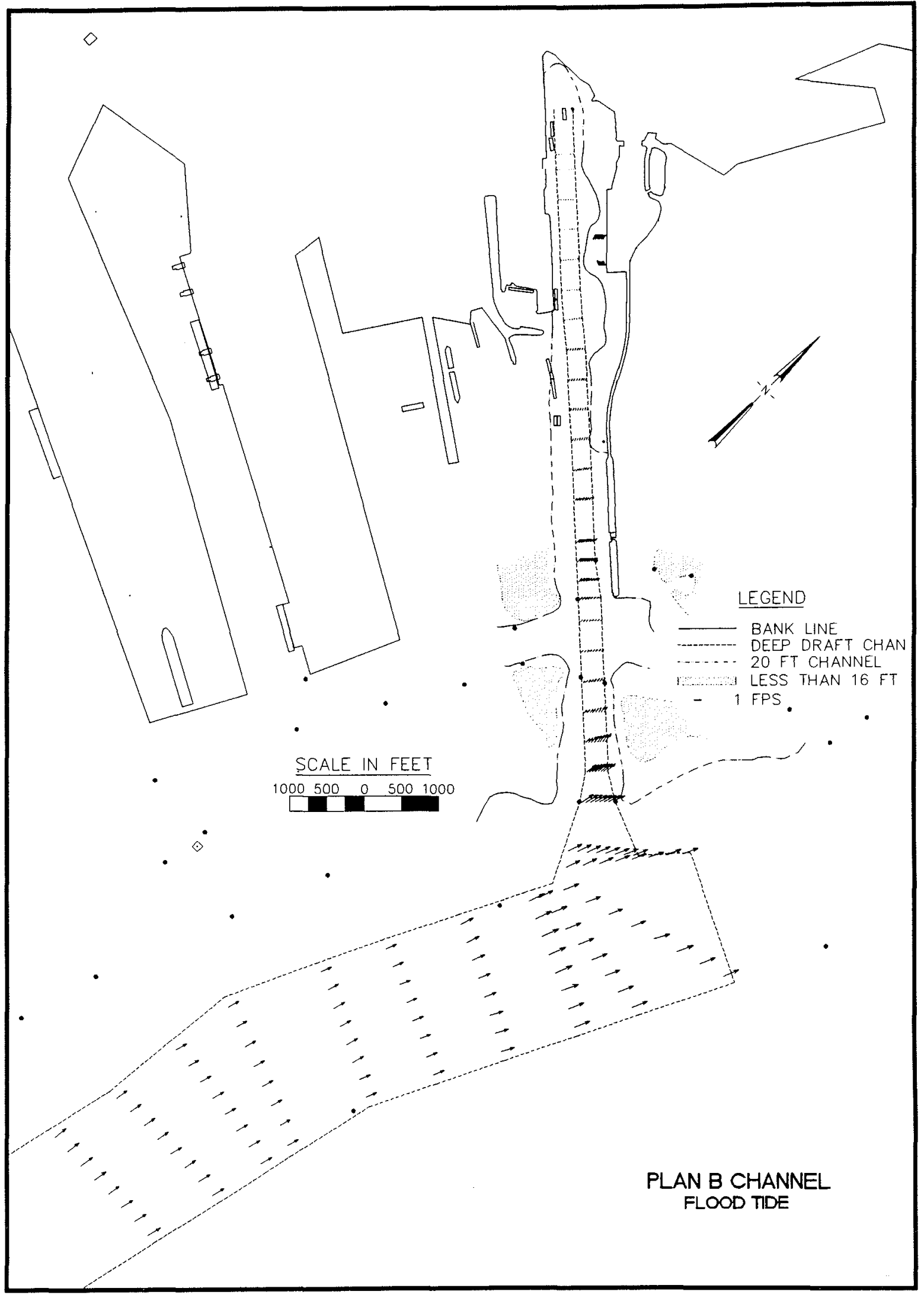

Plate 15 


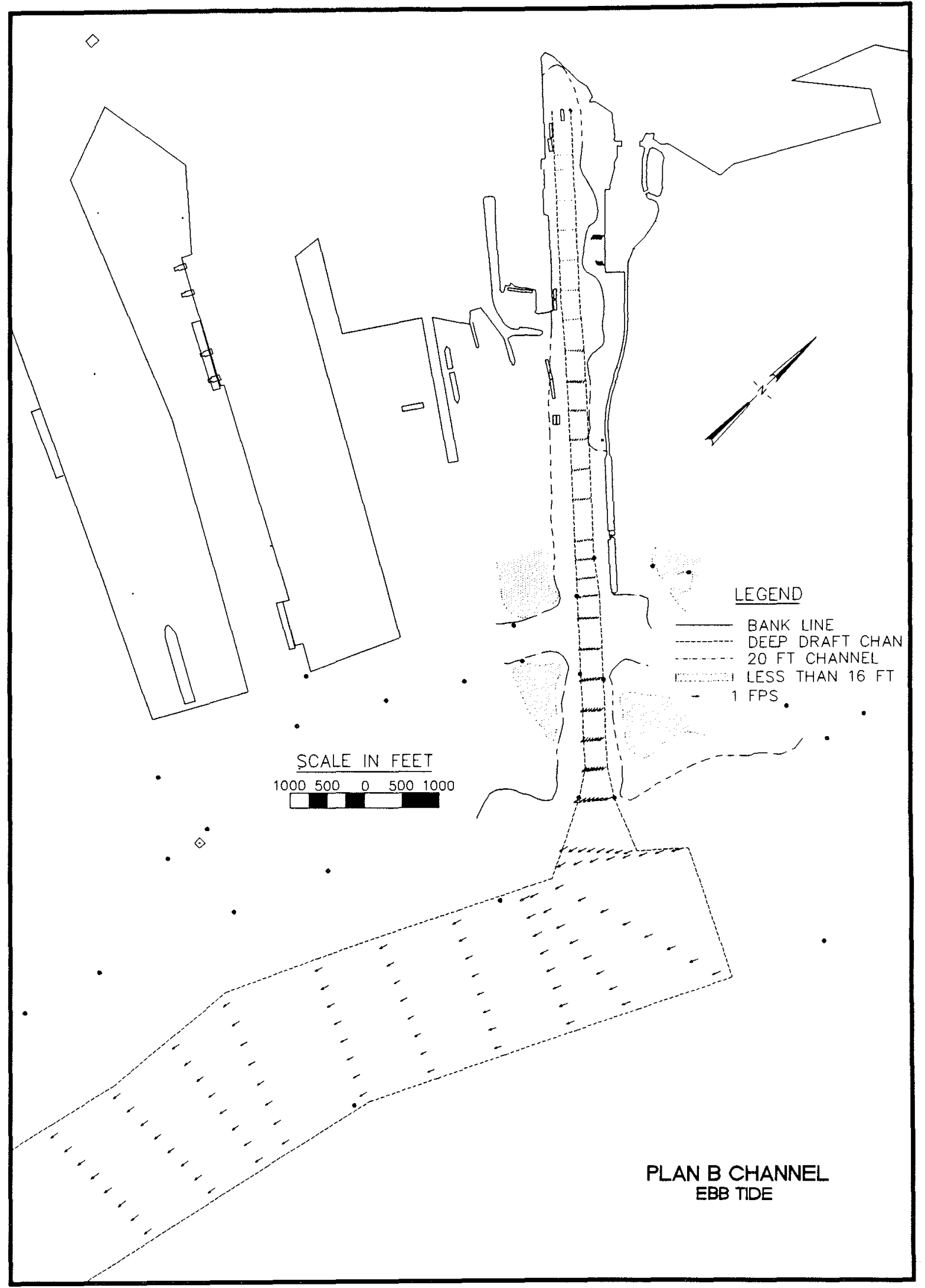

Plate 16 
CLAREMONT TERMINAL CHANNEL SIMULATION STUDY

PILOT RATINGS

PILOT:

RUN CODE:

DATE :

START TIME:

OUTPUT FILE:

END TIME:

The purpose of this questionnaire is to document your evaluation and observations concerning the simulator run you have just completed. Feel free to make any specific comments you feel will be helpful in interpreting you ratings.

1. Rate the difficulty of the run. EASY

$\begin{array}{llllllllll}0 & 1 & 2 & 3 & 4 & 5 & 6 & 7 & 8 & 9\end{array}$

2. Rate the effects of the current on the ship. LITTLE

$\begin{array}{llllllllll}0 & 1 & 2 & 3 & 4 & 5 & 6 & 7 & 8 & 9\end{array}$

3. Rate the bank effects on the handling of the ship. LITTLE

$\begin{array}{llllllllll}0 & 1 & 2 & 3 & 4 & 5 & 6 & 7 & 8 & 9\end{array}$

4. Rate the wind effects on the handling of the ship. LITTLE

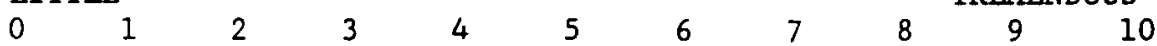

5. Rate the amount of attention required.

\begin{tabular}{lllllllllll}
\multicolumn{2}{l}{ LITTLE } \\
0 & 1 & 2 & 3 & 4 & 5 & 6 & 7 & 8 & 9 & 10
\end{tabular}

6. Rate the danger. of grounding or striking an object.

LITTLE TREMENDOUS

$\begin{array}{lllllllllll}0 & 1 & 2 & 3 & 4 & 5 & 6 & 7 & 8 & 9 & 10\end{array}$

7. Rate the realism of handling the simulator.

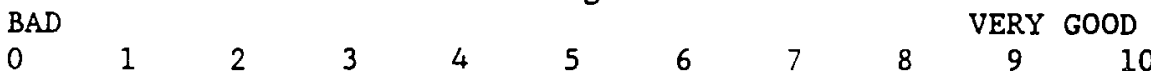

8. Rate the realism of the current effects.

BAD VERY GOOD

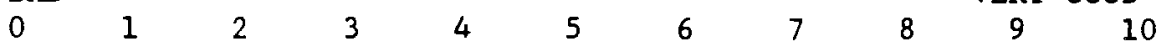

9. Rate the realism of the bank effects. $B A D$

$\begin{array}{llllllllll}0 & 1 & 2 & 3 & 4 & 5 & 6 & 7 & 8 & 9\end{array}$

10. Rate the realism of the wind effects.

BAD 104067 VERY GOOD

$\begin{array}{lllllllllll}0 & 1 & 2 & 3 & 4 & 5 & 6 & 7 & 8 & 9 & 10\end{array}$

11. Rate the difficulty of the turning maneuver (if applicable). LITTLE

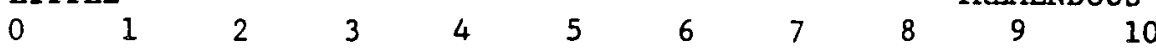

12. Comments : 


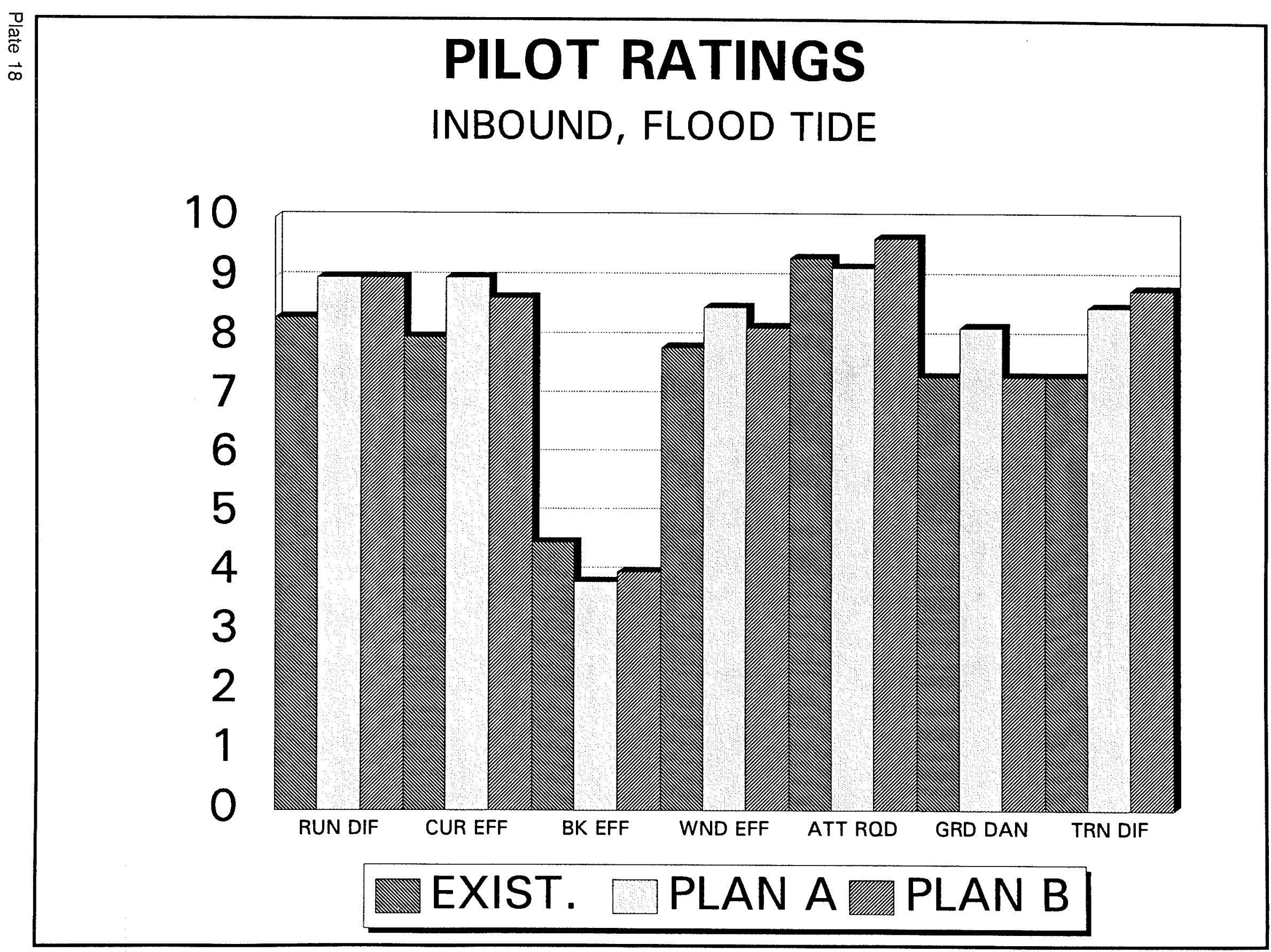




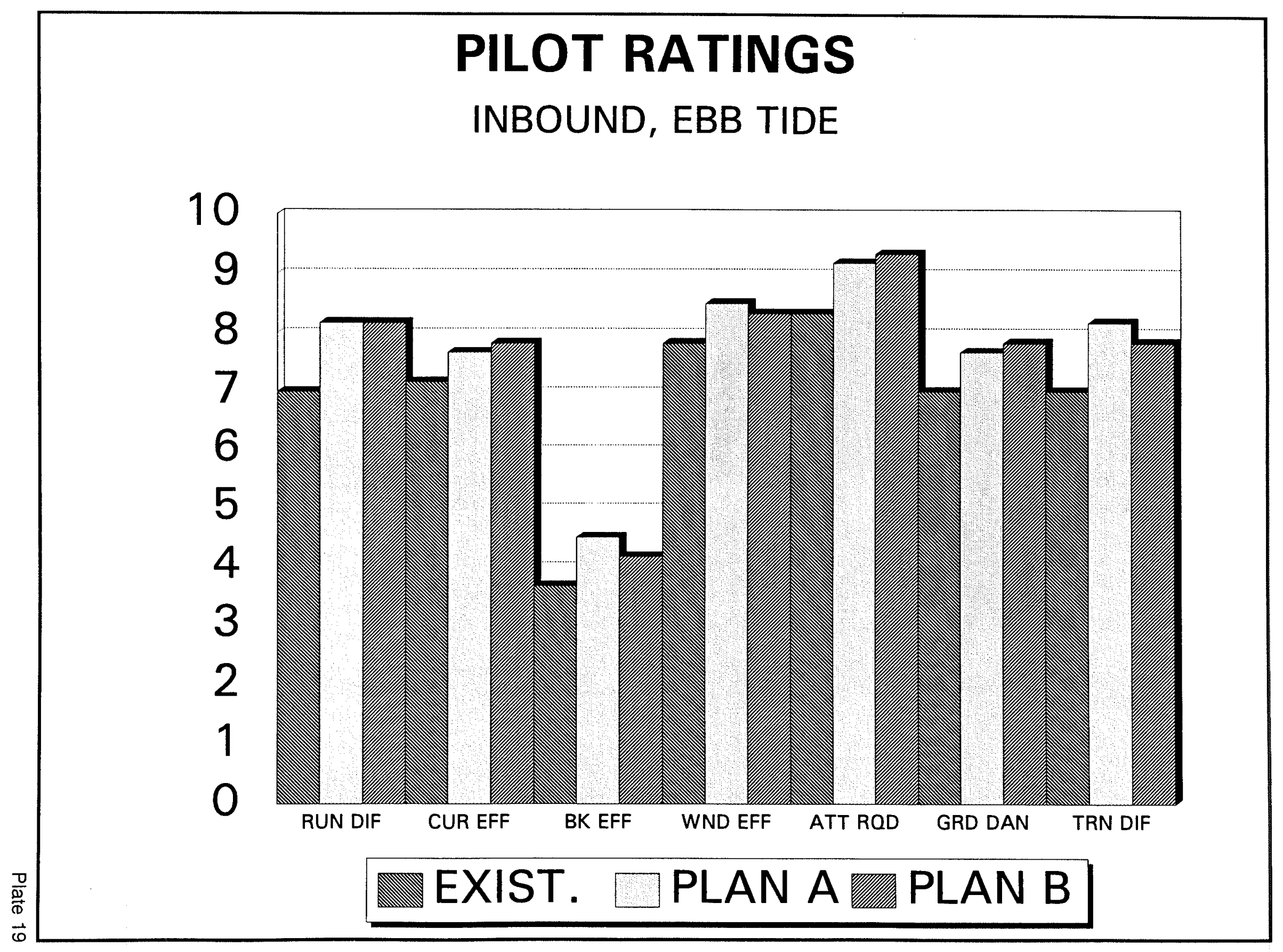




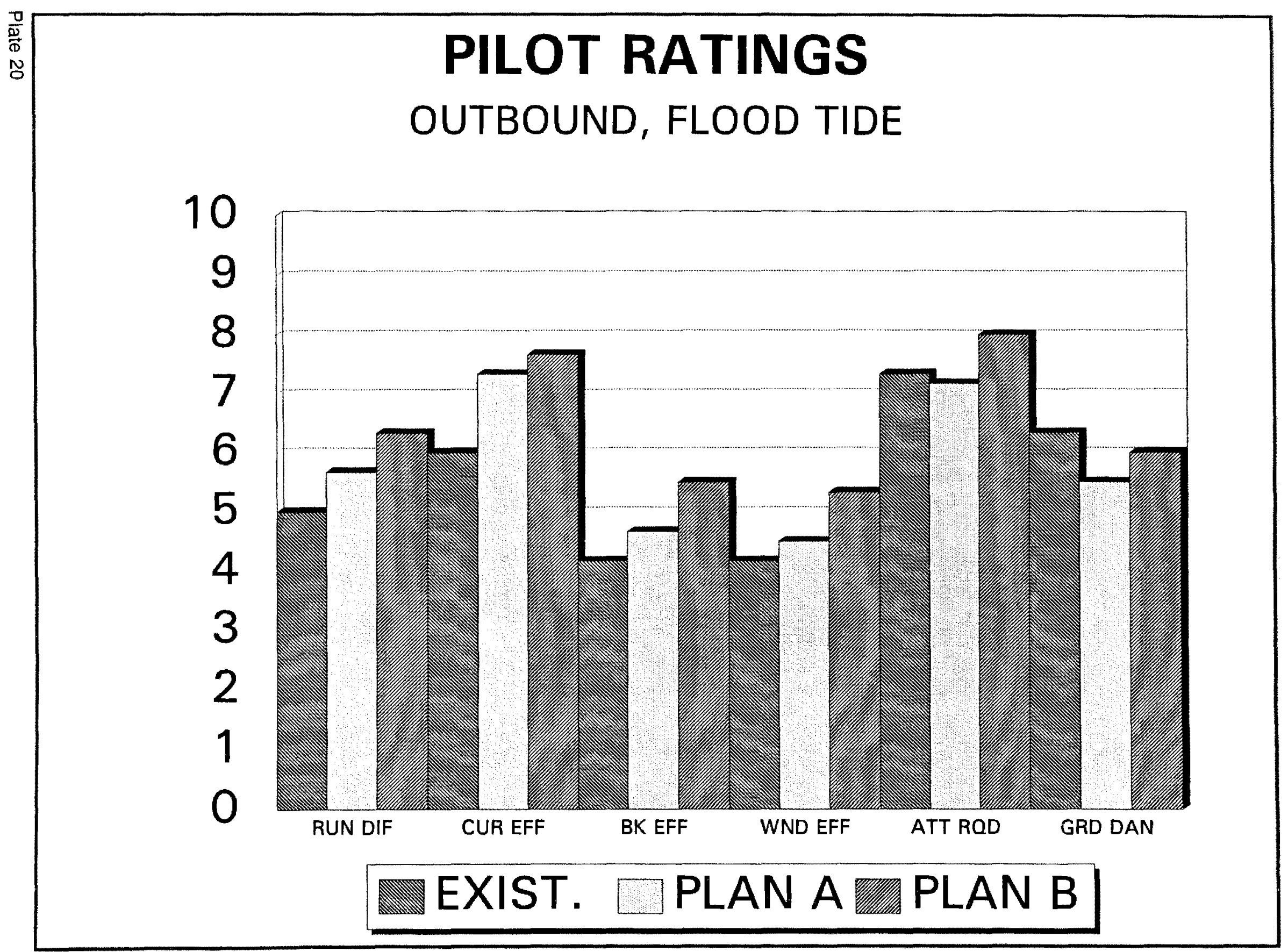




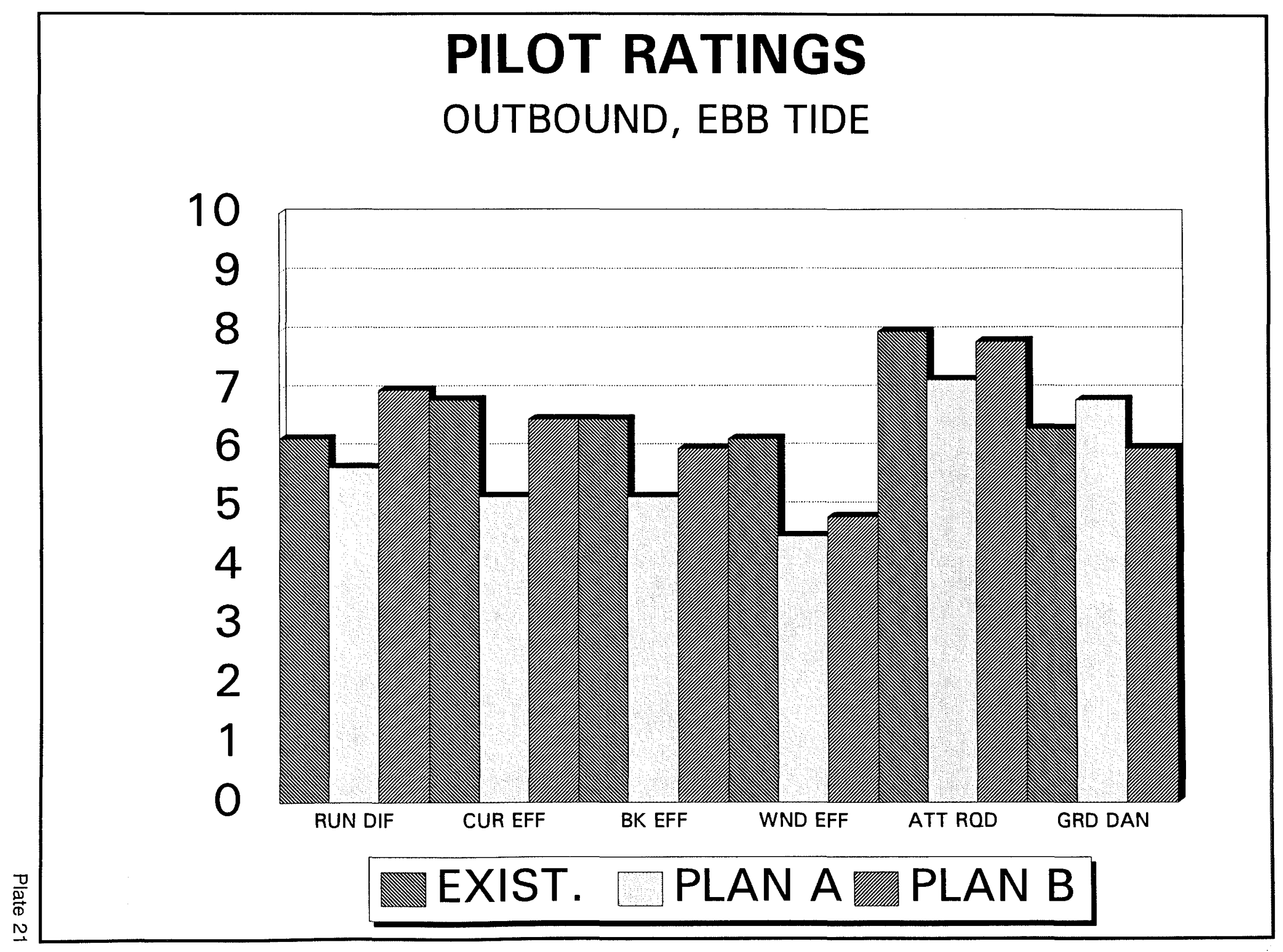




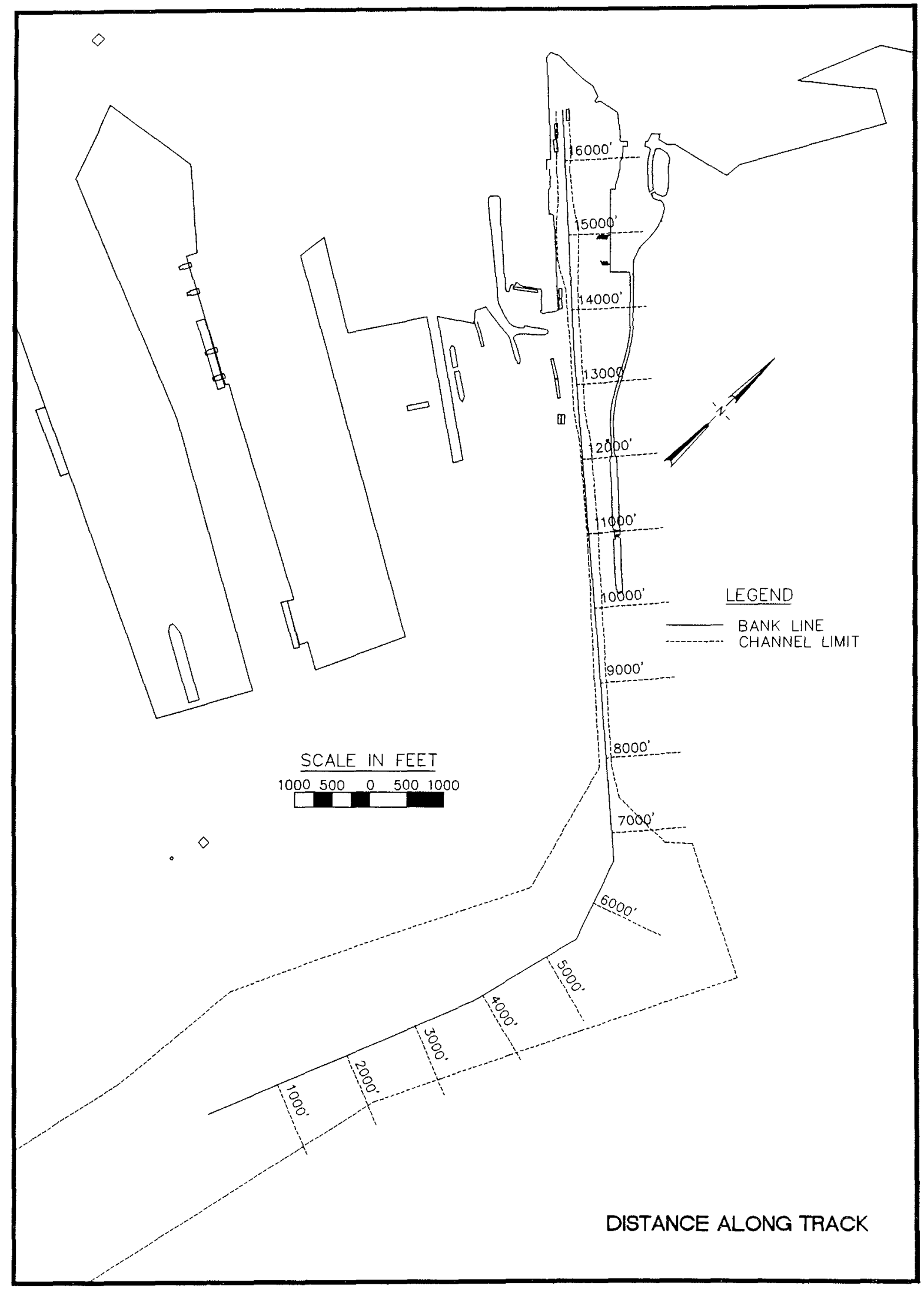

Plate 22 


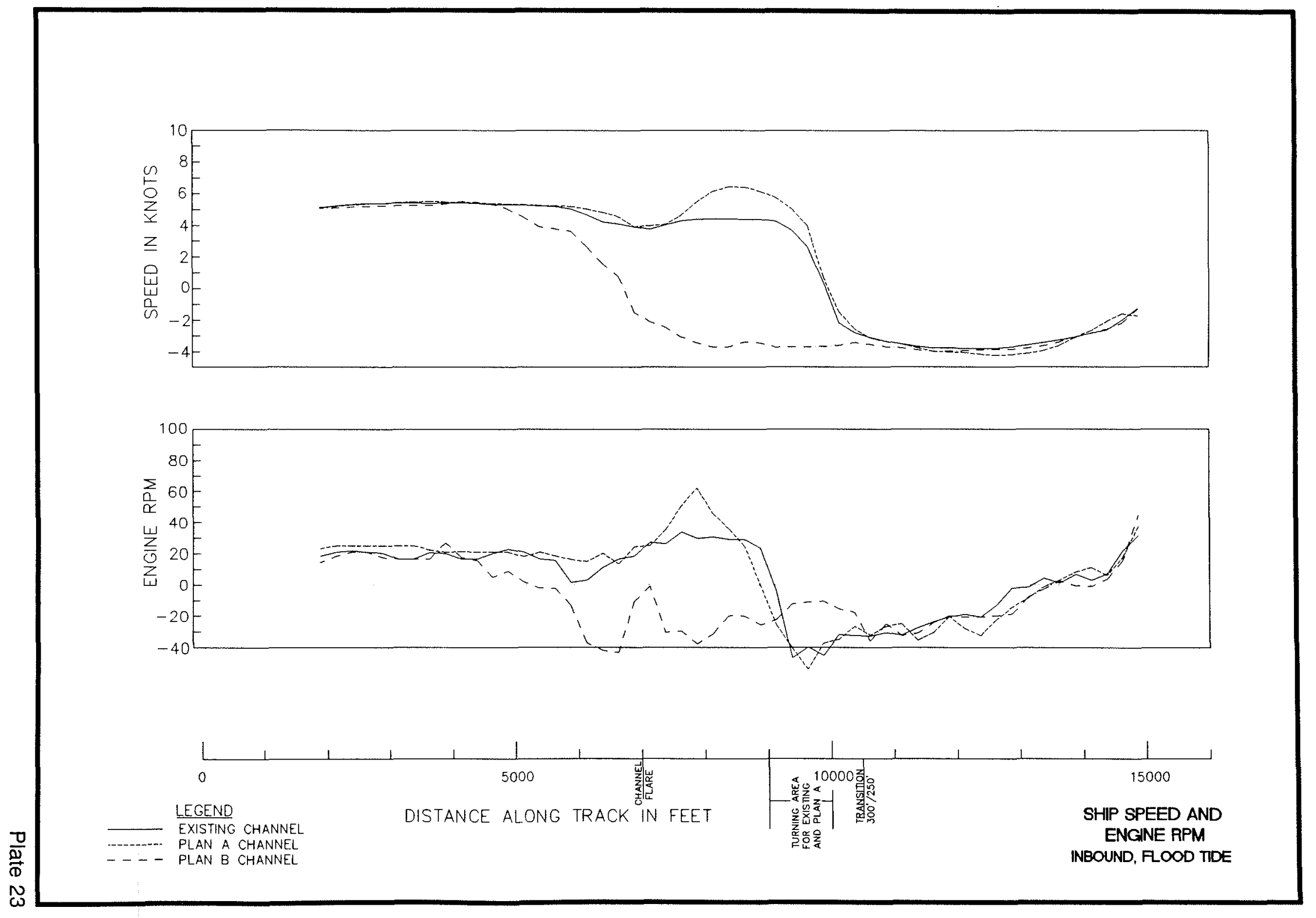




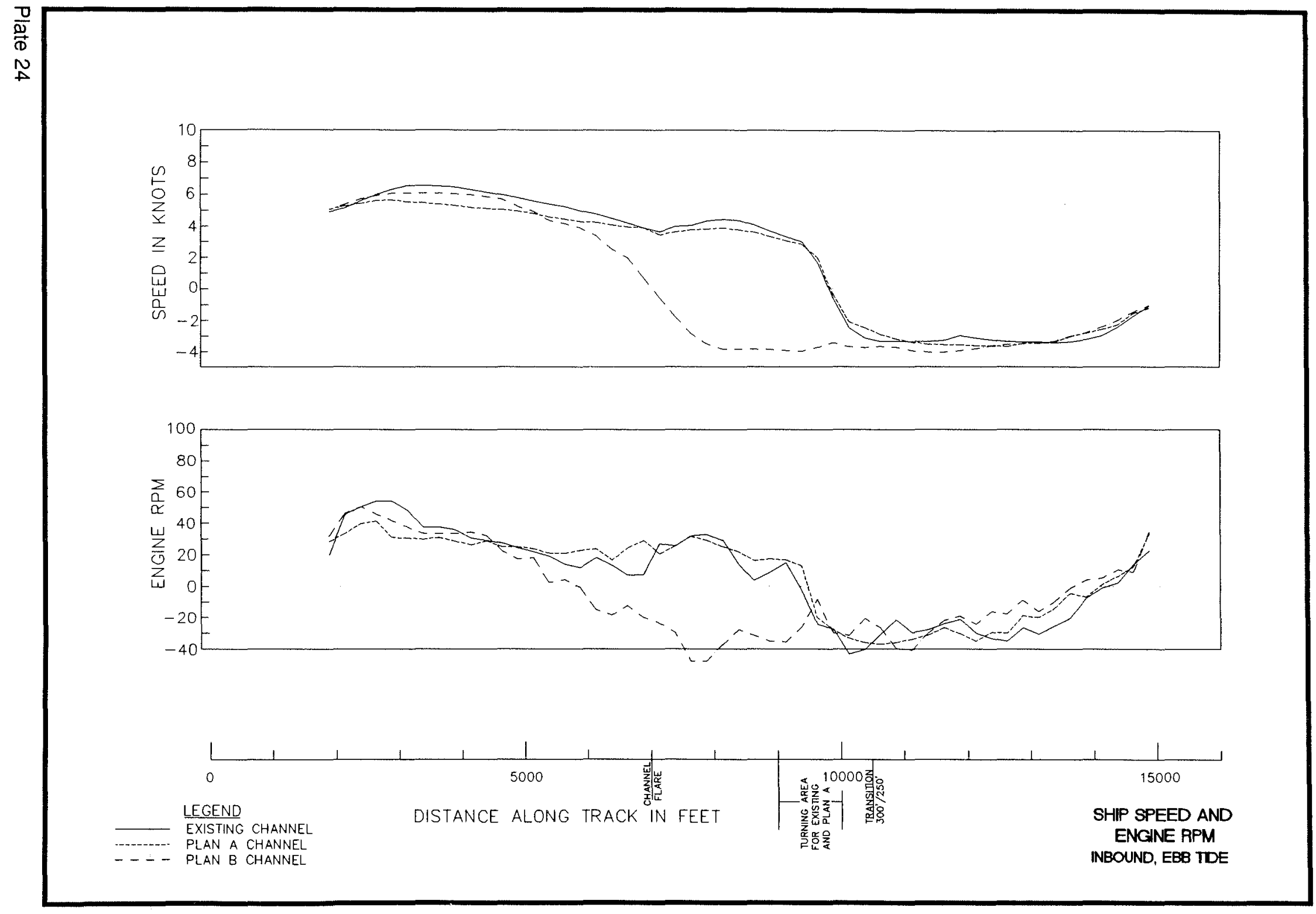




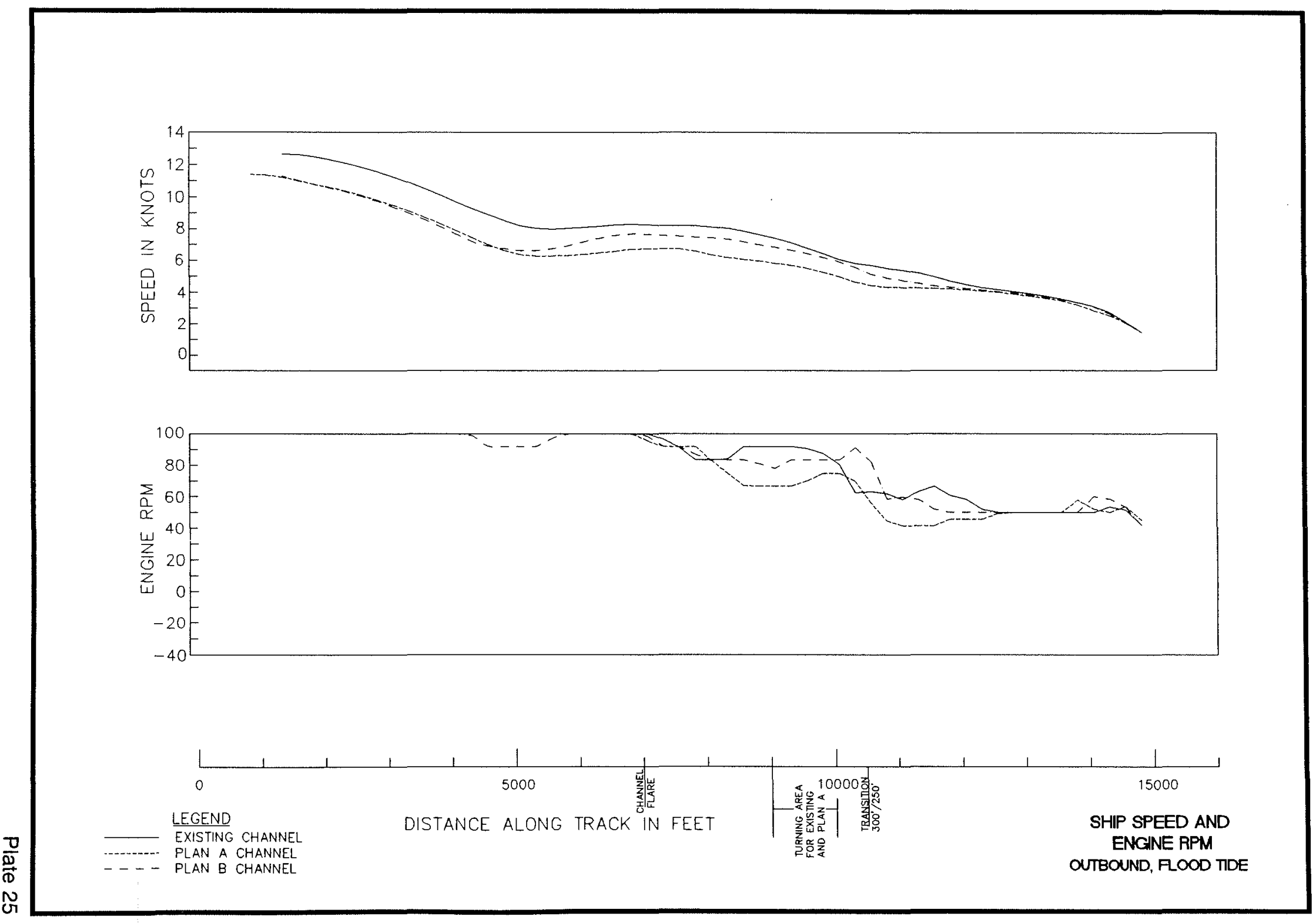




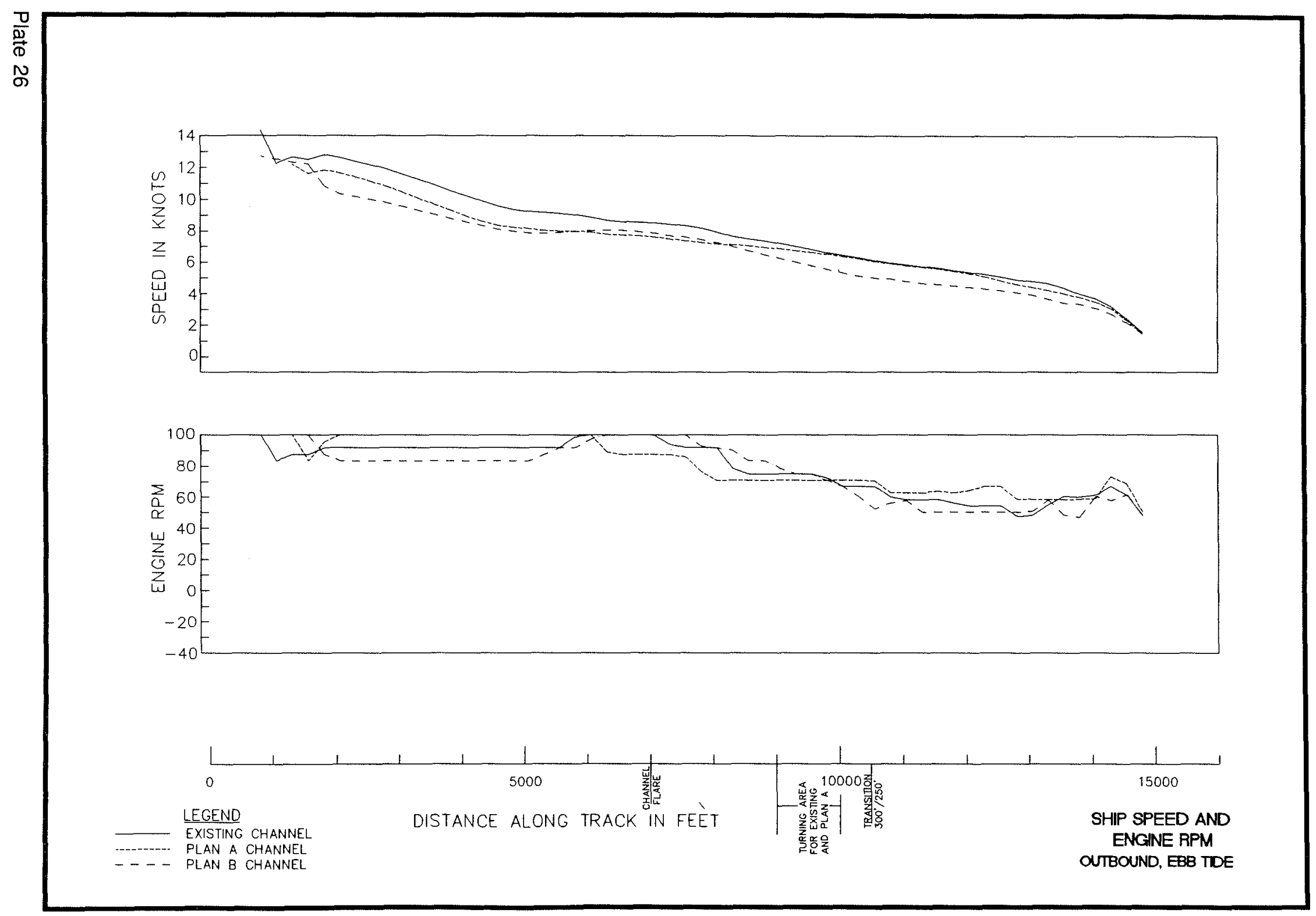




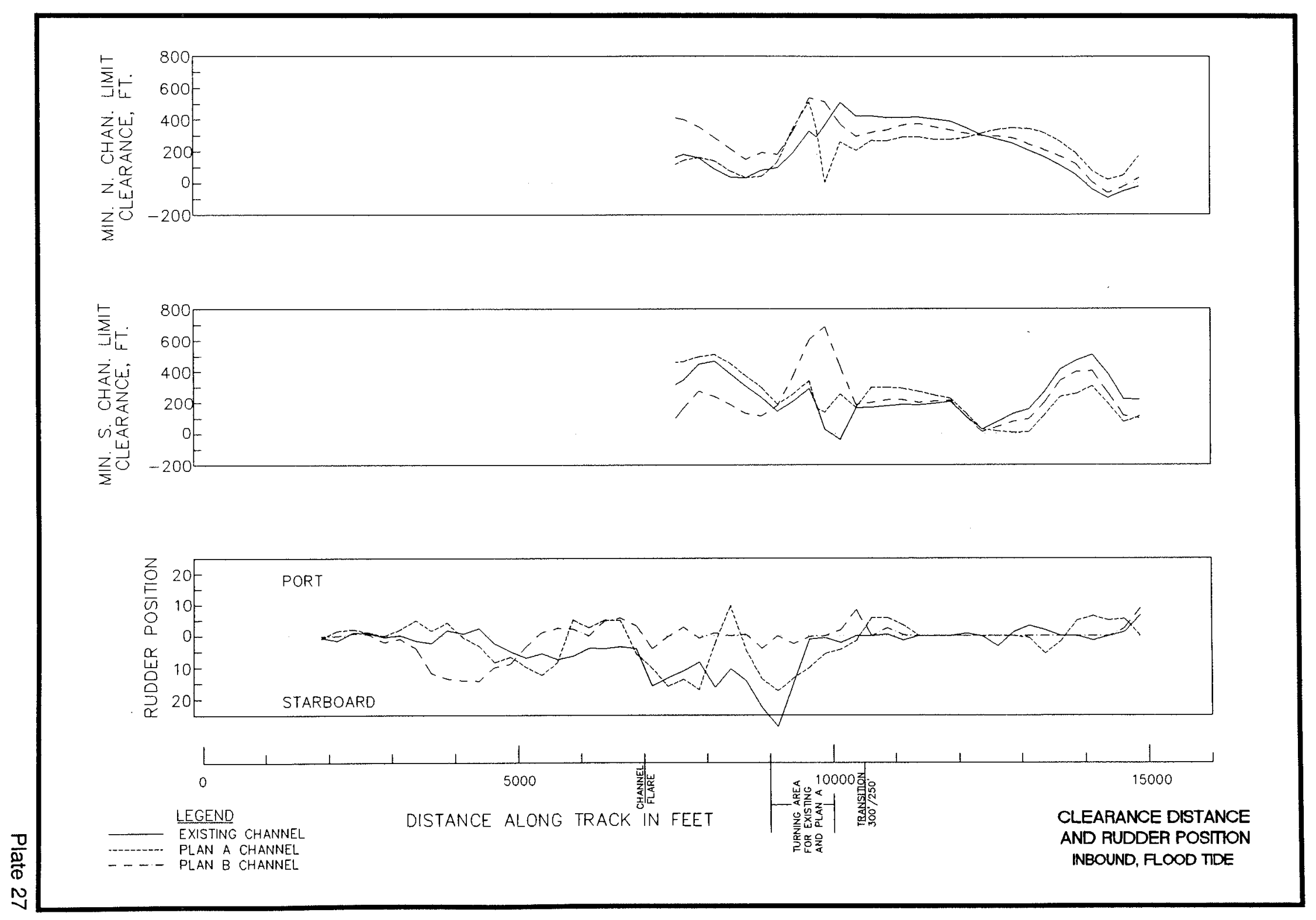




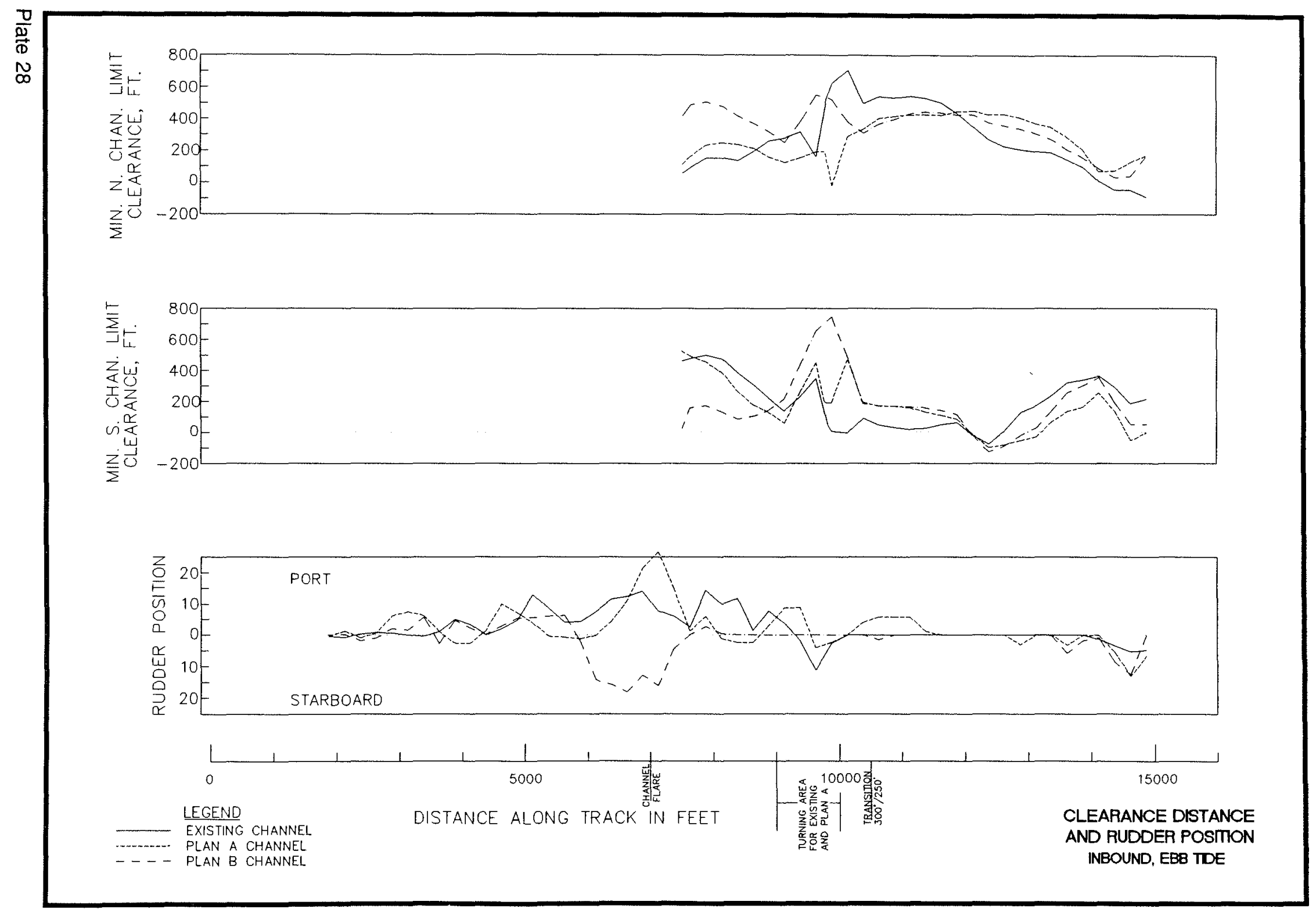




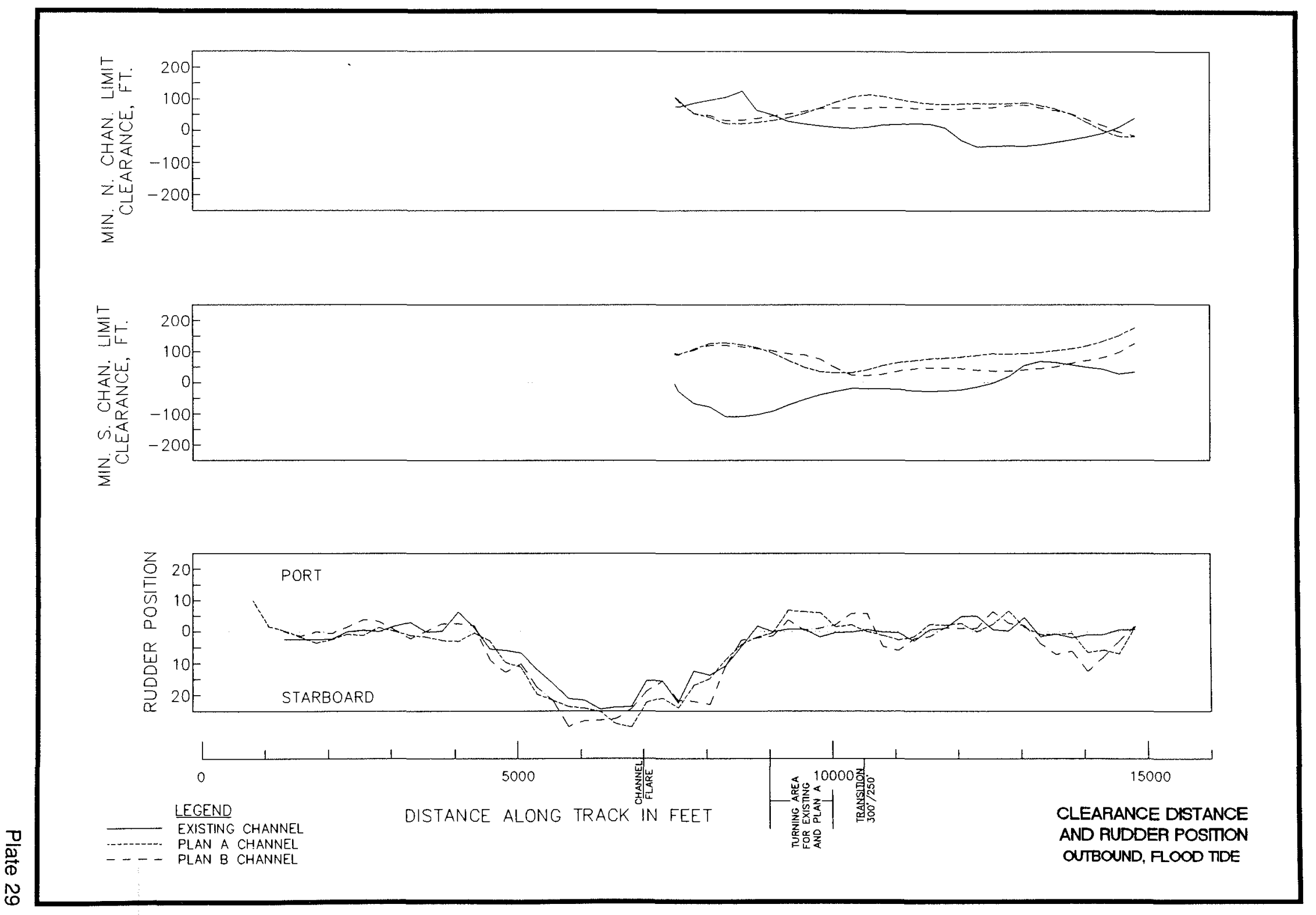




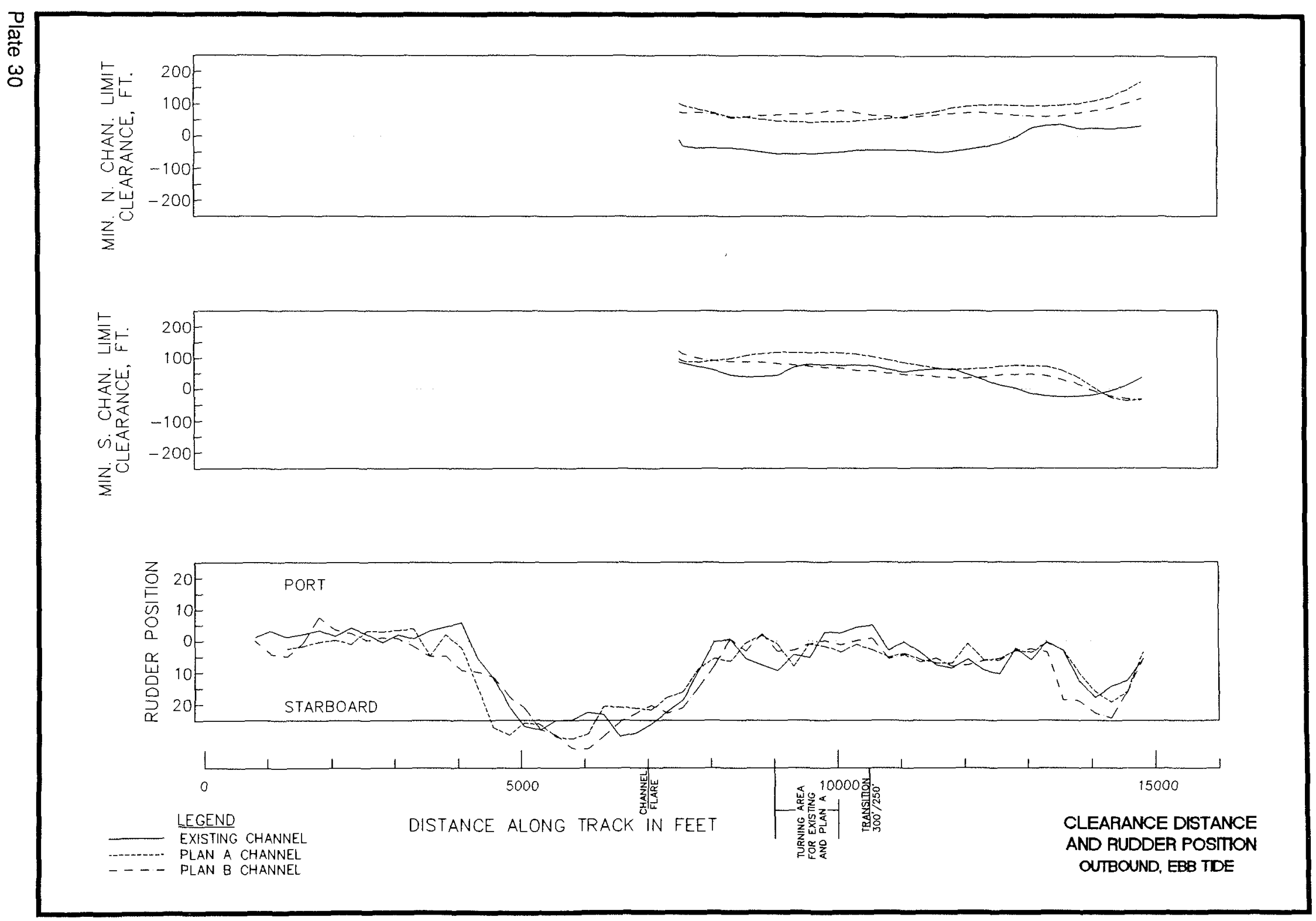




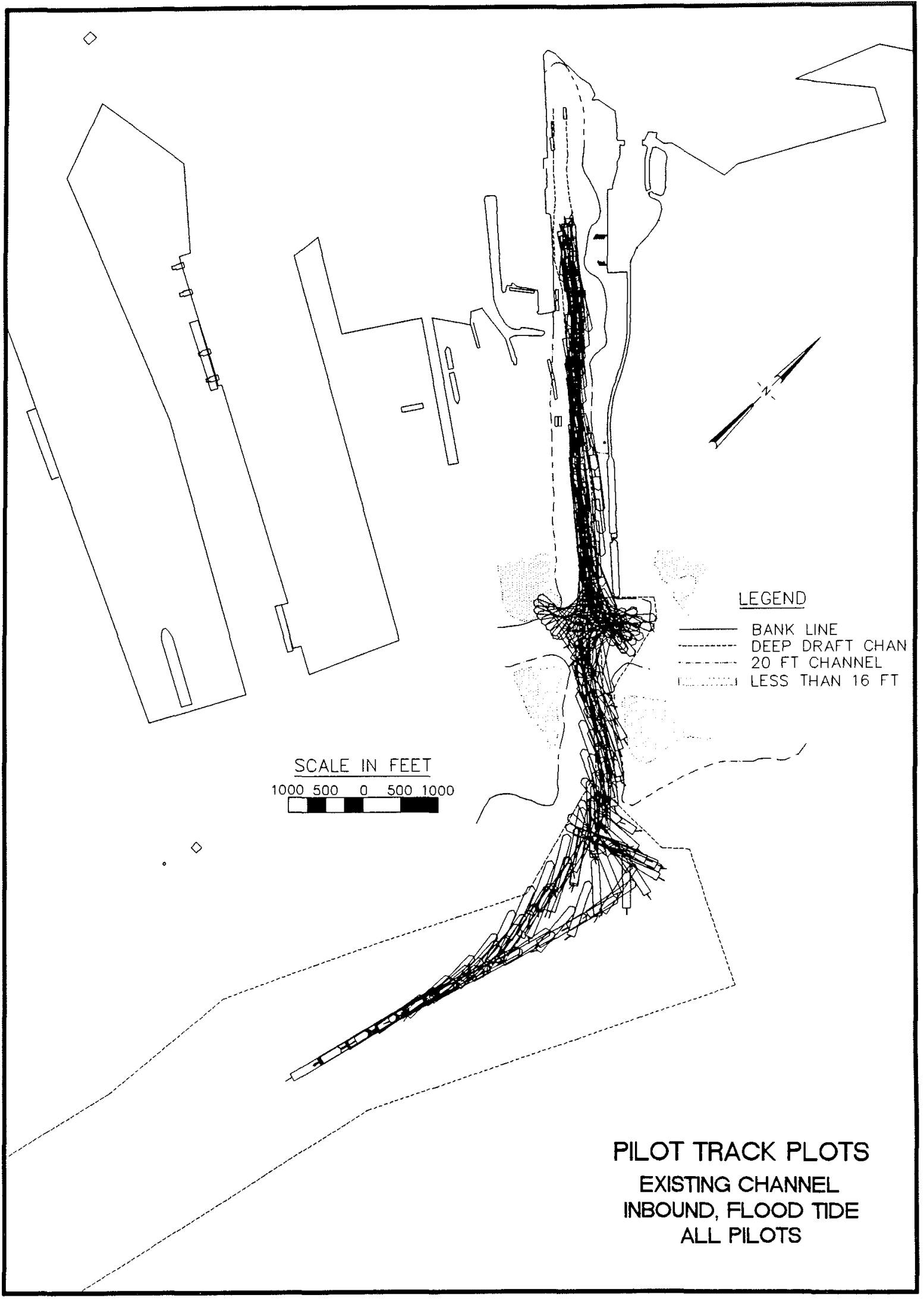

Plate $31 \mathrm{~A}$ 


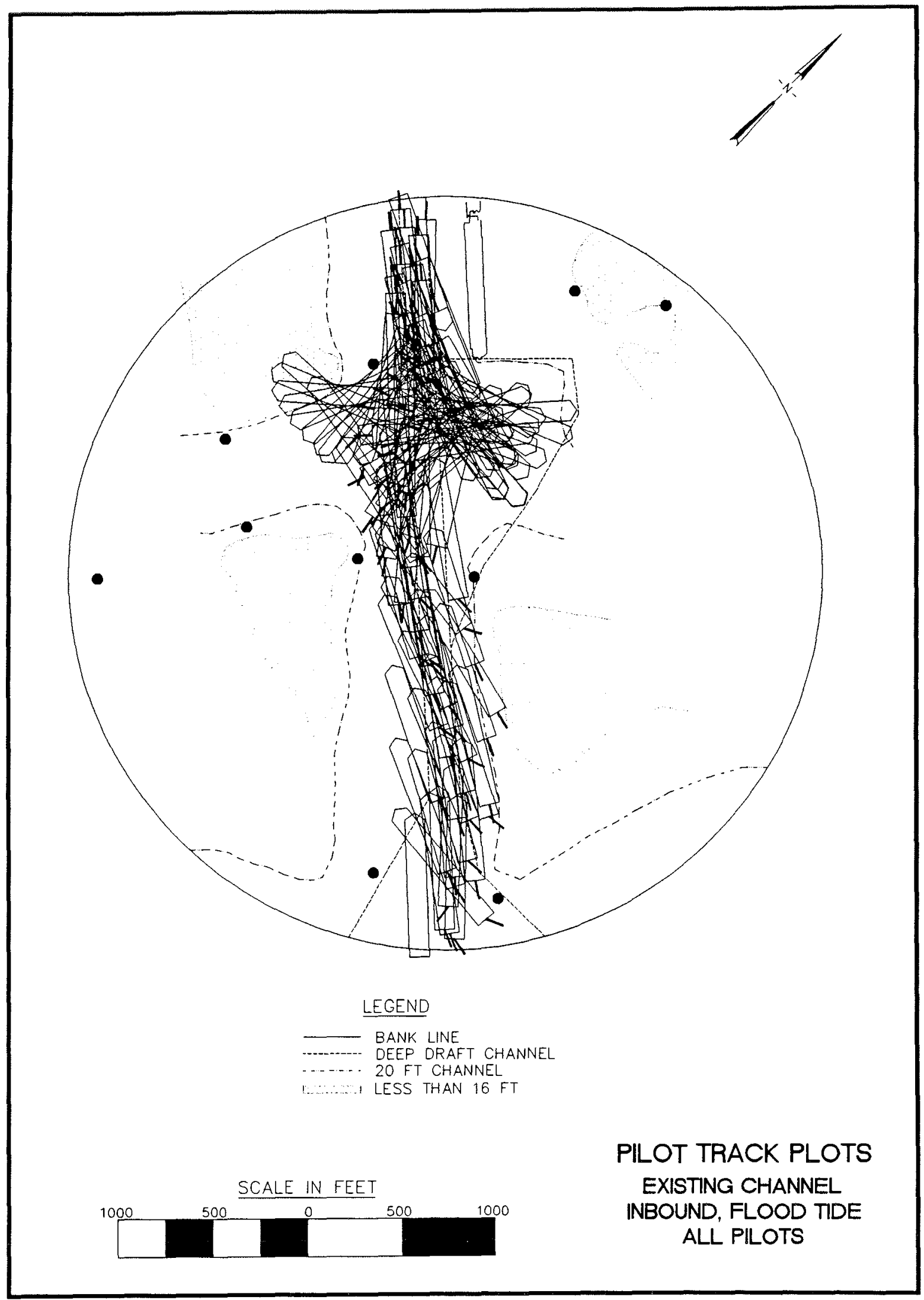

Plate 31B 


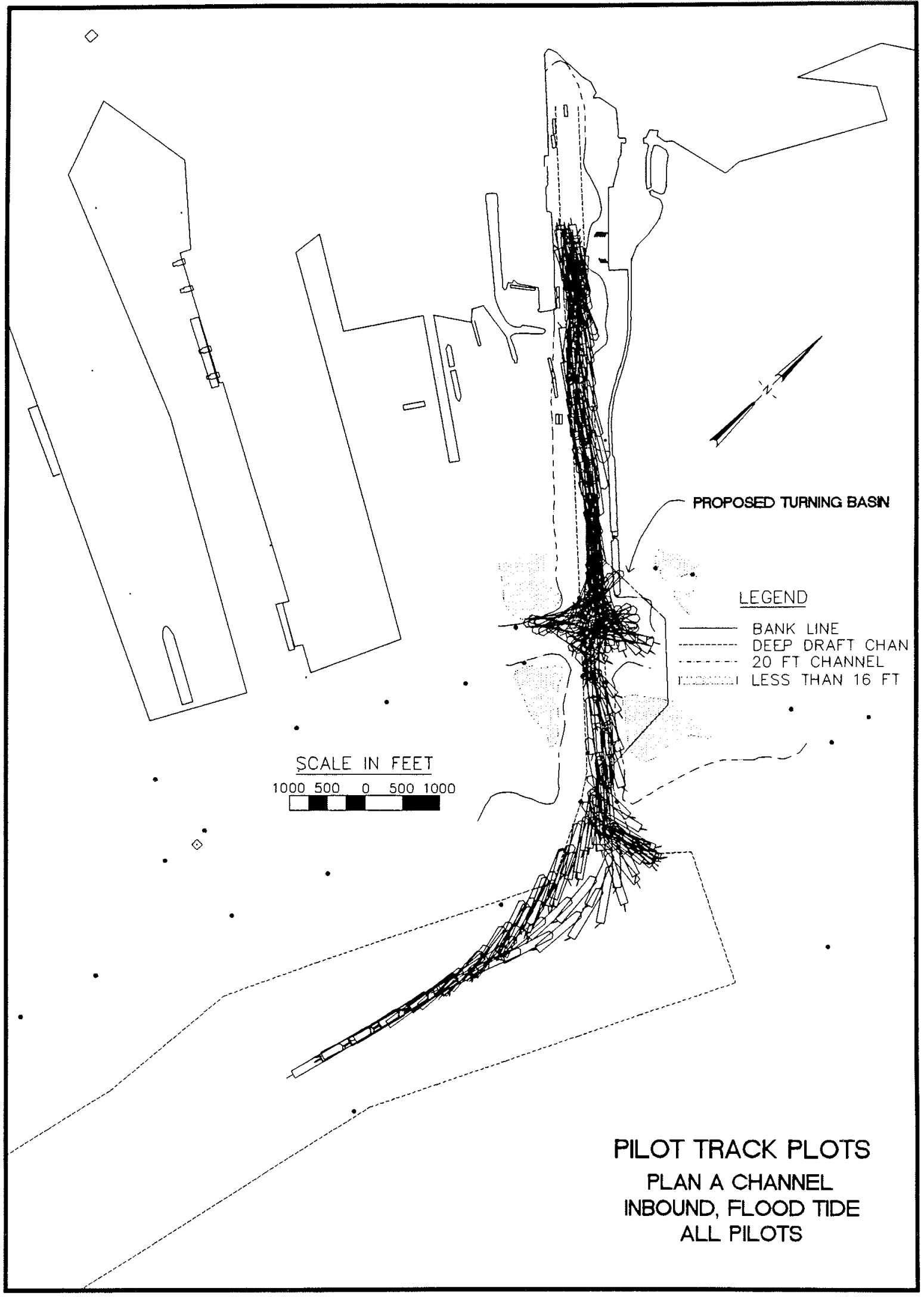

Plate 32A 


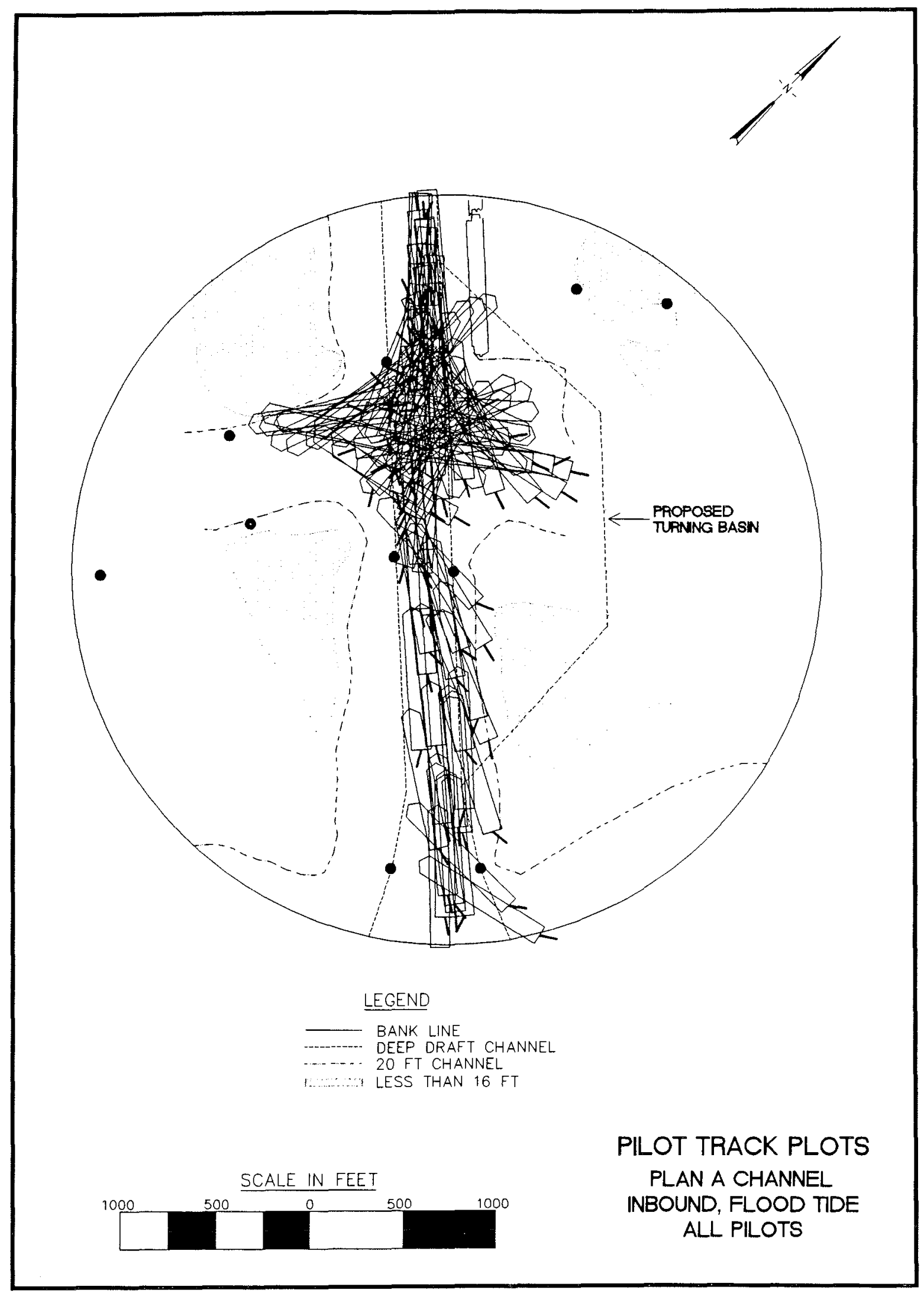

Plate 32B 


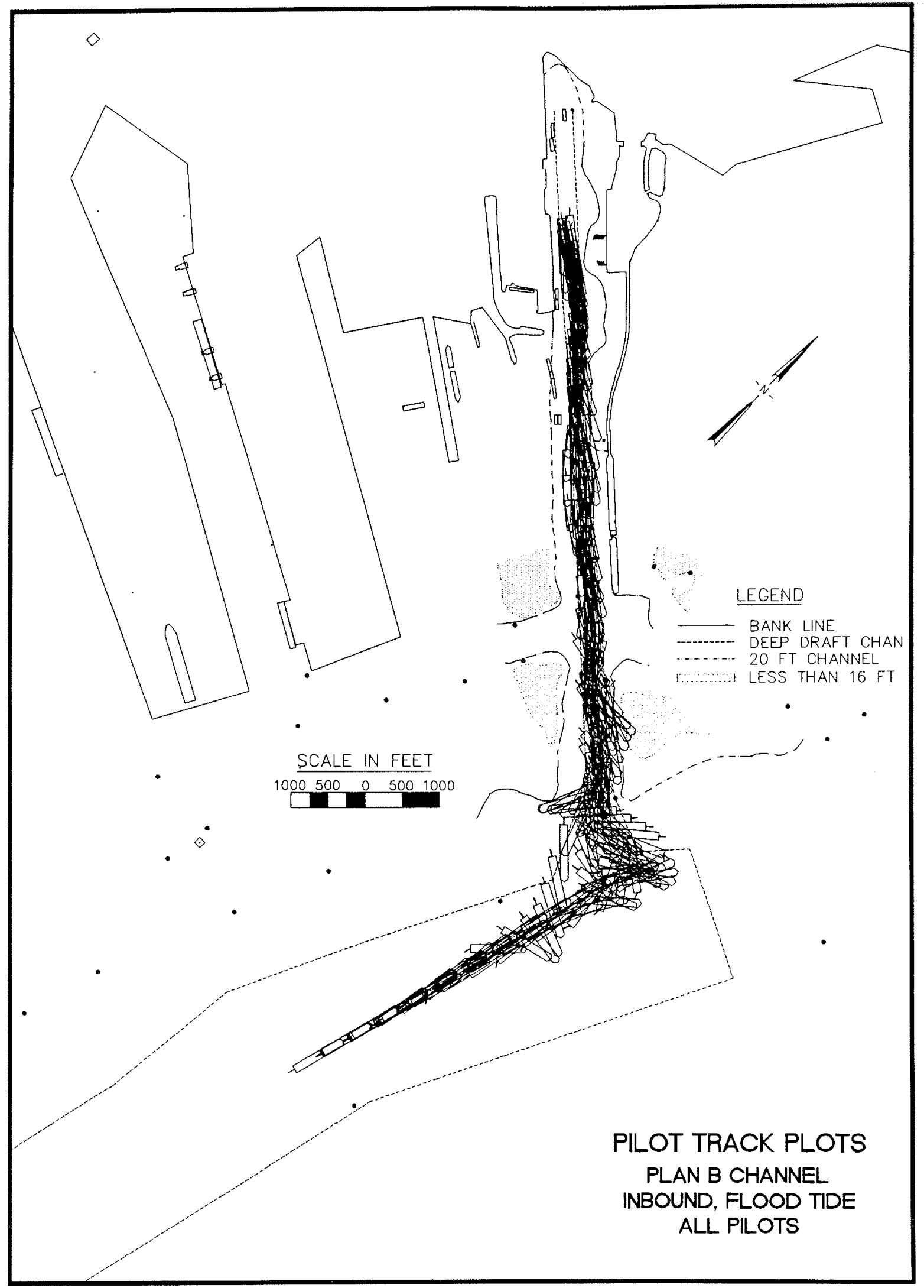

Plate 33A 


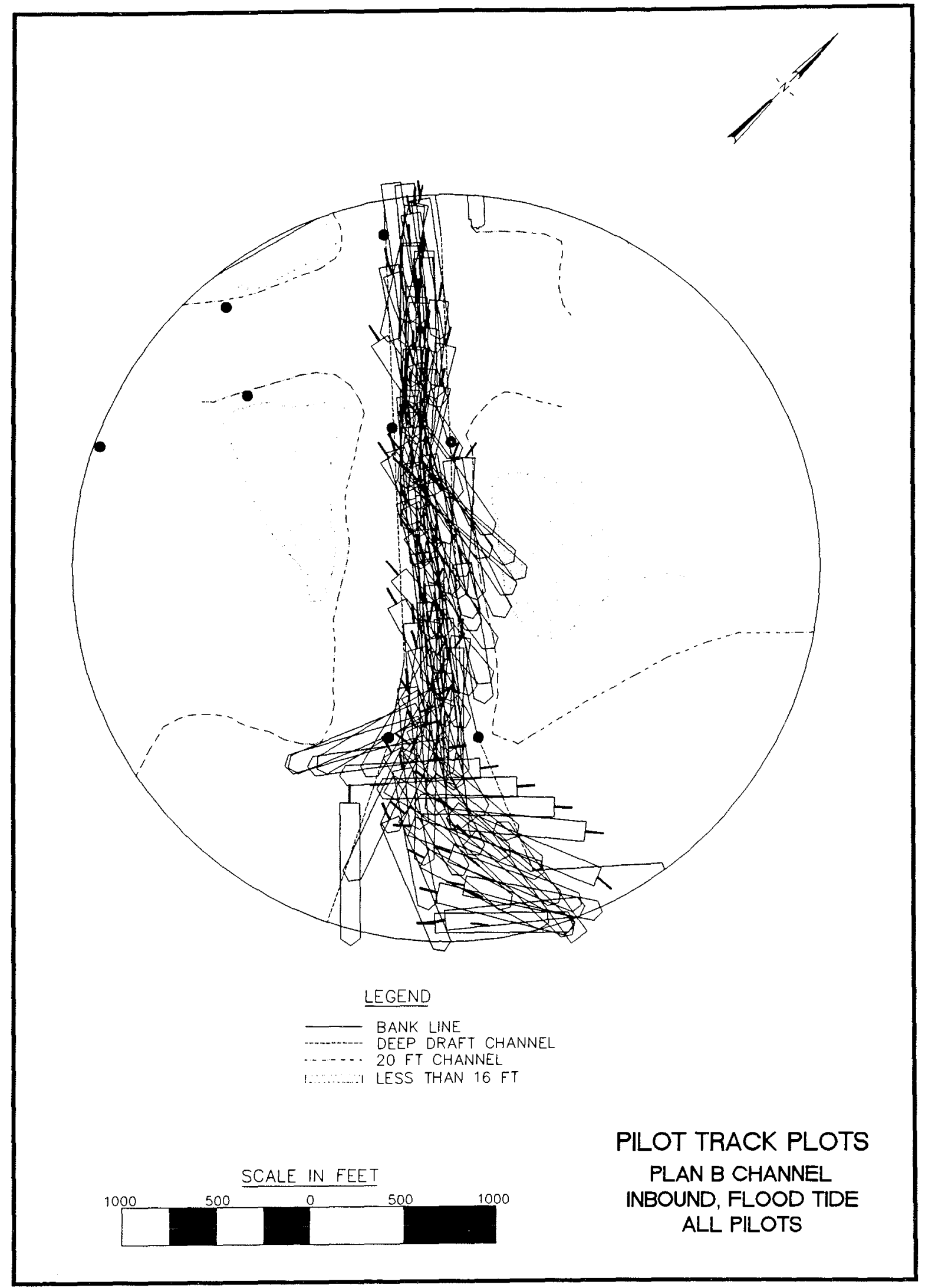

Plate 33B 


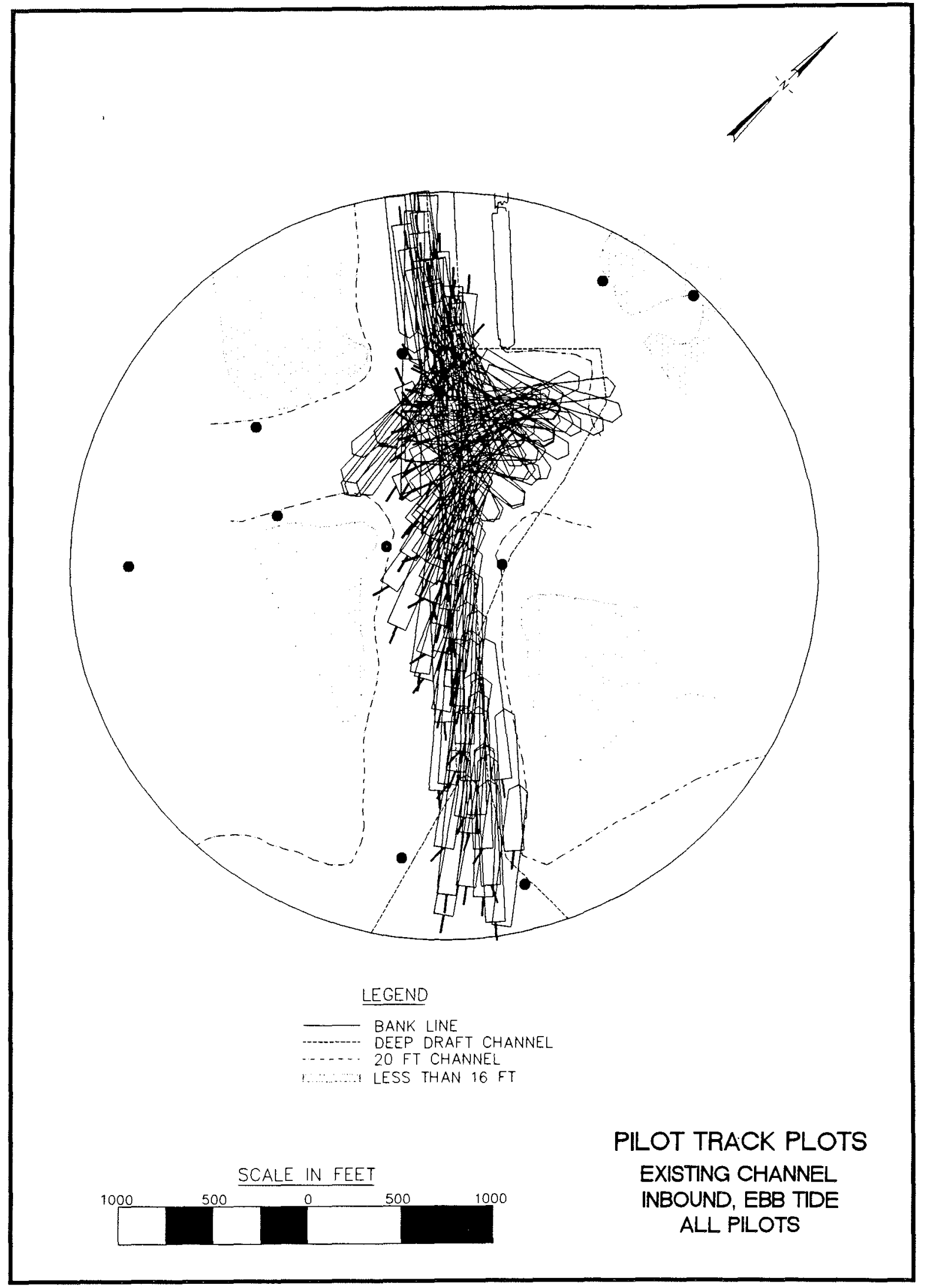

Plate 34B 


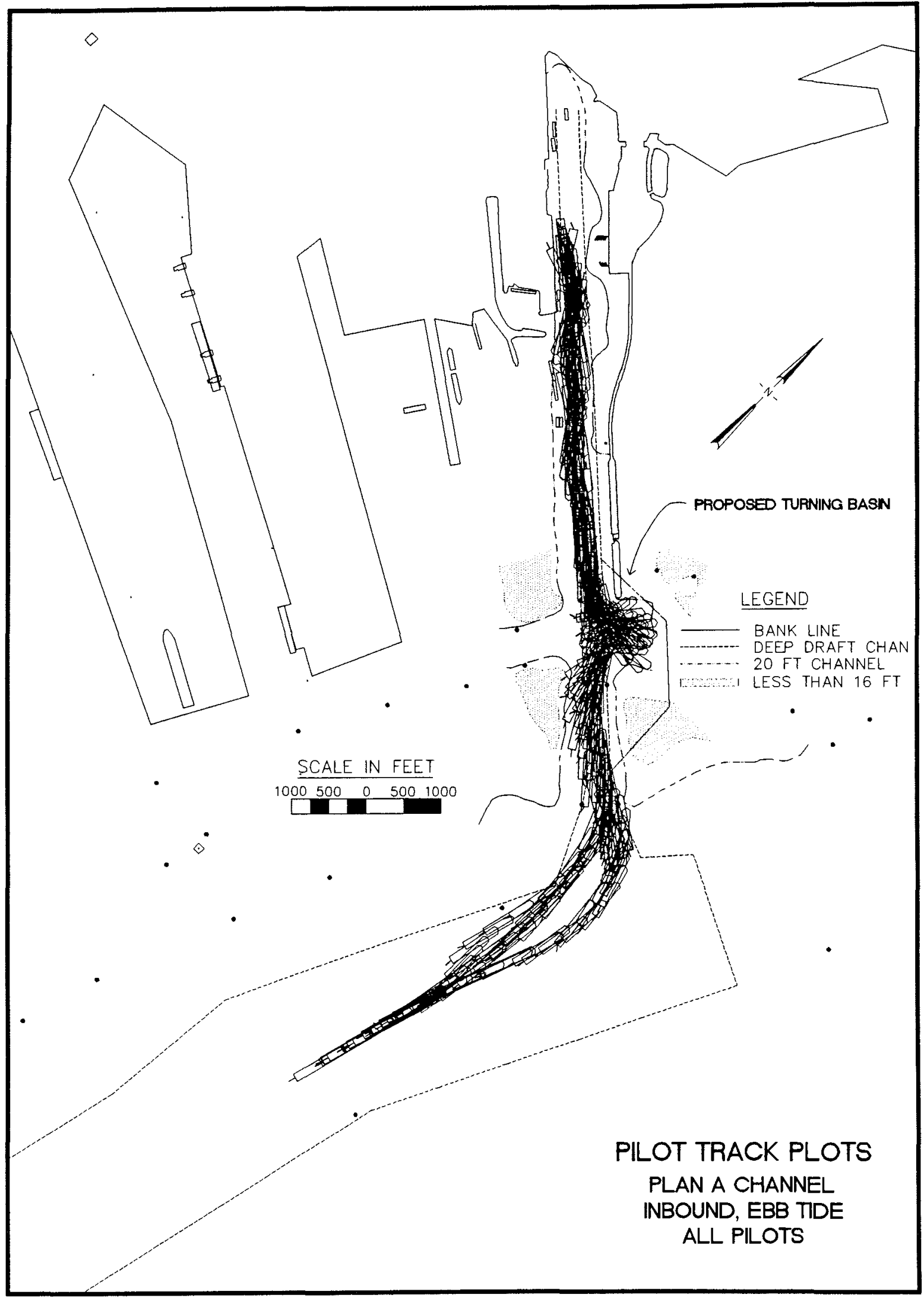

Plate 35A 


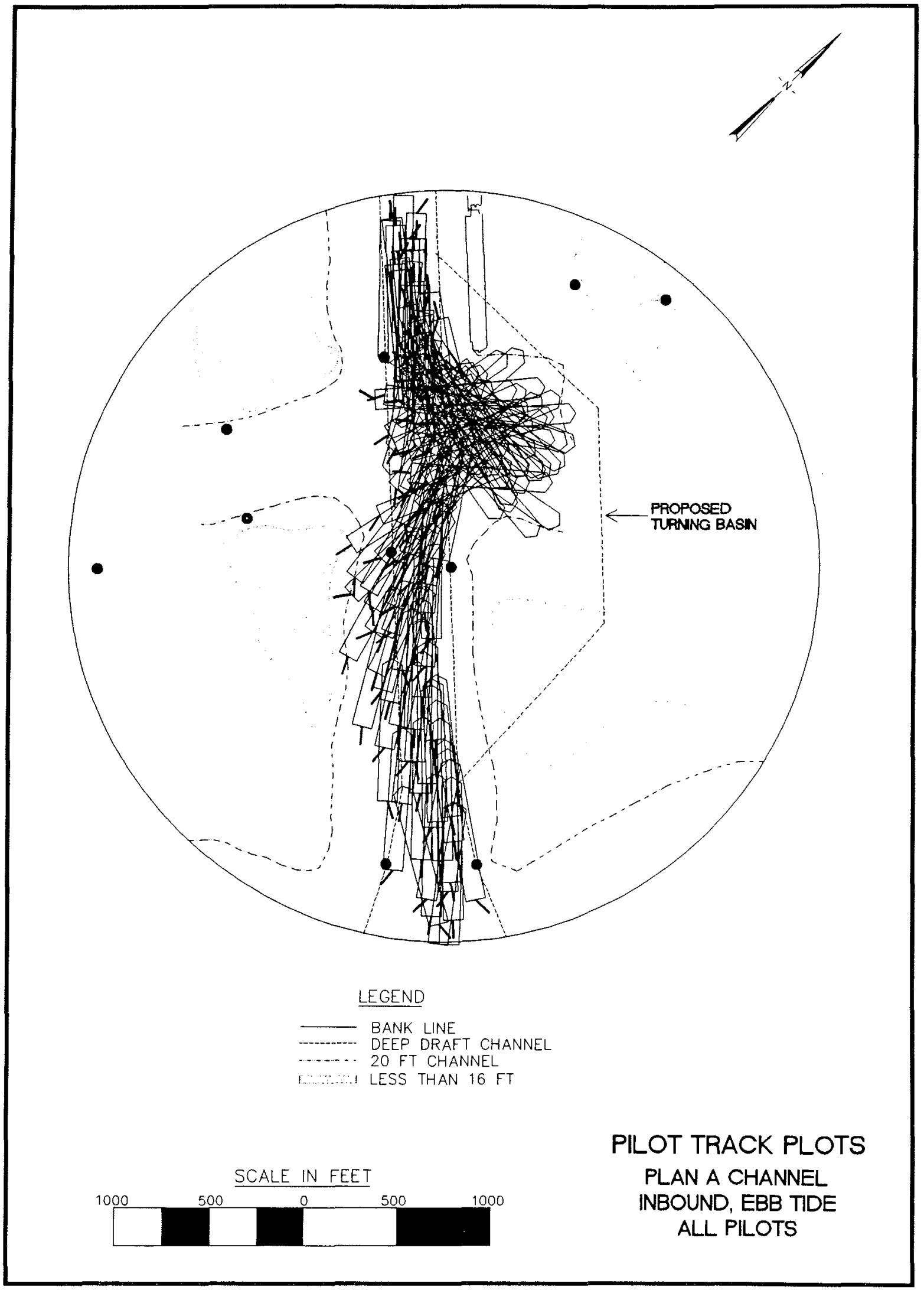

Plate 35B 


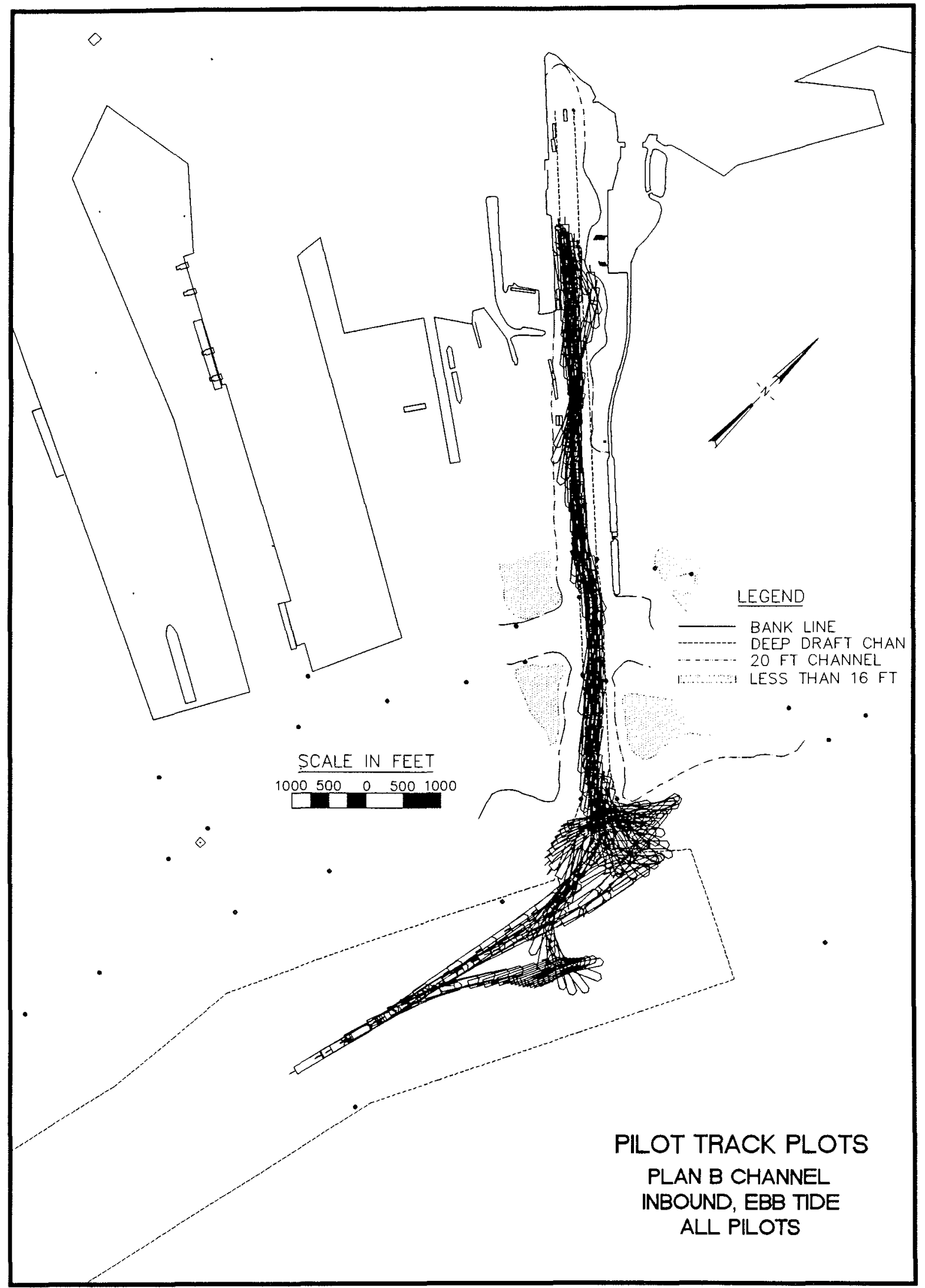

Plate 36A 


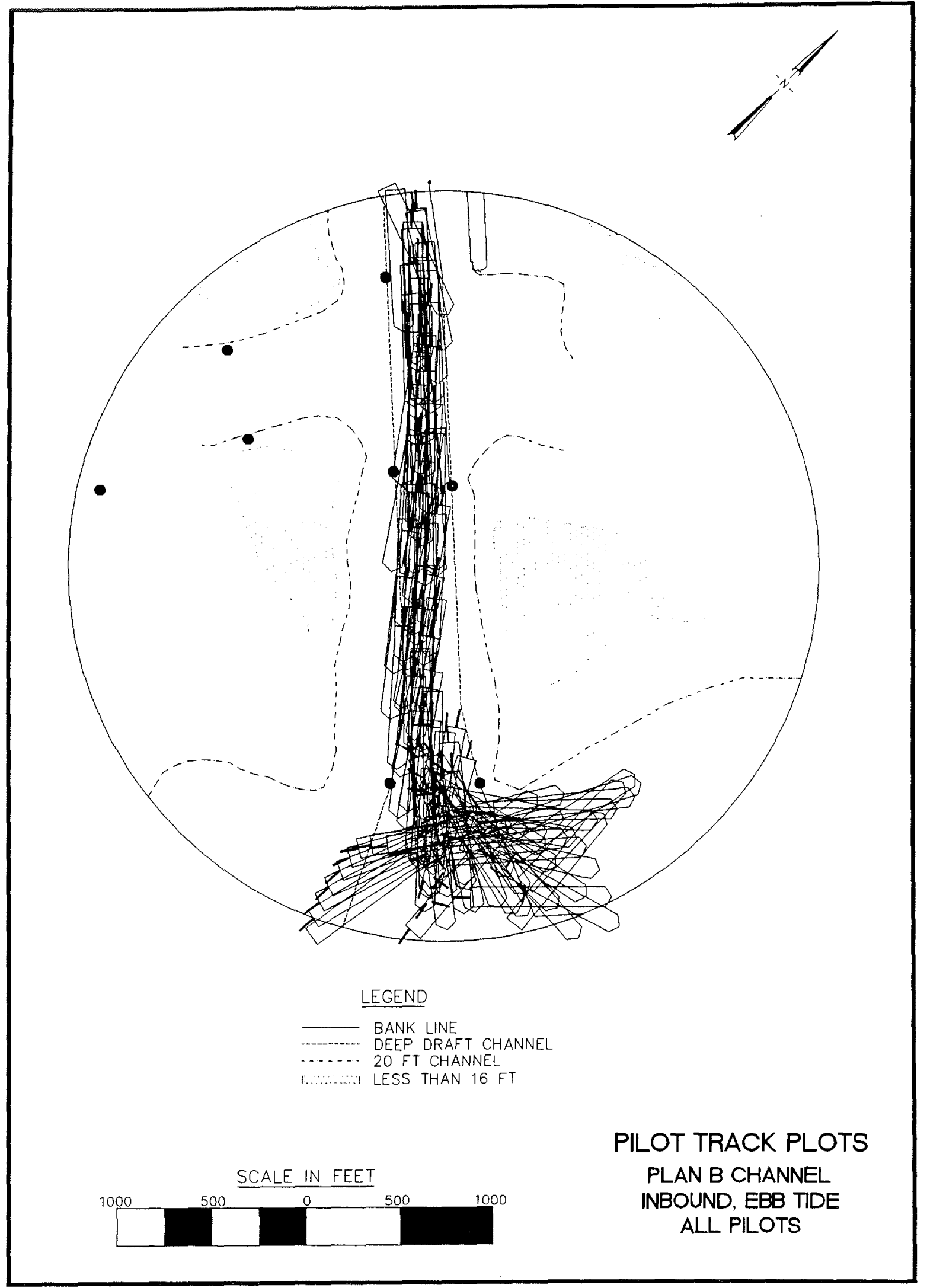

Plate 36B 


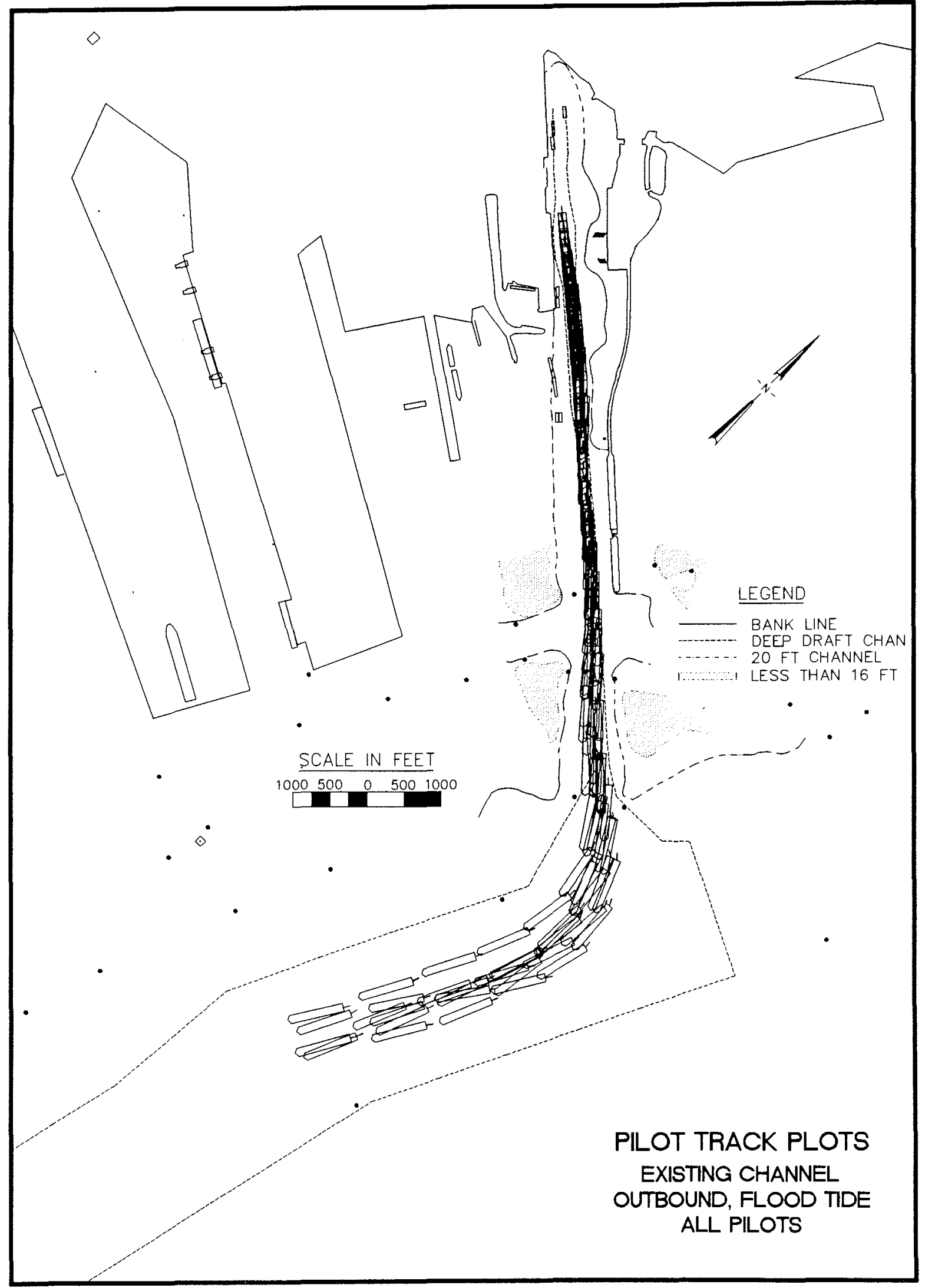

Plate 37 


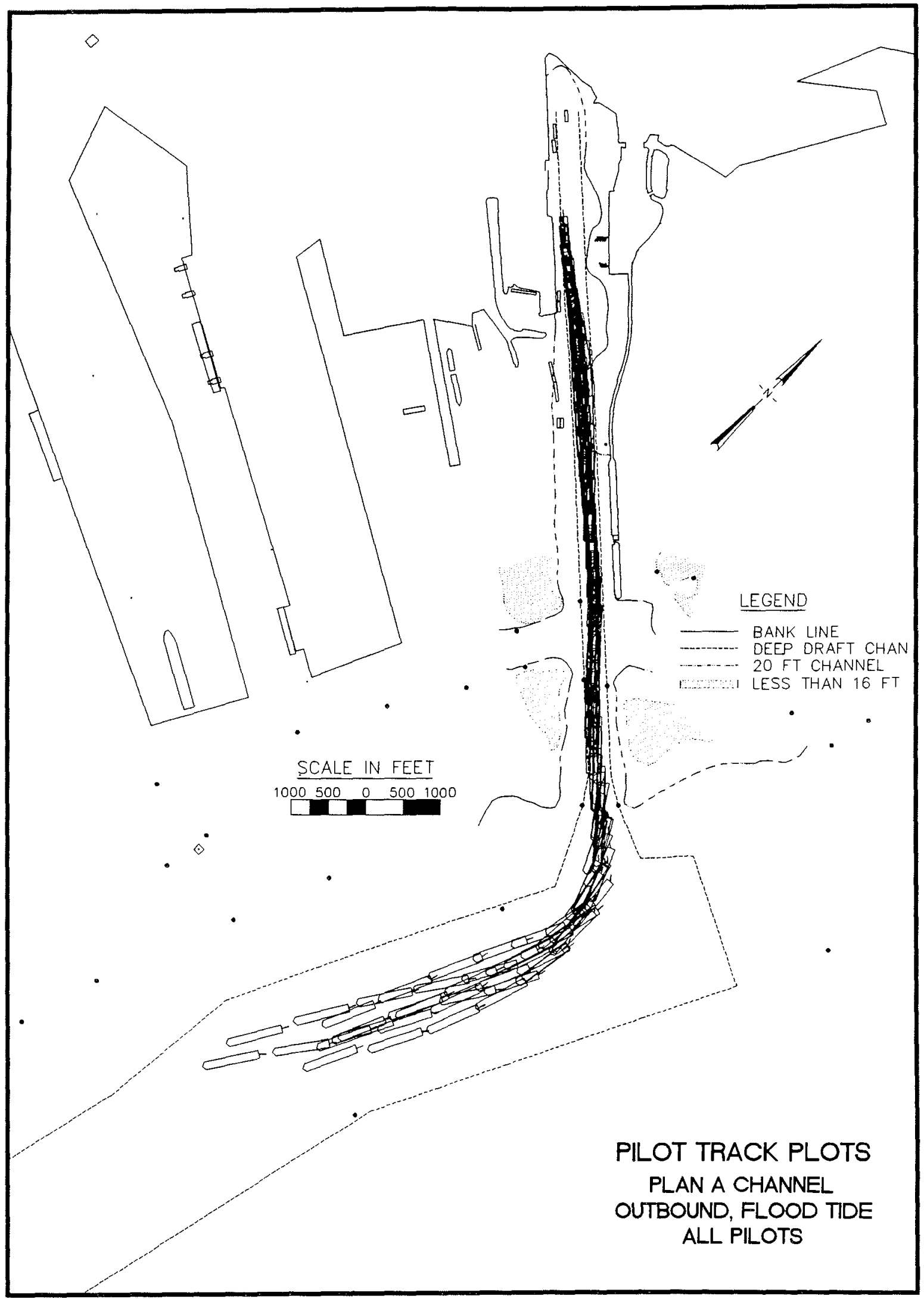

Plate 38 


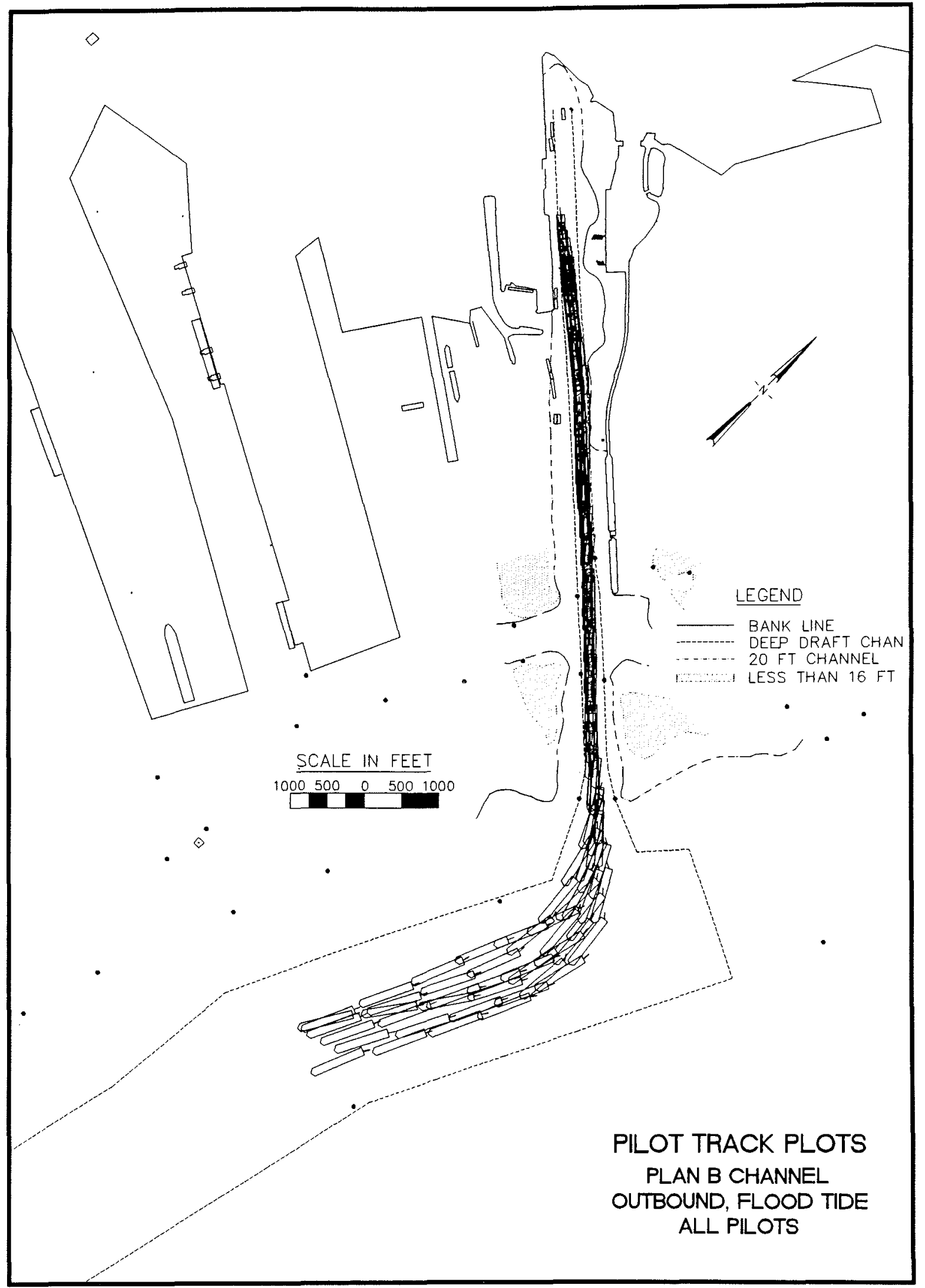

Plate 39 


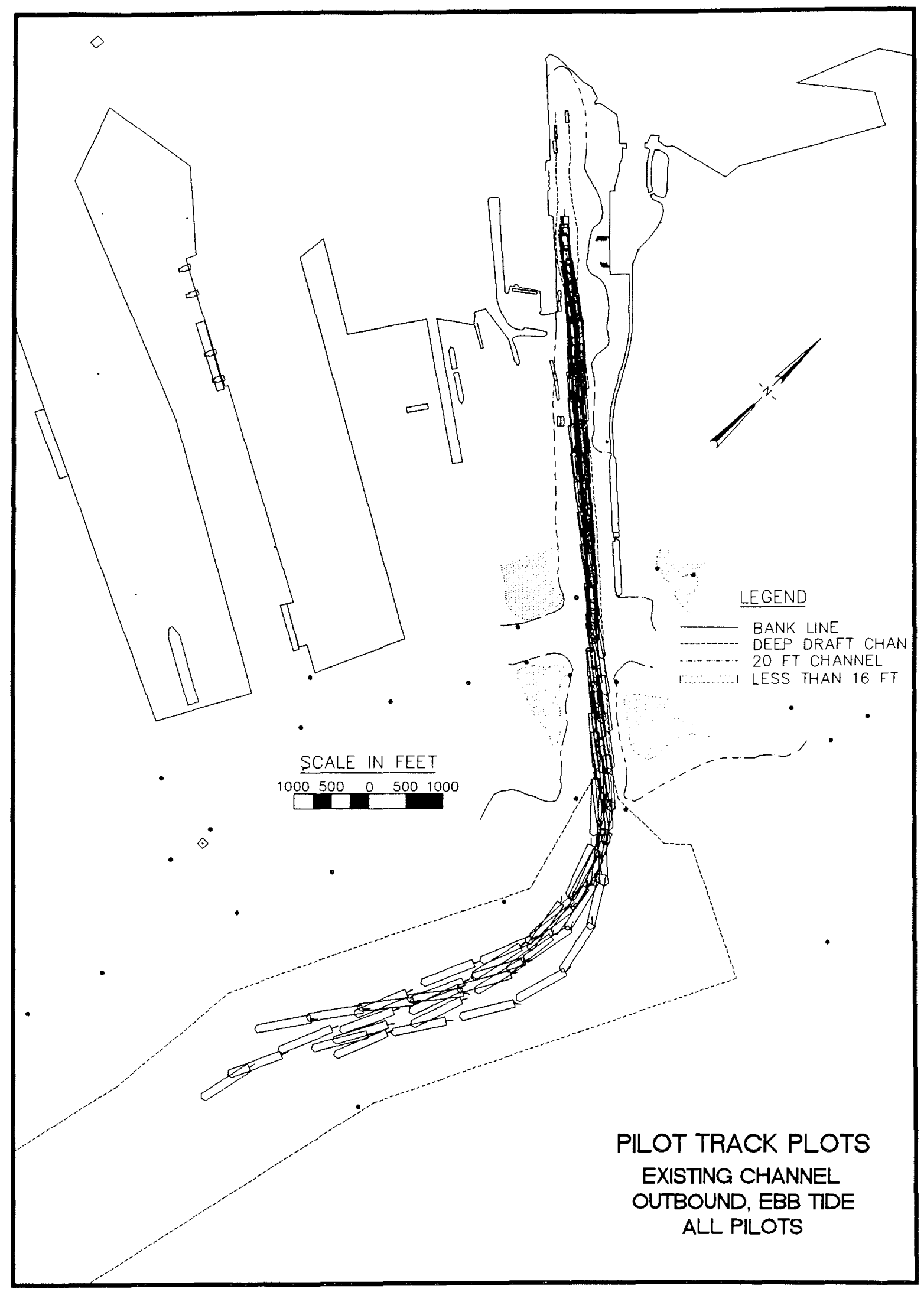

Plate 40 


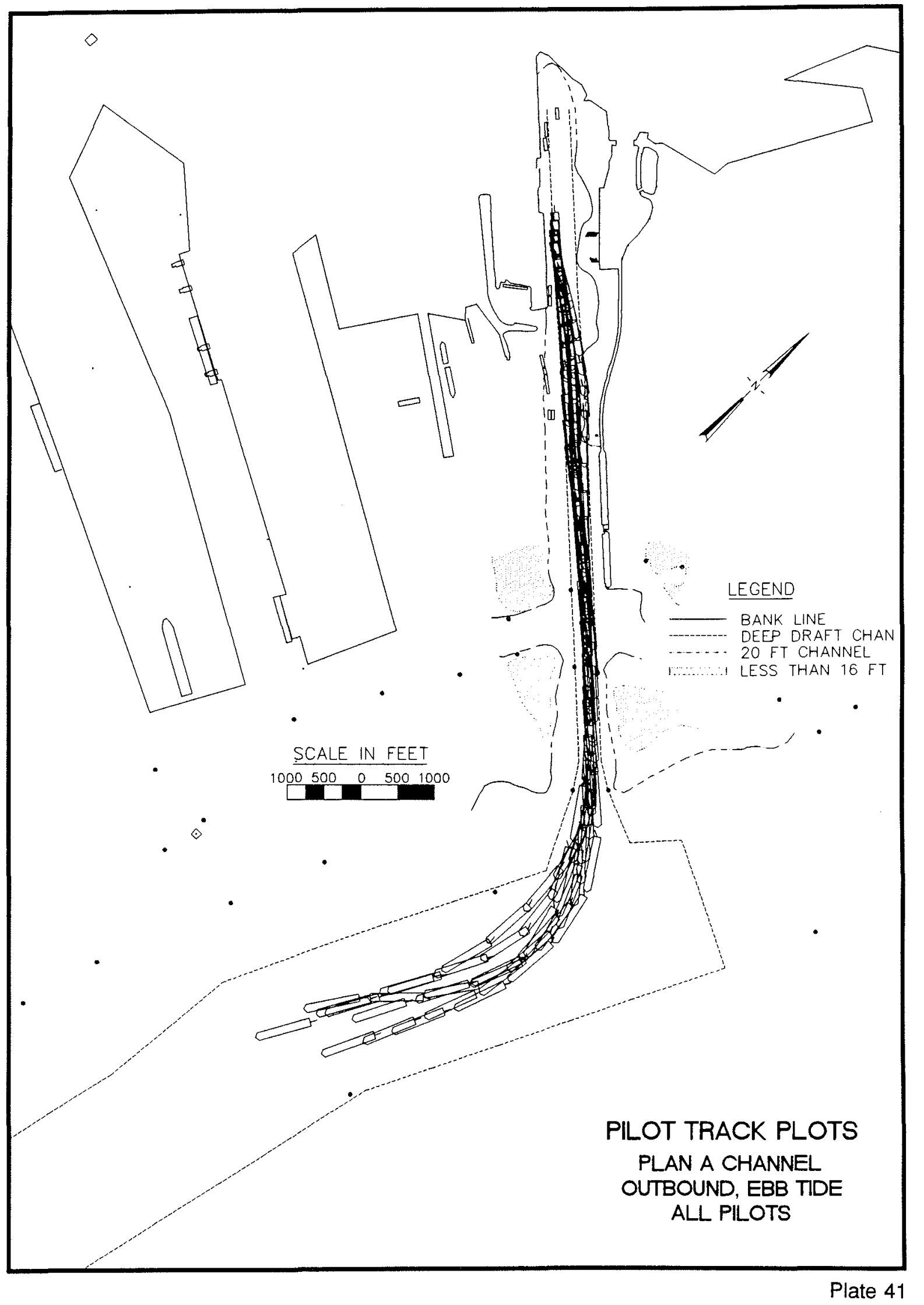




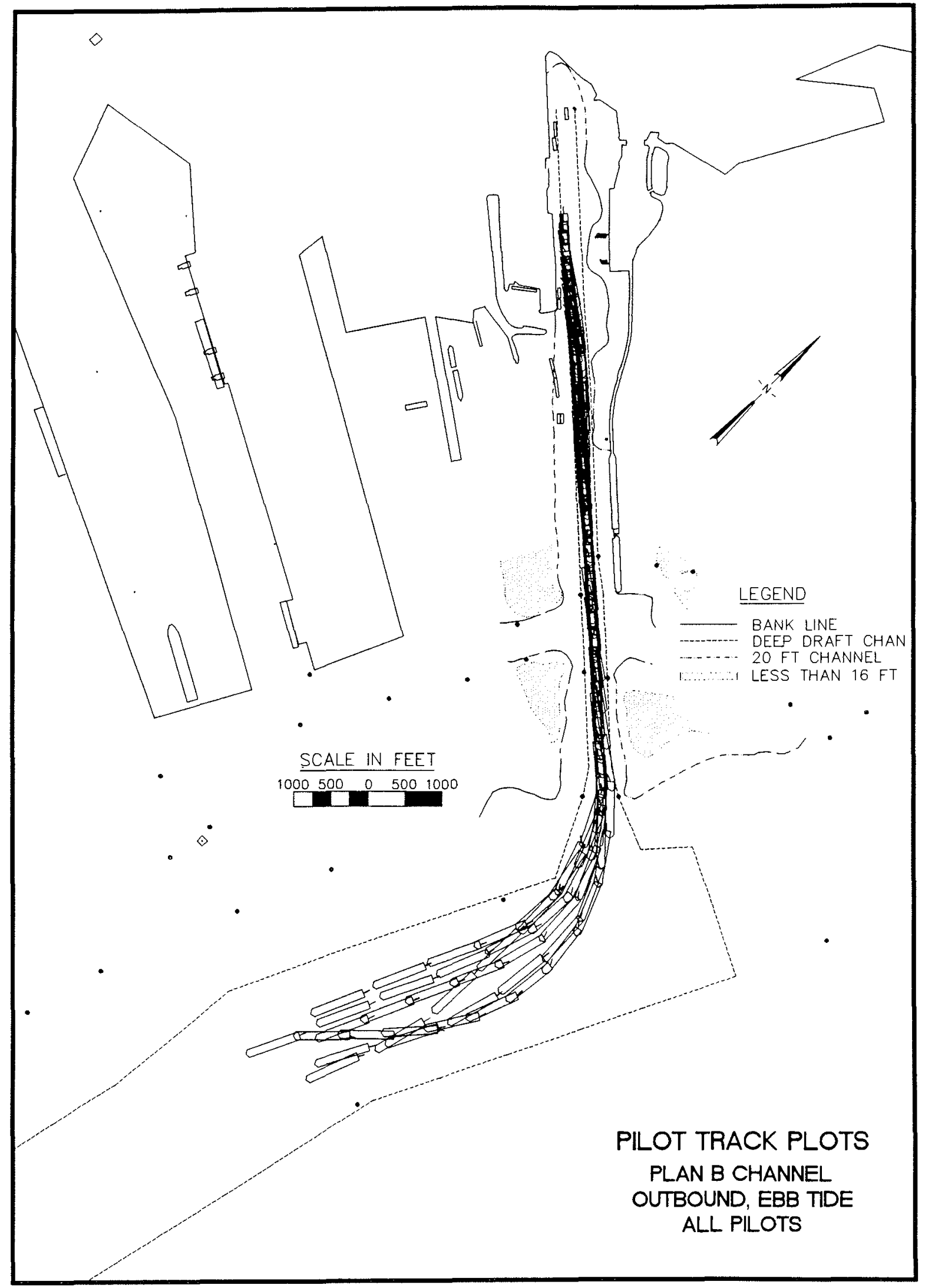

Plate 42 


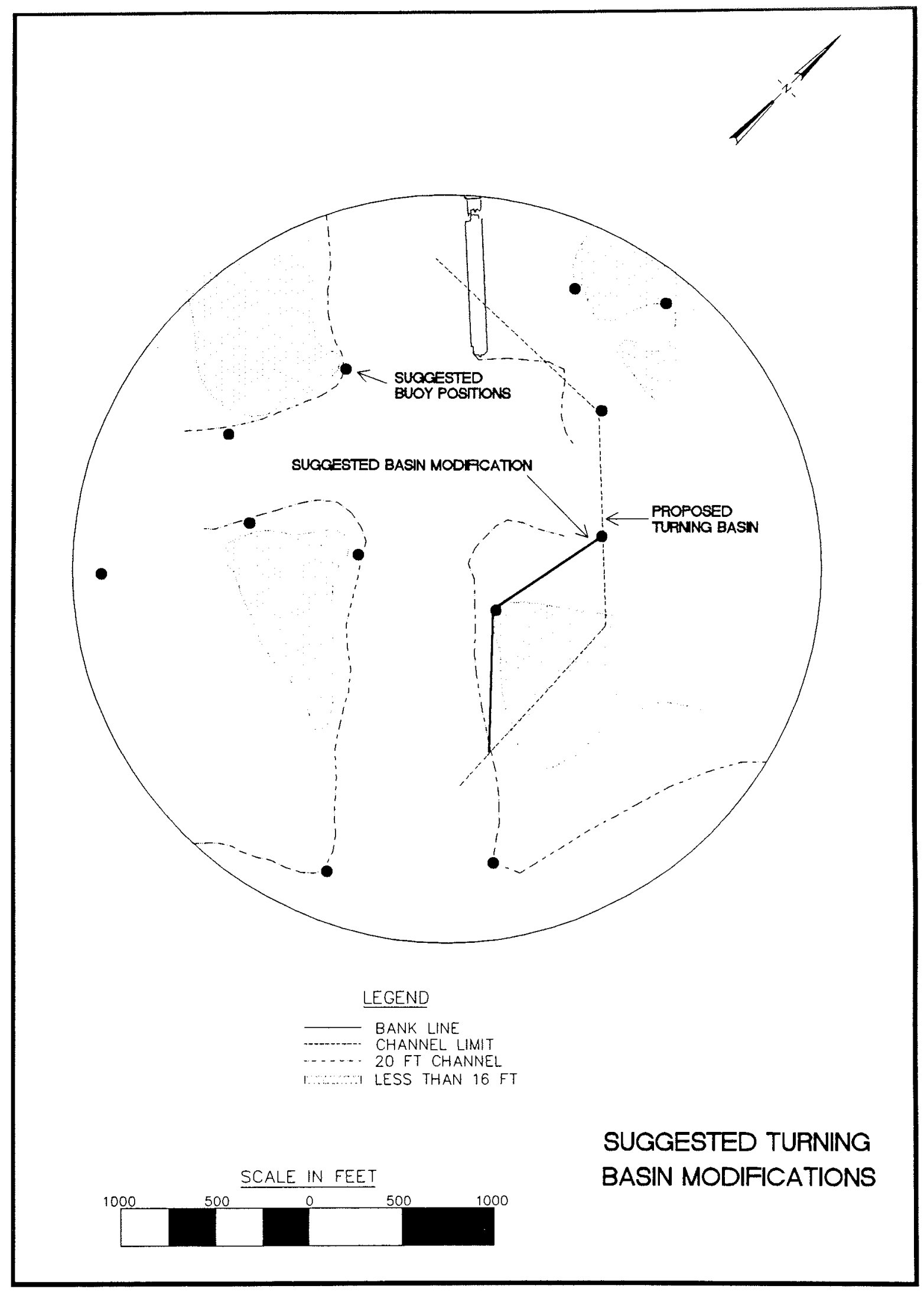

Plate 43 


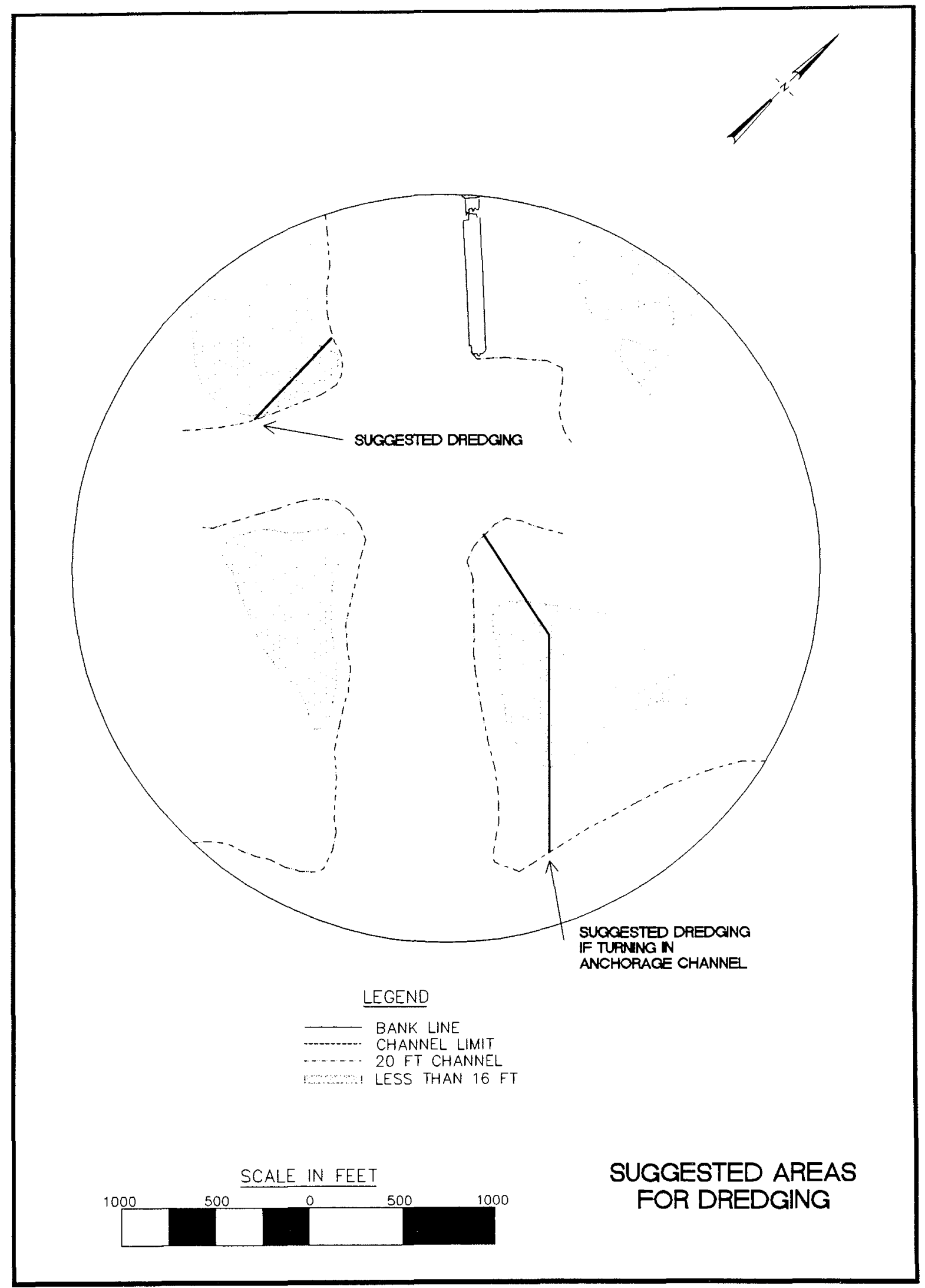

Plate 44 


\section{Appendix A Claremont Channel Ship Simulator Hydrodynamic Study}

\section{Introduction}

This appendix describes a numerical hydrodynamic model study of the Claremont channel portion of the Upper New York Harbor. This model study was conducted to provide current information necessary to study ship navigation for several channel designs located near the docking facility.

\section{Background}

The Claremont channel docking facility is located on the western side of Upper Bay in York Harbor in the state of New Jersey on the borders of Jersey City (Figure A1). A 2-mile (approximately) long access channel connects the facilities at Clarcmont Terminal to Anchorage Channel, the main shipping lane in New York Harbor (Figure A2). The available navigation channel varies in width at a depth from 25 to $27 \mathrm{ft}$ with a minimum width of $150 \mathrm{ft}$ in some locations from the Claremont Terminal to the intersection with the federally maintained Anchorage Channcl. At a nominal depth of $27 \mathrm{ft}$ below mean low water, mlw, the Claremont navigation channel is not decp enough to fully accommodate the dry bulk vessels that export scrap stcel and iron from the metropolis of New York. The depth limitation restricts scrap vessels from fully using their available draft. Coslly rchandling and topping-off operations at other berths are required to minimize the cost per ton during long ocean voyages.

The typical ship using the port is a Panamax bulk carrier with lengths up to $760 \mathrm{ft}$, beam of $106 \mathrm{ft}$, a draft of $16 \mathrm{ft}$ at the bow, $20 \mathrm{ft}$ at the stern in ballast and $30 \mathrm{ft}$ loaded with an even keel. The normal operation involves coming to port in ballast, turn off the end of the Caven Point Pier (also called Ocean Terminal) in the intersections of the Claremont and Pierhead Channels, with the assistance of two $3000 \mathrm{hp} \mathrm{tugs,}$, and back into the dock. The ship is loaded to a draft of $30 \mathrm{ft}$, then the pilot waits for maximum flood tide to transit out. 


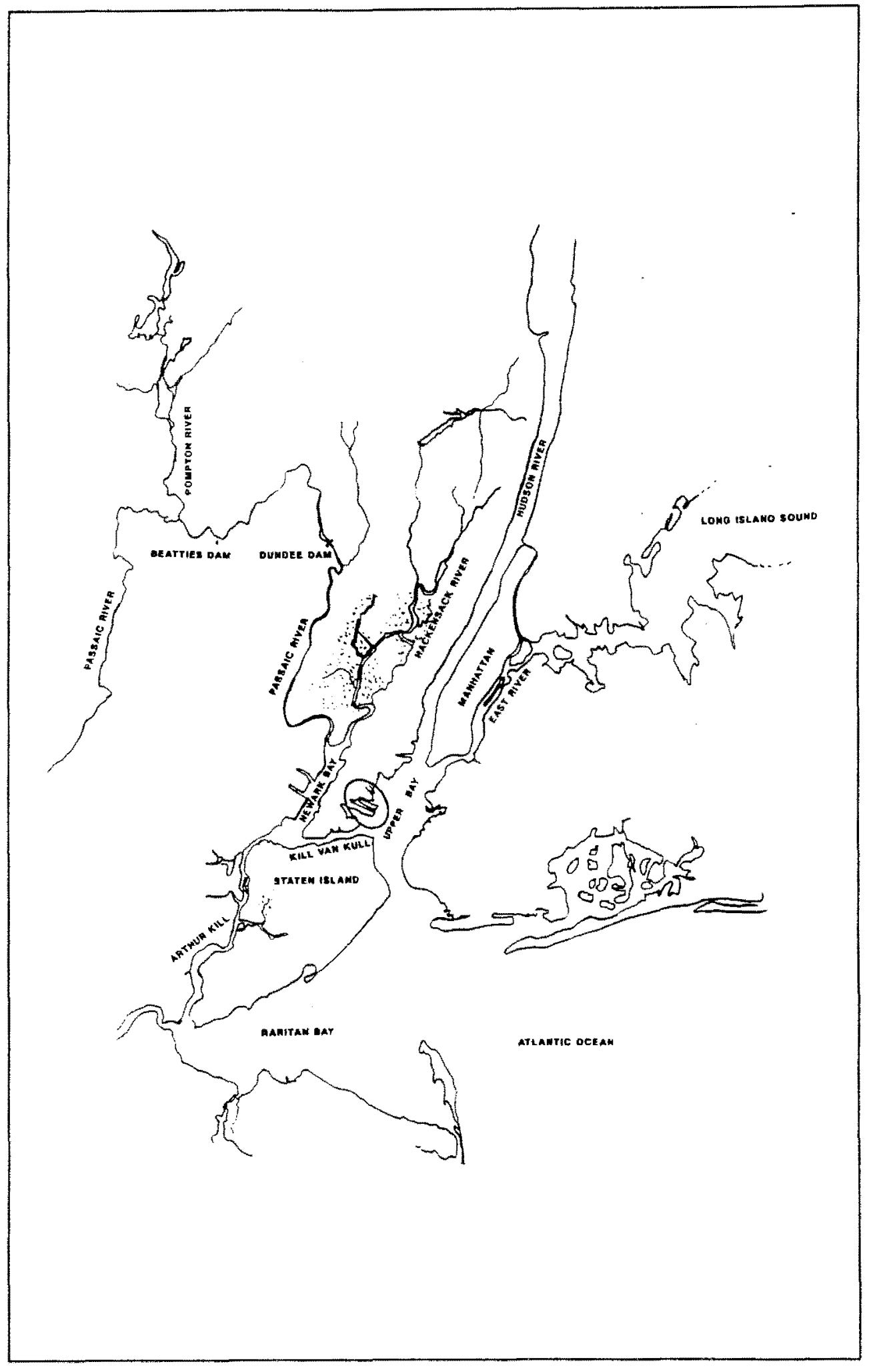

Figure A1. New York Harbor and surrounding area location map 


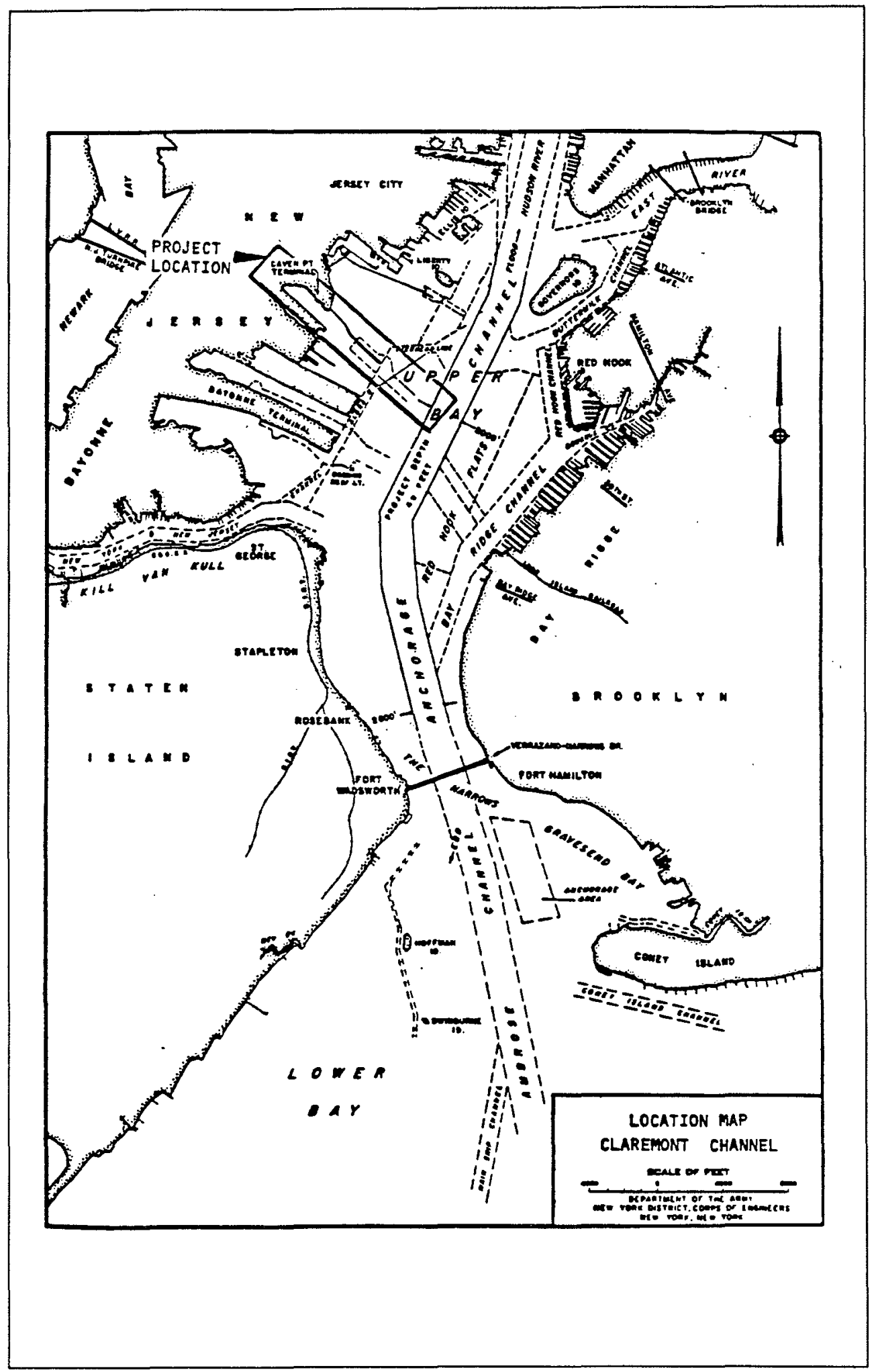

Figure A2. Claremont channel docking facility location map 
This allows a $1.5-\mathrm{ft}$ underkecl clearance (tide range is $4.5 \mathrm{ft}$ ). The proposed channel improvements, if implemented, would convert the facility to a federally maintained channel with a draft of $34 \mathrm{ft} \mathrm{mlw}$ and width of $300 \mathrm{ft}$.

\section{Objective}

The objective of this hydrodynamic ship simulator study is to evaluate various channel configurations and develop recommendations for a safe and cost-effective channel design. The objective of the hydrodynamic study was to provide current velocity information for ship/tow-simulation (both inbound and outbound).

\section{Scope}

This appendix addresses the hydrodynamic model development, validation, and testing.

\section{Technical Approach}

The technical approach for the Claremont investigation is described below:

a. Discuss existing docking procedures with the New York pilots.

b. Design the Claremont numerical model computational mesh building upon results of previous work performed by CEWES-HL in New York Harbor. In particular, the mesh developed for the Port Jersey (located just south of Claremont) hydrodynamic numerical study was evaluated and improved.

c. Validate the hydrodynamic modcl.

d. Create tidal harmonic boundary conditions.

e. Run the TABS-MD Claremont hydrodynamic numerical model (RMA2) for the existing channel conditions as defined by the summer 1992 survey of the berthing arca.

f. Incorporate the existing condition predicted velocities at critical stages of the tidal cycle into the ship simulator.

g. Modify the TABS-MD computational mesh to reflect the NAN channel design (Plan A).

h. Run the TABS-MD hydrodynamic model (RMA2) for the proposed NAN channcl design (Plan A). 
$i$ Incorporate the Plan A predicted velocities at critical stages of the tidal cycle into the ship simulator.

j. Modify the TABS-MD computational mesh to reflect the WES proposed channel design (Plan B).

$k$. Incorporate the Plan B predicted velocities at critical stages of the tidal cycle into the ship simulator.

\section{Hydrodynamic Numerical Modeling}

\section{The TABS-MD Modeling System}

The TABS-MD (TABS Multi-Dimensional) numerical modeling system is composed of several finite clement models and pre- and post-processing programs. The finite element formulation is isoparametric which allows the mesh to precisely follow the channel alignment and geometry of the pier site. A summary of the TABS-MD system is provided in Appendix B. The RMA2 hydrodynamic model was used to simulate channel velocities and depths under different channel configurations. RMA2 is a time dependent, non-linear, twodimensional (2D) vertically averaged model for open-channel hydrodynamics. The model solves the depth integrated $x$ - and $y$-momentum equations along with the continuity equation (Reynolds form of Navier-Stokes equations). FastTABS, an interactive graphical user interface for TABS-MD, was extensively used for this project.

\section{Computational Environment}

The Claremont channel hydrodynamic modeling for ship simulation was run on the WES Cray Y-MP super computer during the winter of 1992 through the spring of 1993. The model contained over 13,400 aclive equations with a front width of 333 . Model spin-up was approximately 24 hours. The total simulation was run for 72.0 hours with a maximum of 3 iterations per 15 minute time step. A simulation on the Cray Y-MP required 3 megawords of memory and the typical total central processor time on the loaded computer was 3 hours.

\section{The Computational Meshes}

A numerical computational mesh was developed for each bathymetric condition to which RMA2 was applied. For this study there were 3 meshes; existing condition (Base), Plan A, and Plan B. Each of these have the same computational domain, but differ only in the design definition for the Claremont channel width and depth. 
The computational domain is shown in Figure A3. The model extends from Troy, NY on the Hudson River, south to the Atlantic Ocean and from the Passaic River at Passaic, NJ, east to Montauk Point on Long Island Sound. The mesh for this study differs from its predecessor Port Jersey study mesh in several ways. The original computational mesh for the Port Jersey study is shown in Figure A4, part a. A subset of the entire Claremont computational mesh is shown in part b of Figure A4 for comparison. Note that the exterior boundaries of the mesh are rounded near the study area in an effort to decrease the boundary break angles and thercby increase the local accuracy in the conservation of mass. This is illustrated by the rounded shape of the ship terminal area. Additional resolution was used throughout. For instance, the constriction along the lower bay at the narrows now has a 13-element crosssection where previously the cross-section had only 6-elements. In addition, the exterior boundaries were moved far from the primary study area to eliminate any boundary sensitivity effects from the results. This was economically accomplished with a one clement wide, llat river bottom profile for the extended river boundary regions of Arthur Kill, Passaic River, Hackensack River, and upper Hudson River.

The geometry for the primary Claremont study area was derived from the summer of 1992 survey conducted under the guidance of the New York District. All coordinates were converted with the North American Datum Conversion (NADCON) program developed by the National Geodetic Survey, to reference the Long Island coordinate system. The following National Ocean Service/National Occanic and Atmospheric Administration (NOAA) nautical charts were used extensively:

\begin{tabular}{|l|l|l|l|}
\hline Chart No. & Location & Scale & Date \\
\hline \hline 274 & Harlem River & $1: 10000$ & 1951 \\
\hline 284 & Albany to Troy & $1: 40000$ & 1969 \\
\hline 13205 & Block Island Sound & $1: 80000$ & 1983 \\
\hline 12327 & New York Harbor & $1: 40000$ & 1982 \\
\hline 12333 & Kill van Kull \& N. Arthur Kill & $1: 15000$ & 1982 \\
\hline 12335 & Hudson and East Rivers & $1: 10000$ & 1980 \\
\hline 12339 & Tallman Isl to Queensboro Bridge & $1: 10000$ & 1984 \\
\hline 12343 & Hudson R., New York to Wappinger Creek & $1: 40000$ & 1984 \\
\hline 12345 & Hudson R., George Washington Bridge & $1: 10000$ & 1983 \\
\hline 12346 & Hudson River, Yonkers to Piermont & $1: 10000$ & 1979 \\
\hline 12347 & Hudson R., Wappinger Creek to Hudson & $1: 40000$ & 1985 \\
\hline 12354 & Eastern part of Long Isl Sound & $1: 80000$ & 1985 \\
\hline 12363 & Long IsI Sound, Western part & $1: 80000$ & 1985 \\
\hline
\end{tabular}




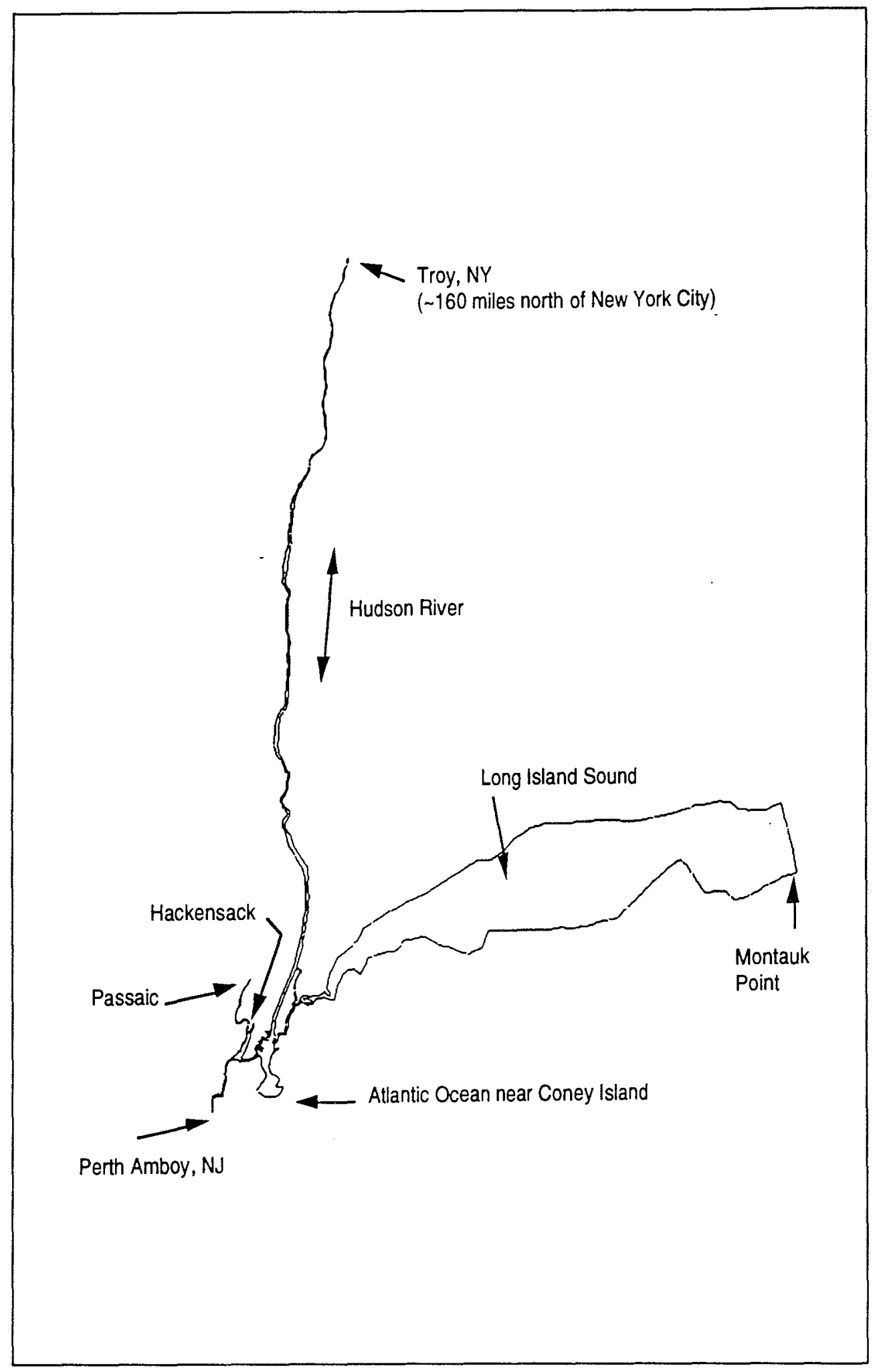

Figure A3. Outline of computational mesh domain 


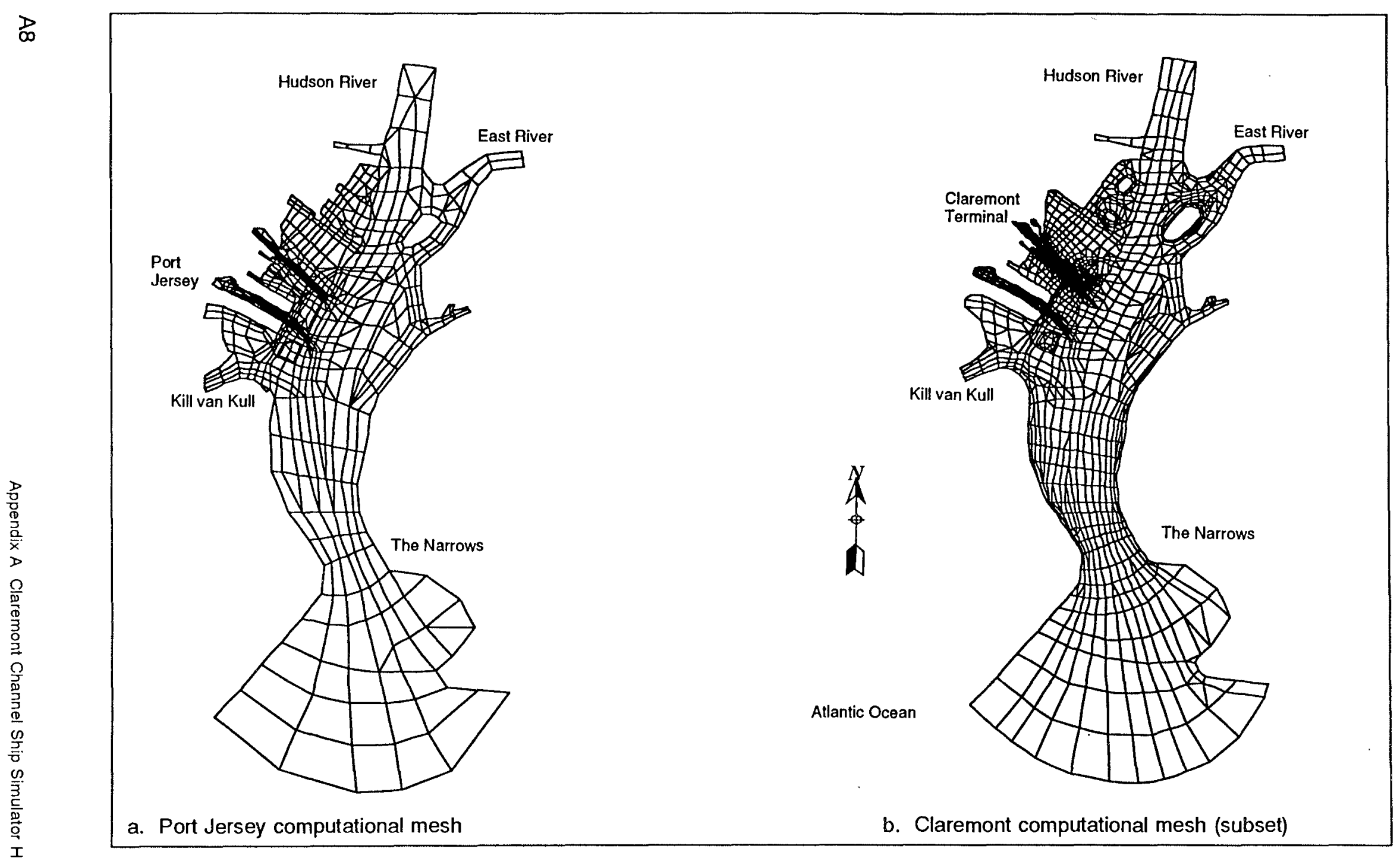

Figure A4. Comparison of the Claremont mesh and the predecessor Port Jersey mesh 
All bathymetric data referenced mlw and were converted to an elevation with an arbitrary datum plane of 200 feet. The bathymetry for the model ranges from $6.0 \mathrm{ft}$ deep in the shallows of New York Harbor to $164 \mathrm{ft}$ deep in Long Island Sound. All parts of the computational domain remain submerged during the period of simulation.

Existing Condition - Base. The existing condition (Base), Mesh 1, has 2712 elements and 8656 nodes. Figure A5 shows an enlarged view of the mesh from The Narrows to the Battery. Figure A6 illustrates the resolution for the existing Claremont channel. Approximately 600 elements define the primary study area. The dark shaded area is the Claremont terminal area, the light gray is the pier channel that intersects the primary Claremont channel. Figure A7 is a gray scale shaded map of the bathymetry as defined by the summer 1992 survey conducted under contract by the New York District. The bathymetric readings reference an arbitrary datum of $200 \mathrm{ft}$. The average element size within the Claremont channel is approximately $190 \mathrm{ft}$ longitudinally and 165 laterally, or $31,350 \mathrm{sq} \mathrm{ft}$. The Claremont channel tracking area was resolved to allow for approximately 2 to 3 elements per ship length, and 1 element per ship width. The existing primary Claremont channel is privately maintained at approximately $27 \mathrm{ft}$ deep at $\mathrm{mlw}$ and $150 \mathrm{ft}$ wide.

Proposed Design (Plan A). Mesh 2 represents the channel design proposed in the Claremont Terminal Channel Feasibility Report, Sept 1986. Mesh 2 has 2709 elements and 8667 nodes. Figure A8 illustrates the mesh with proposed changes in the channel design. As shown in the depth contours of Figure A9, Plan A has the channel deepened to $34 \mathrm{ft}$ and widened to $300 \mathrm{ft}$. For reference, the pier channel is outlined.

Proposed Design (Plan B). Mesh 3 has 2712 elements and 8656 nodes. Figure A10 illustrates the mesh with the WES proposed changes in the channel design. As shown in the depth contours of Figure A11, Plan B has the channel deepened to $34 \mathrm{ft}$ but narrows from $300 \mathrm{ft}$ wide to $250 \mathrm{ft}$ wide at the tip of the Ocean Terminal Pier. For refcrence, the pier channel is outlined. Note that the southern edge of the primary Claremont channel did not change, only the northern edge was moved to reflect the narrowing.

\section{Hydrodynamic Validation}

The rigorous verification of a numcrical model requires extensive synoptic field data stations strategically located throughout the modcling domain. Moored water surface elevation gages and velocity meters are usually employed to sample for a non-aliasing data set over several months. These data provide the necessary input for calculating harmonic constituents for the tidal boundary condition and interior verification stations. A detailed velocity profile data set within the primary area of interest for a full tidal cycle is needed also. These data are used to compare numerical model predictions with the prototype. The data collection process can be expensive, and involves 


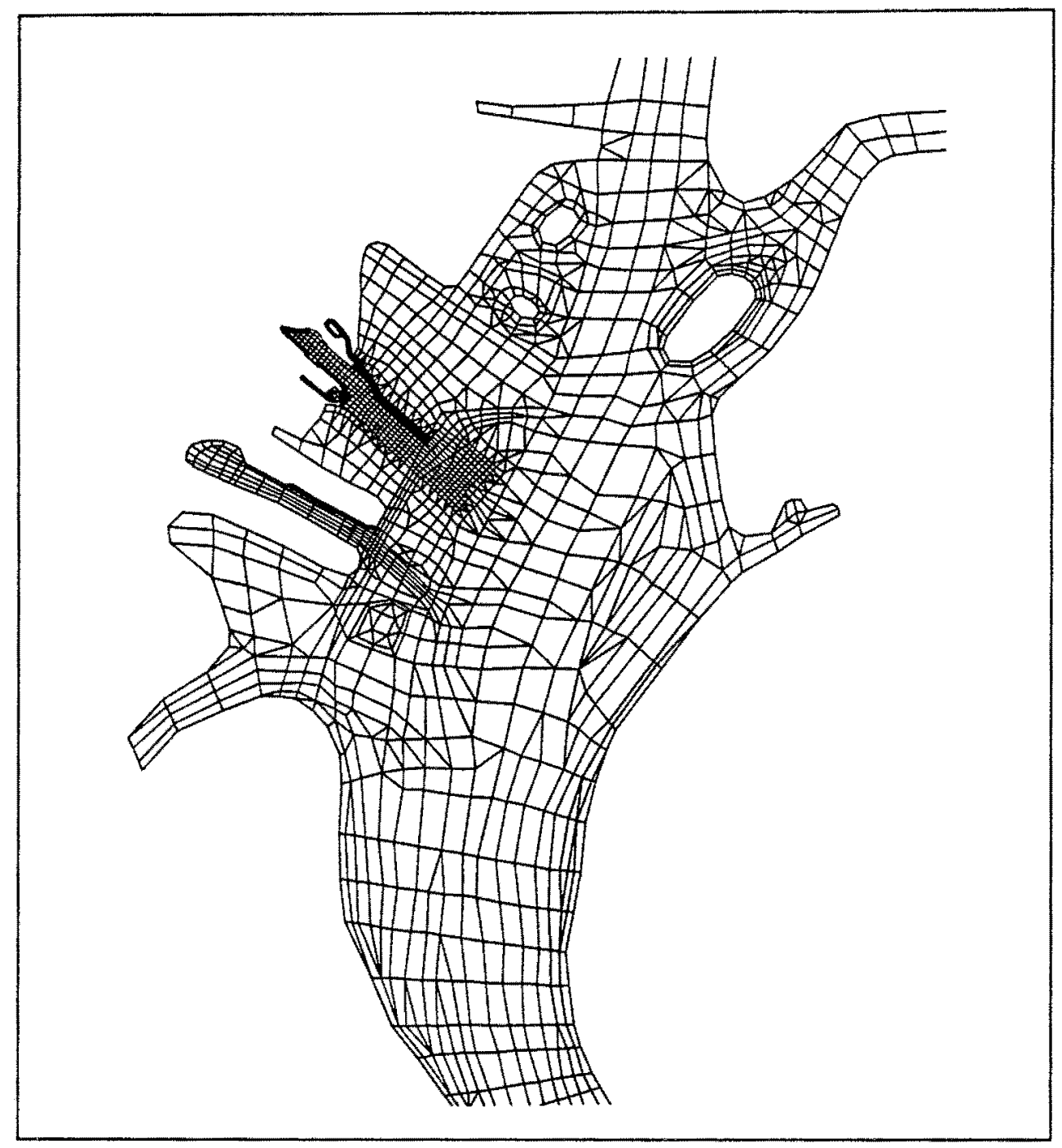

Figure A5. Computational mesh from lower bay to the Battery

careful logistics. However, it remains the primary method of illustrating that the model predicts the behavior of the prototype condition.

Time and budget constraints dictated that a less rigorous method be employed to validate the numerical model. There have been successful TABSMD hydrodynamics generated for ship simulator applications which did not have large data sets from the prototype. For example the hydrodynamics for the Valdez Alaska project was validated on the basis of NOAA predicted tide tables, pilot interview, and engincering judgement. The hydrodynamics for the ship simulation of Humboldı Bay was validated on the basis of harmonic tides from the TIDE1 Rise and Fall ${ }^{1}$ (tide prediction software for the PC) and pilot

1 TIDE1 Rise and Fall, tide prediction software for the IBM PC, Micronautics, Inc., Rockport, Maine (207-236-0610). 


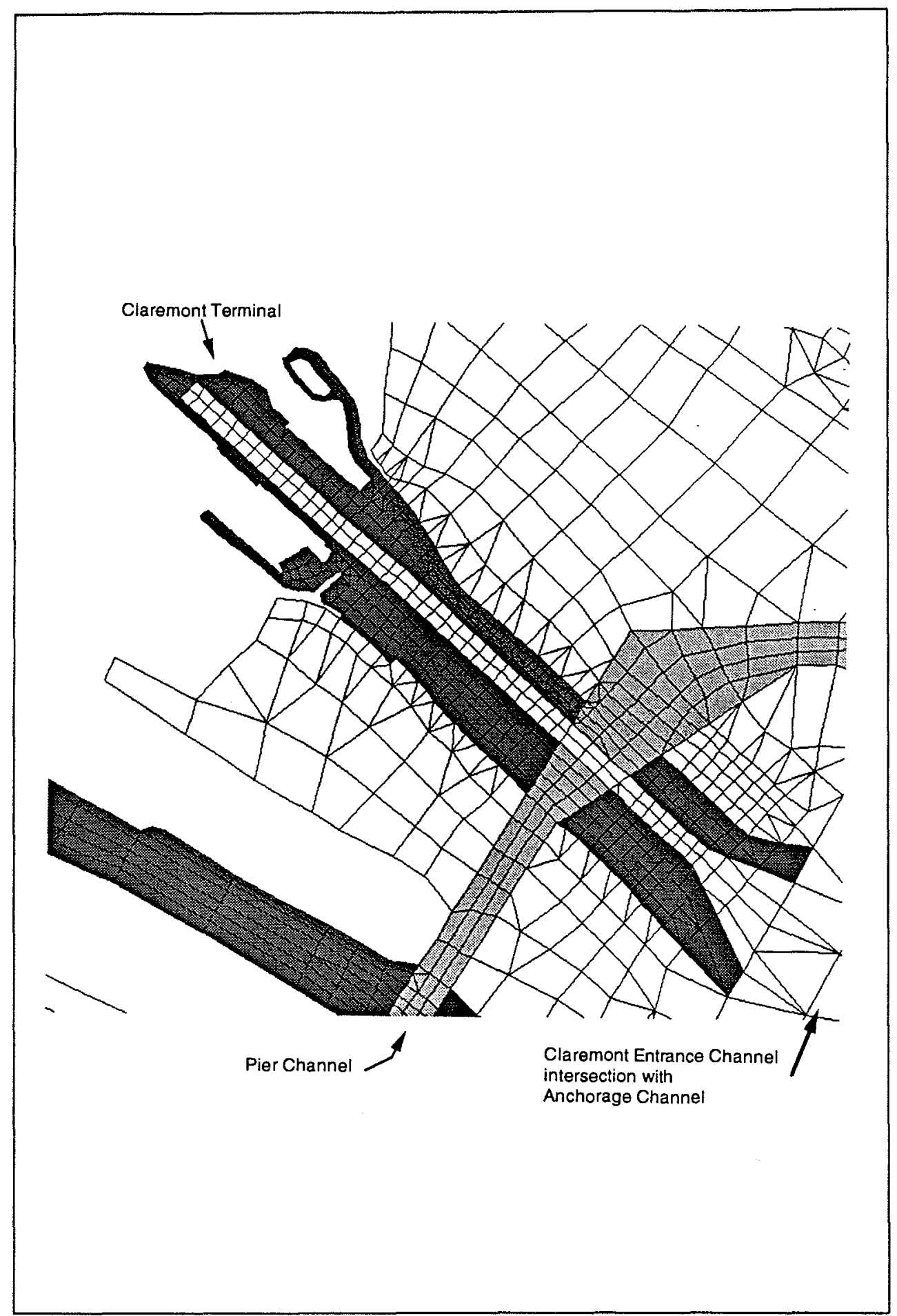

Figure A6. Claremont channel resolution

feedback during simulation with predicted currents. This less rigorous approach was selected for the Claremont hydrodynamic for ship simulation study. 


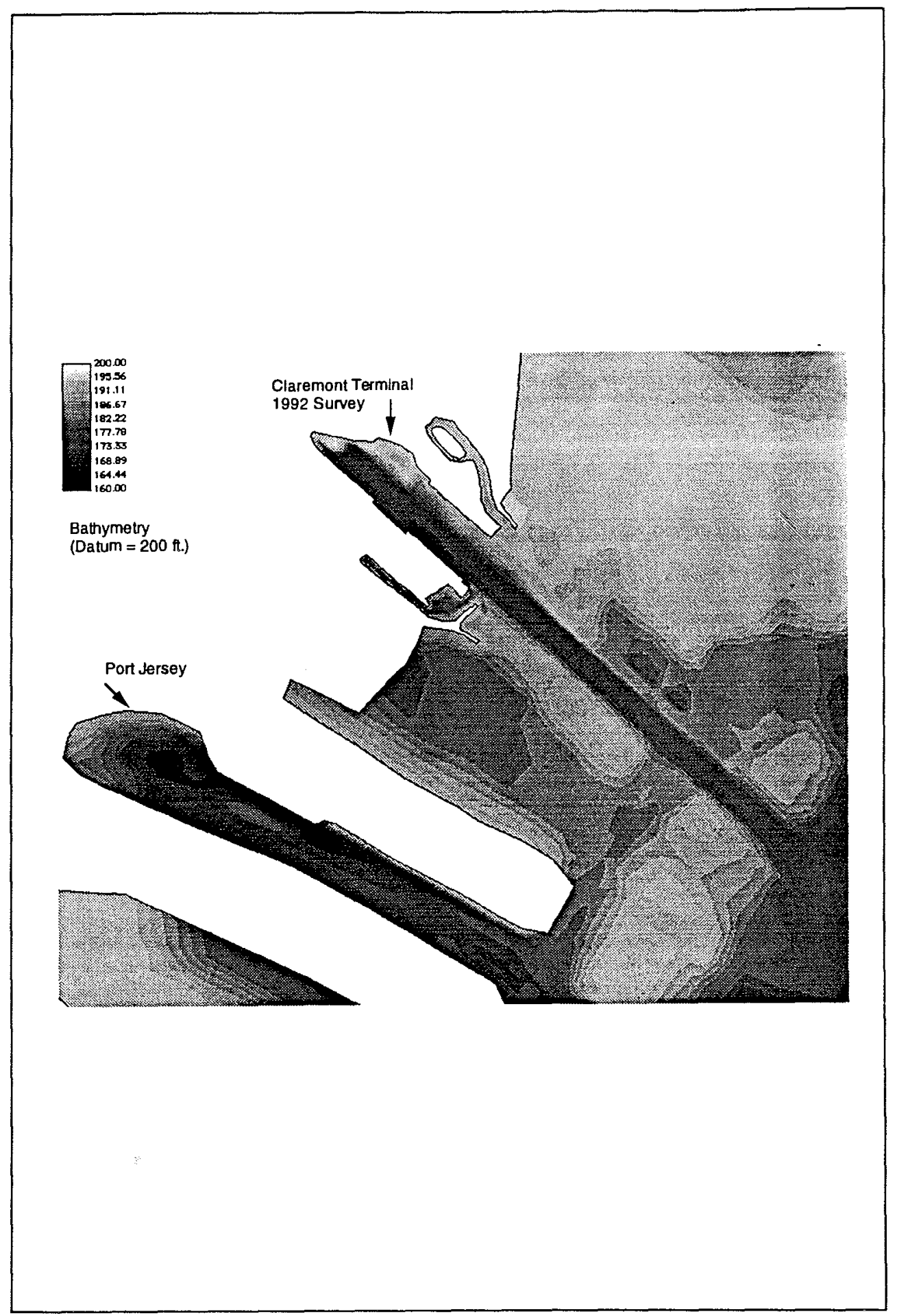

Figure A7. Claremont channel existing (1992) bathymetry

Successful hydrodynamic prediclion depends upon on accurate geometric represcntation and well-posed boundary conditions. In provious numerical model studies of the New York Harbor, boundary conditions were set fairly 


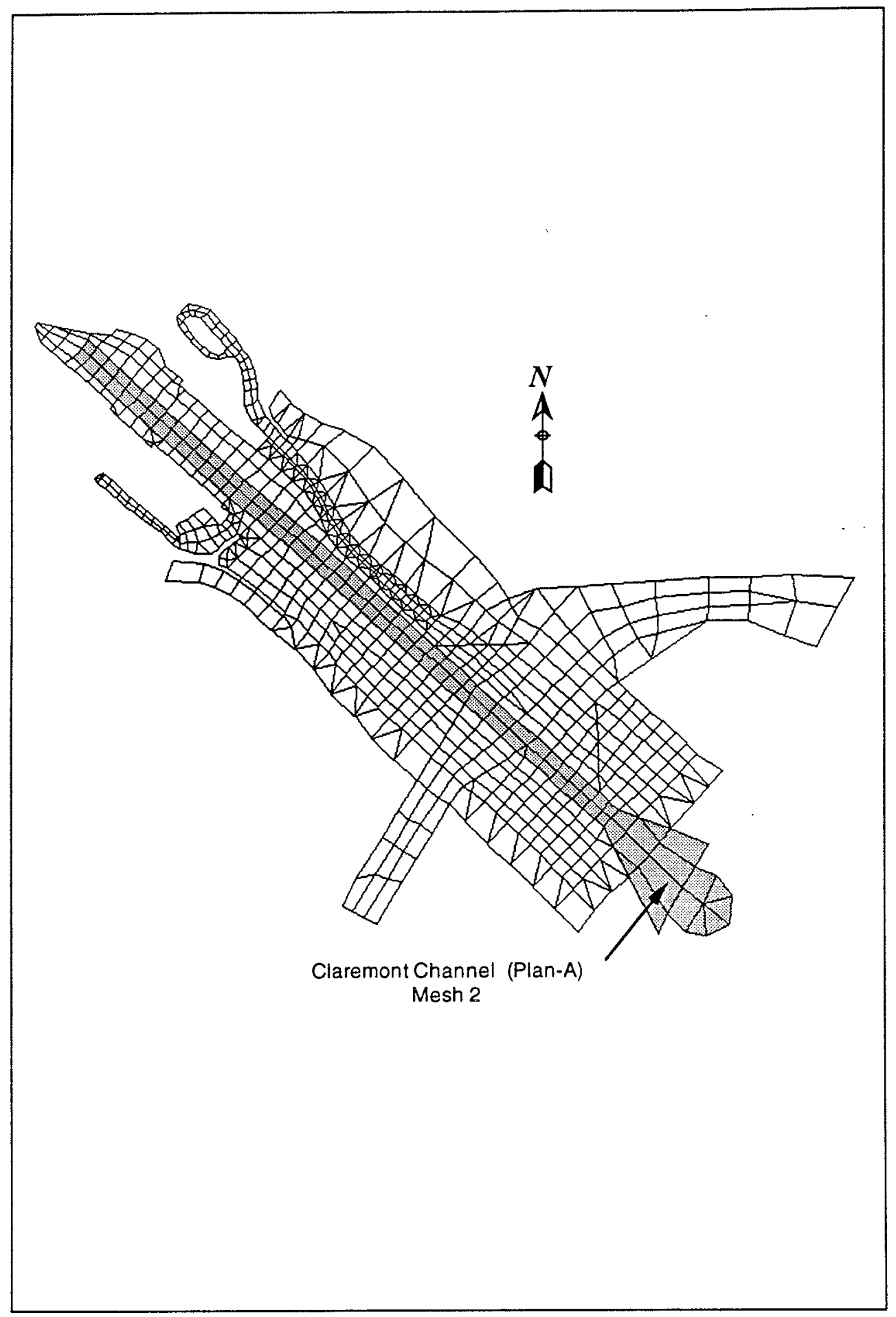

Figure A8. Claremont channel, Plan A design 


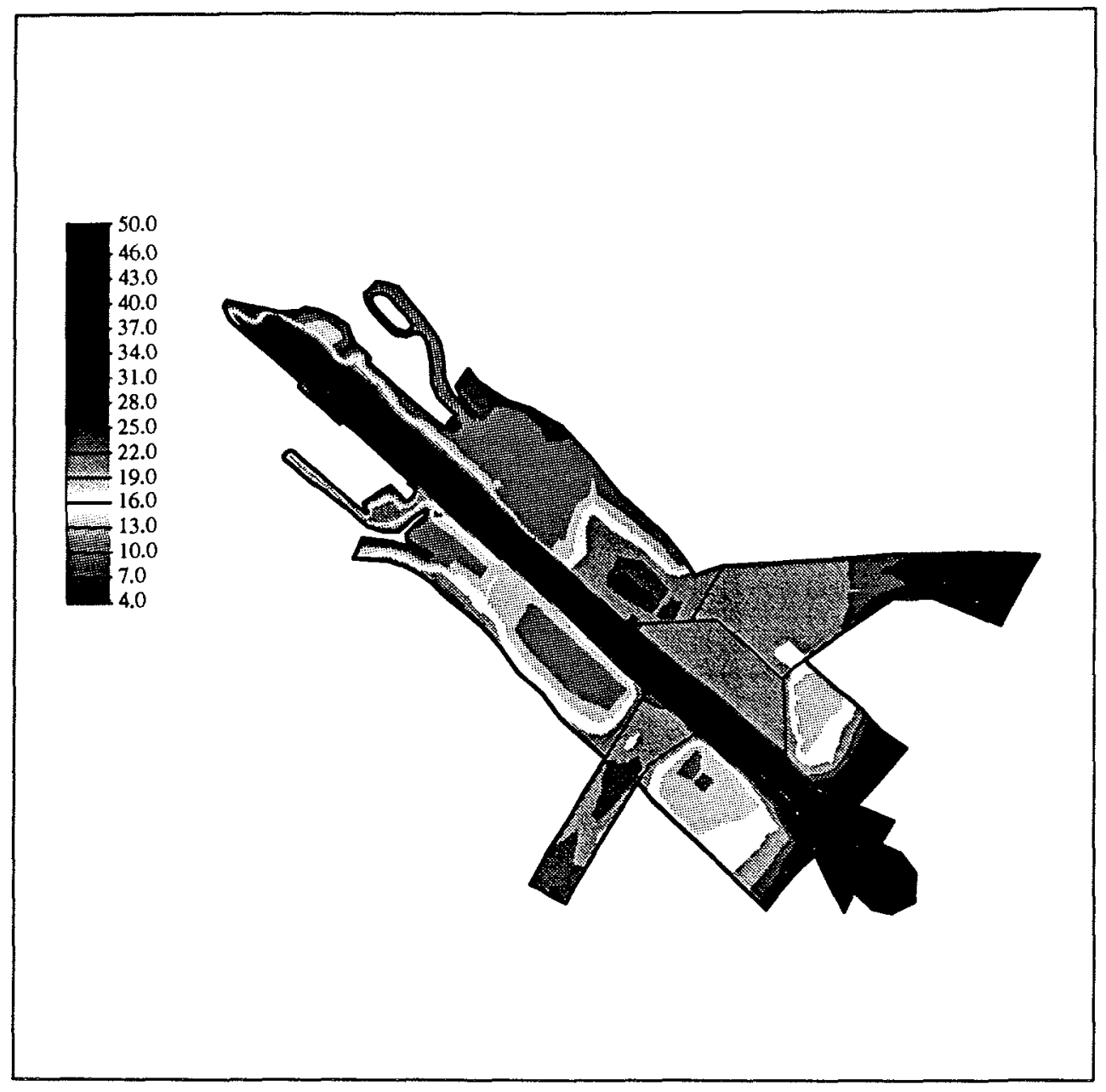

Figure A9. Claremont channel bathymetry, Plan A

close to the study area (Figure A4a) to correspond with the New York Harbor physical model tide and/or velocity stations. An evaluation of the impacts of these close boundary conditions revealed that the model was highly sensitive to minor tidal phase discrepancies and excessive clevation changes at critical sections of the tidal cycle. In an effort to remove discrepancies, the boundary control points were moved far from the study area, as shown in Figures A3 and A12. In addition, predicted tidal harmonic data, obtained from the TIDE1 Rise and Fall software package, were used to ensure accurate phase relationships at the boundaries. Other steps were taken to avoid numerical instability; including a shorter time step, tidal harmonic boundary conditions, gradual exterior boundary break angles, and damping the tidal signal during model spin-up. Furthermore, data obtained from physical model tests were used as general guidelines.

The hydrodynamic validation was accomplished for the base condition, using existing geometry, for a spring tide event. This validation was performed to ensure, within engineering judgement, that the model was responding within required limits of accuracy to: 


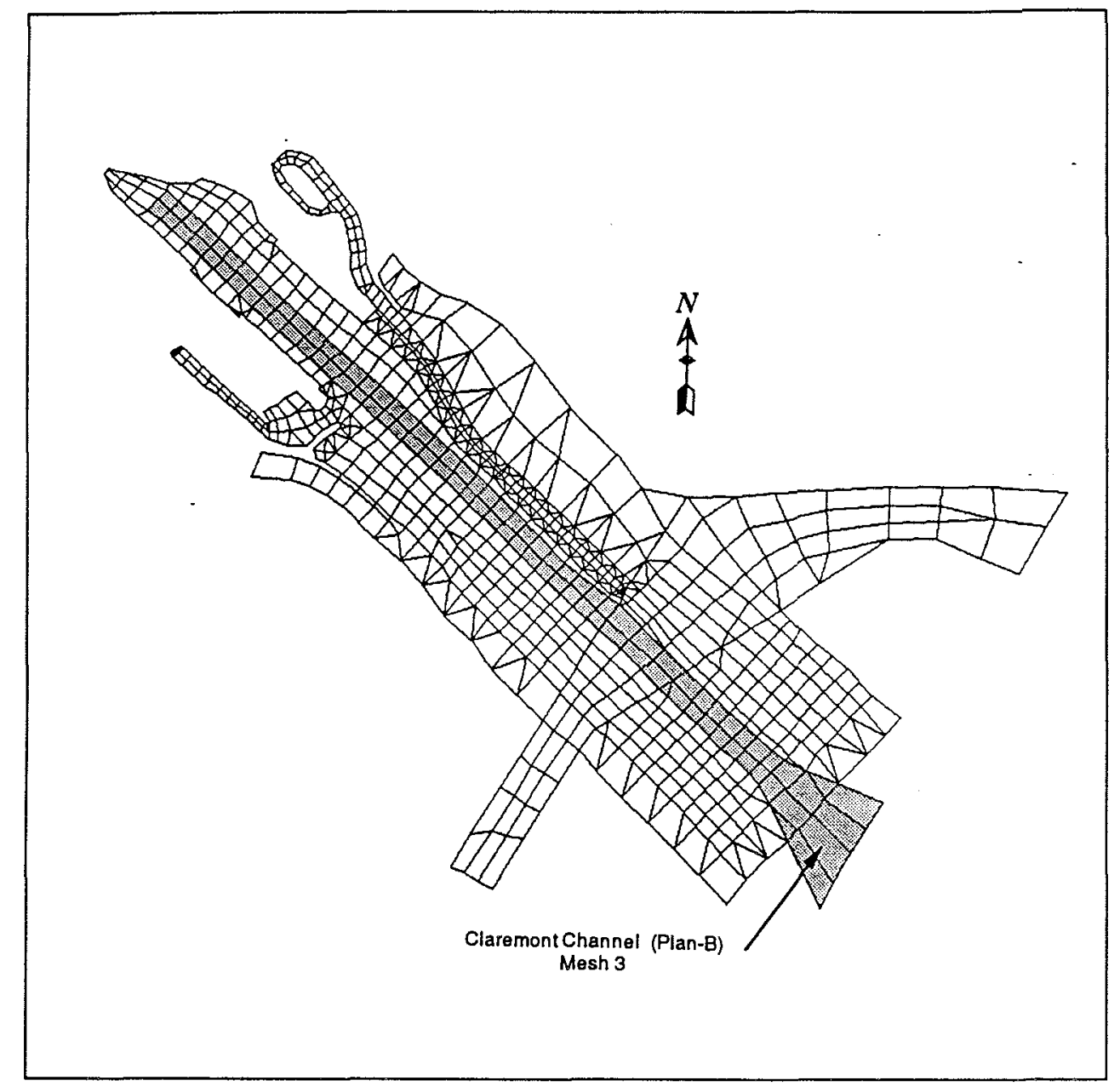

Figure A10. Claremont channel, Plan B design

a. Avoid the effects of start up (spin-up).

b. Achieve numerical stability.

c. Examine residual currents.

d. Compare interior stations with tidal harmonics

e. Observe ship pilots' reaction to predicted currents.

Tidal Boundary Conditions. A spring tidal condition was chosen as a representative challenge for ship maneuvcrability. The water surface elevations were assigned across the tidal boundaries (Figures $\mathrm{A} 3$ and $\mathrm{A} 12$ ). The documented spring tide range are provided in Table A1. As shown in Table 1, the harmonic tidal predictions for the day sclected (17 May 92 or Julian day 138) fit the characteristic values for a spring tide event. Figure A13 illustrates how these boundary conditions inter-relate with one another and are all referenced 


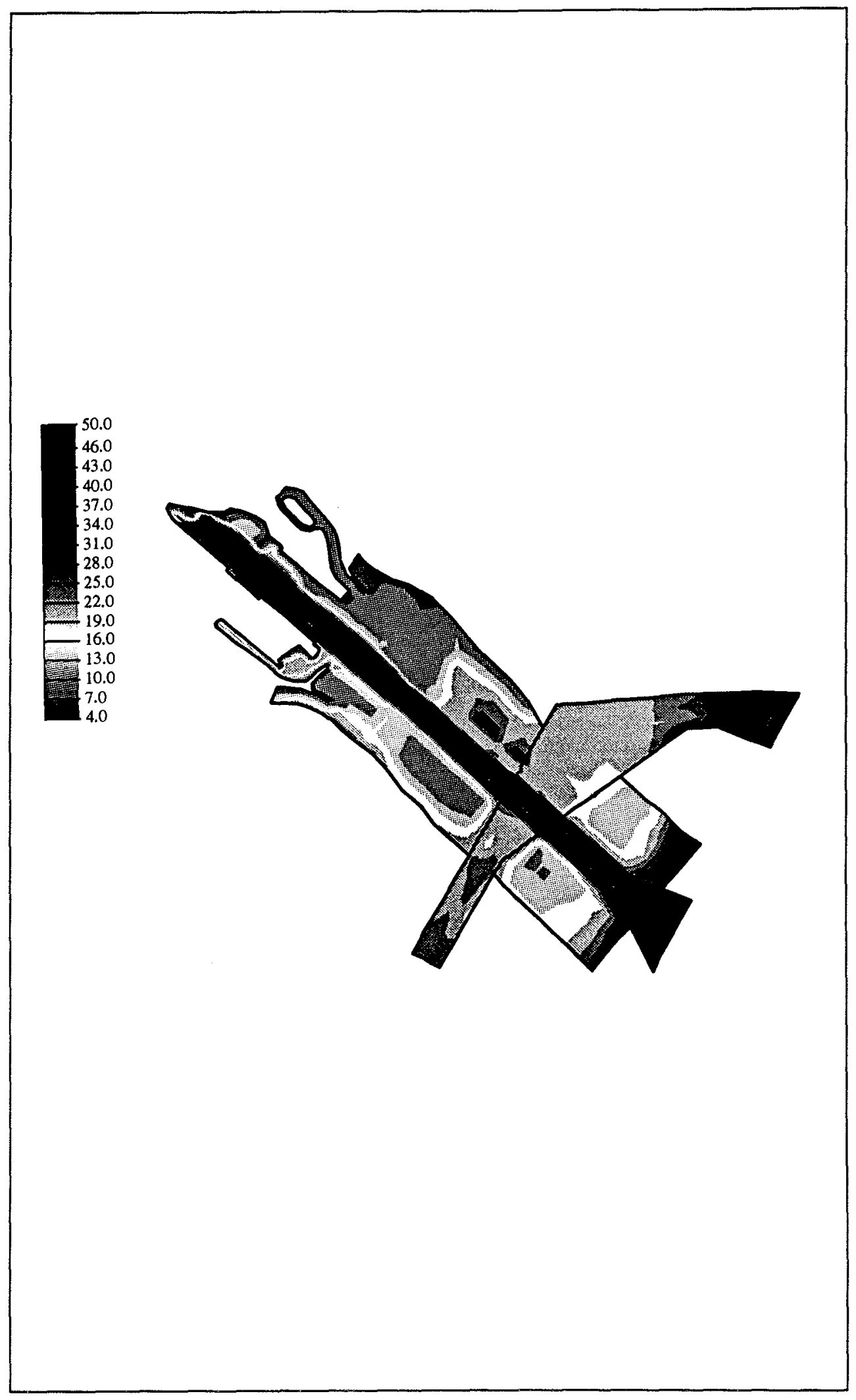

Figure A11. Claremont channel, Plan B bathymetry 


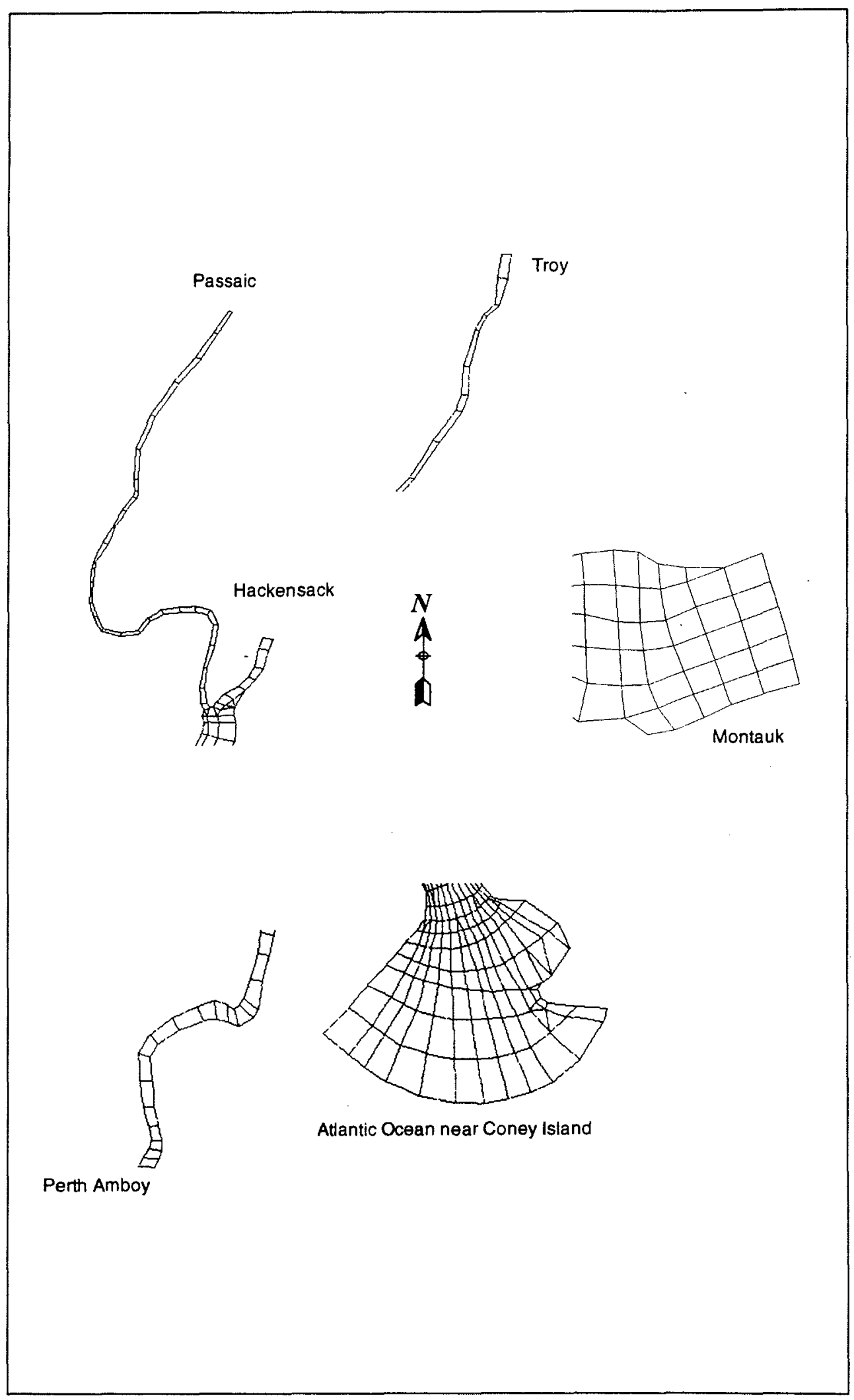

Figure A12. Hydrodynamic boundary control points 


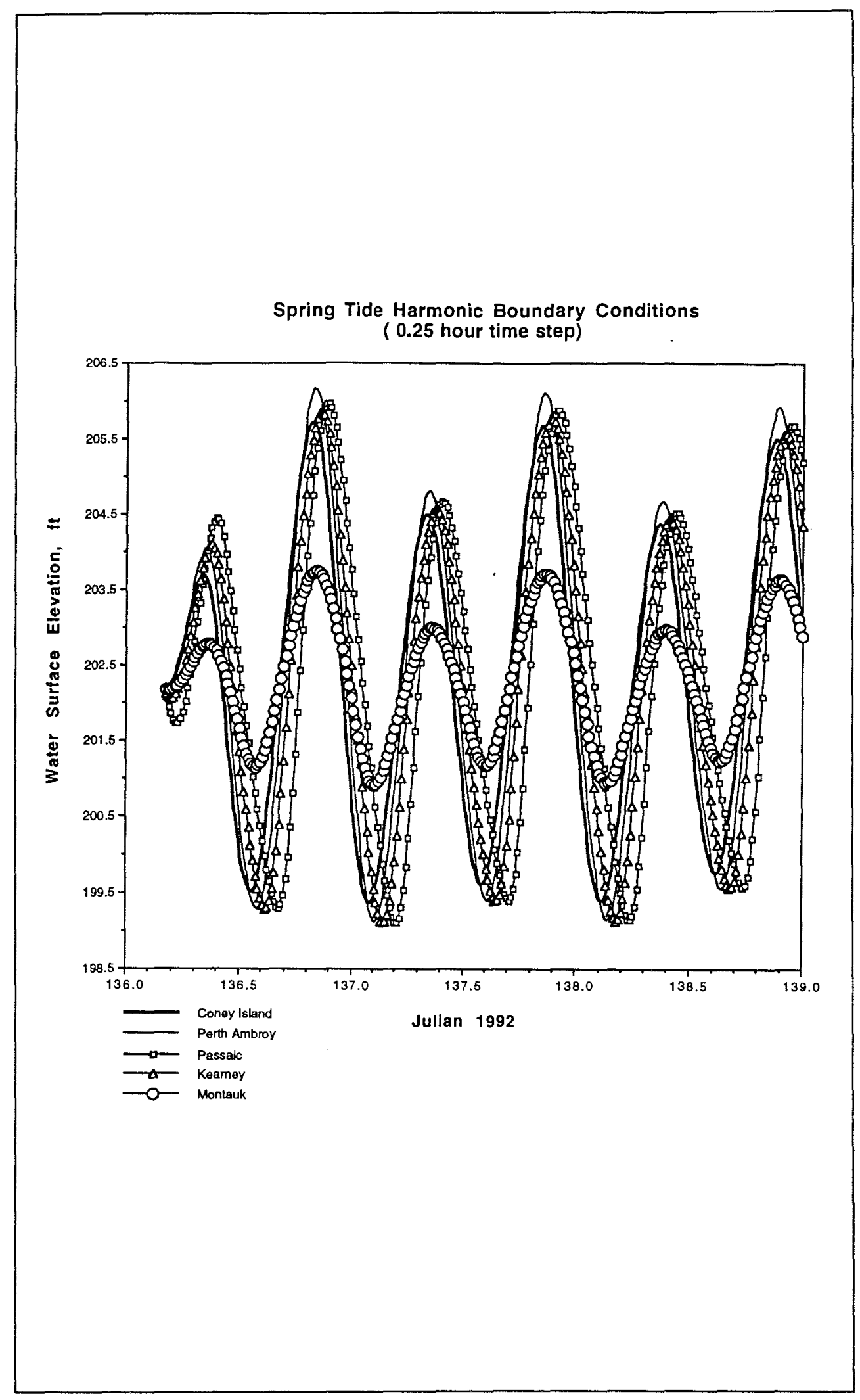

Figure A13. Tidal harmonic boundary conditions 
to the mean water surface elevation of the model $(202.2 \mathrm{ft})$. Note that the tidal signals were originally damped then gradually amplified to full range within the first 12 hours of the simulation.

\begin{tabular}{|c|c|c|c|c|}
\hline \multicolumn{5}{|c|}{$\begin{array}{l}\text { Table A1 } \\
\text { Tidal Boundary Conditions }\end{array}$} \\
\hline \multicolumn{3}{|c|}{ Location } & \multirow{2}{*}{$\begin{array}{l}\text { Documented Spring Tide } \\
\text { Range (tt) }\end{array}$} & \multirow{2}{*}{$\begin{array}{l}17 \text { May } 1992 \\
\text { Tide Range }(\mathbf{f t}\end{array}$} \\
\hline Station & Latitude & Longitude & & \\
\hline Coney Is| & $40^{\circ} 34^{\prime} \mathrm{N}$ & $73^{\circ} 59^{\prime} \mathrm{W}$ & 5.7 & 5.7 \\
\hline Perth Amboy & $40^{\circ} 30^{\prime} \mathrm{N}$ & $74^{\circ} 16^{\prime} \mathrm{W}$ & 6.3 & 6.3 \\
\hline Passaic Riv & $40^{\circ} 51^{\prime} \mathrm{N}$ & $74^{\circ} 07^{\prime} \mathrm{W}$ & 6.2 & 6.1 \\
\hline Kearney Pt & $40^{\circ} 44^{\prime} \mathrm{N}$ & $74^{\circ} 06^{\prime} \mathrm{W}$ & 6.1 & 6.0 \\
\hline Montauk Pt & $41^{\circ} 04^{\prime} \mathrm{N}$ & $71^{\circ} 52^{\prime} \mathrm{W}$ & 2.5 & 2.4 \\
\hline
\end{tabular}

Discharge Boundary Condition. The boundary condition for the Hudson River at Troy (location of the head of tide) was a discharge specification. The documented mean river discharge of 6,000 cfs was applied at Troy.

Hydrodynamic Coefficients. User specified coefficients for the hydrodynamic model, RMA2, include Manning's n-value and eddy viscosity. Both were controlled by the element material type (IMAT) descriptor. By grouping elements in IMAT categories, the roughness and viscosity values were easily assigned. Table A2 describes the coefficients for each material type used in the computational mesh. Table A3 provides the actual coeflicients used for the hydrodynamic spring tide simulation.

The column marked maximum Peclet \# in Table A3 can be used as an indicator of numerical stability. A value of 20 or less is typically recommended for numerical stability. In Table A3, the maximum or "worst case Peclet number" indicates the largest element and the highest velocity within an IMAT group over a tidal cycle. The formula for the Peclet number is given below:

$$
P=\frac{u \Delta x(1.94)}{E}
$$

where

$$
\begin{aligned}
\mathrm{P} & =\text { Peclet number } \\
\mathbf{u} & =\text { streamwise velocity }(\mathrm{fps}) \\
\Delta \mathrm{X} & =\text { length of the element in the streamwise direction }(\mathrm{ft}) \\
\mathrm{E} & =\text { eddy viscosity }\left(\mathrm{lb}-\mathrm{sec} / \mathrm{ft}^{2}\right) \\
1.94 & =\text { required for non-SI calculations }
\end{aligned}
$$




\begin{tabular}{|c|c|c|c|c|}
\hline \multicolumn{5}{|c|}{$\begin{array}{l}\text { Table A2 } \\
\text { Element Material Type Assignments }\end{array}$} \\
\hline \multirow[b]{2}{*}{ IMAT } & \multirow[b]{2}{*}{ Description } & \multicolumn{2}{|c|}{ Average Length (ft) } & \multirow[b]{2}{*}{ Average Area (sq. tt.) } \\
\hline & & $x$ & 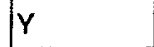 & \\
\hline 1 & Shallows (less than $15 \mathrm{ft}$. deep) & 800 & 785 & 345,401 \\
\hline 2 & Perimeter of islands & 820 & 950 & 339,723 \\
\hline 3 & Dead end zones & 1,245 & 913 & 593,220 \\
\hline 4 & Ambrose and Anchorage Channel & 1,125 & 1,435 & $1,026,923$ \\
\hline 5 & Piers along deep channels & 760 & 1,625 & 495,301 \\
\hline 6 & Red Hook and southern East River & 900 & 940 & 435,693 \\
\hline 7 & Eastern Kill van Kull approach & 995 & 835 & 477,956 \\
\hline 8 & Pier cross channel near Port Jersey & 410 & 412 & 94,894 \\
\hline 9 & Port Jersey & 615 & 470 & 100,408 \\
\hline 10 & Coney Island Atlantic Ocean Boundary & 3,554 & 4,114 & $8,706,075$ \\
\hline 11 & Southern Hudson River & 1,963 & 3,722 & $3,762,872$ \\
\hline 12 & Western Kill van Kull & 1,795 & 1,203 & 725,990 \\
\hline 13 & East River near Williamsburg Bridge & 1,180 & 1,118 & 693,160 \\
\hline 14 & Upper Hudson River to Troy & 3,587 & 5,553 & $12,436,735$ \\
\hline 15 & Arthur Kill, Newark Bay, Passaic & 2,005 & 2,140 & $2,218,114$ \\
\hline 16 & Harlem River & 832 & 1,125 & 496,308 \\
\hline 17 & Hellsgate and beginning Long IsI Sound & 2,955 & 3,313 & $10,672,000$ \\
\hline 18 & Eastern Long Island Sound & 14,775 & 17,565 & $259,522,875$ \\
\hline 19 & Unused & 0 & 0 & 0 \\
\hline 20 & Claremont Ship Channel & 270 & 270 & 37,723 \\
\hline 21 & $\begin{array}{l}\text { Intersection of Pier Channel \& } \\
\text { Claremont }\end{array}$ & 357 & 335 & 54,601 \\
\hline 22 & Claremont Terminal general vicinity & 207 & 220 & 25,300 \\
\hline
\end{tabular}

Residual Currents. Examination of Eulcrian residual currents (velocities averaged over a tidal cycle) can provide insight concerning model accuracy. Net effects, such as eddy patterns, can indicate if there is sufficient resolution. Figure A14 illustrates residual vectors obtained from processing hours 37.0 through 49.5 of the RMA2 spring tide simulation (average over a 12.5 -hour period). Velocities less than 0.10 ips are plotted as a dot.

Residual Error, Figure A15 illustrates results from a residual error analysis. For the time of maximum ebb, integration of the residual error in the continuity equation reveals that the least crror is in the study area where the mesh 

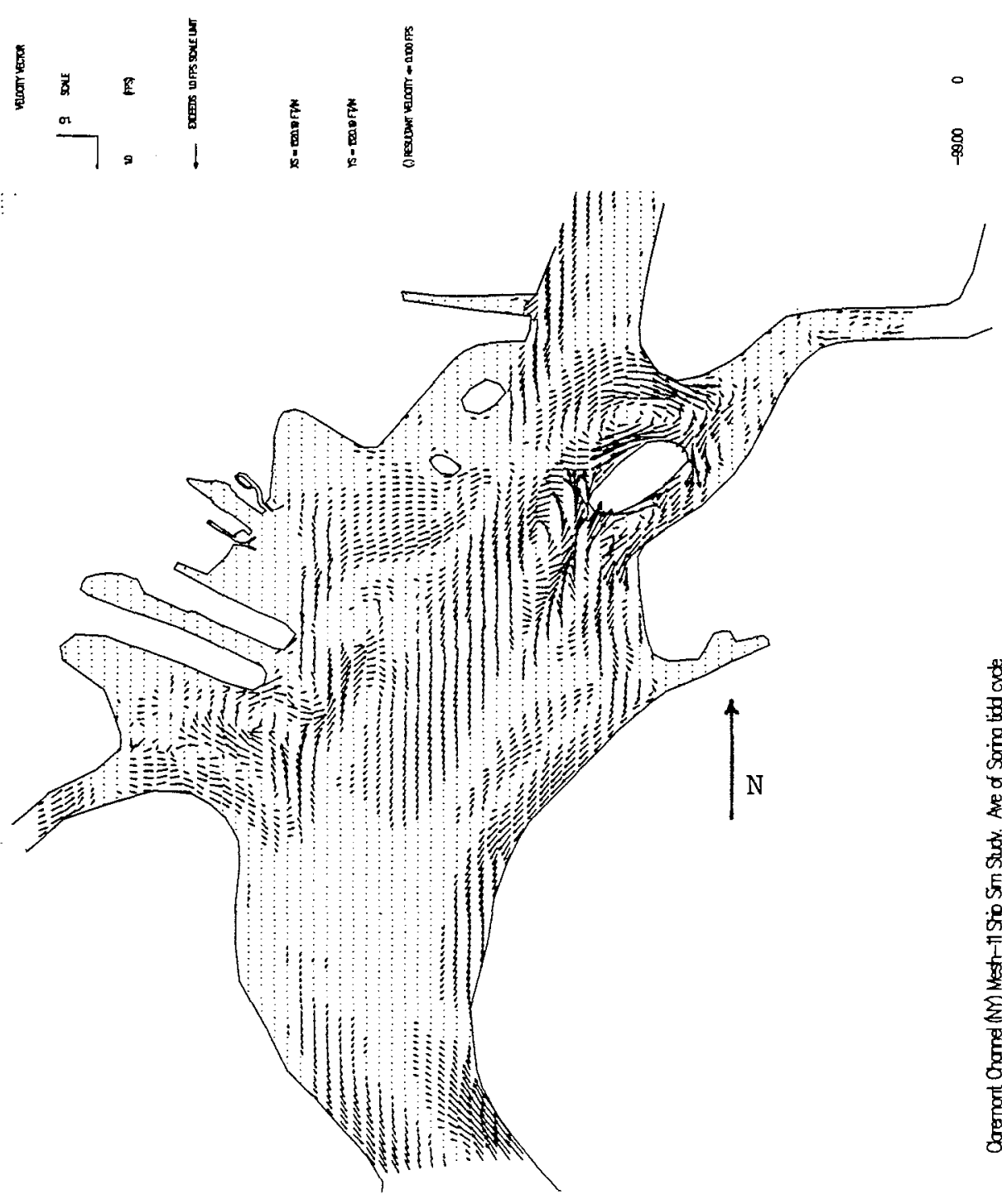

Figure A14. Velocities averaged over a 12.5-hour spring tidal cycle 


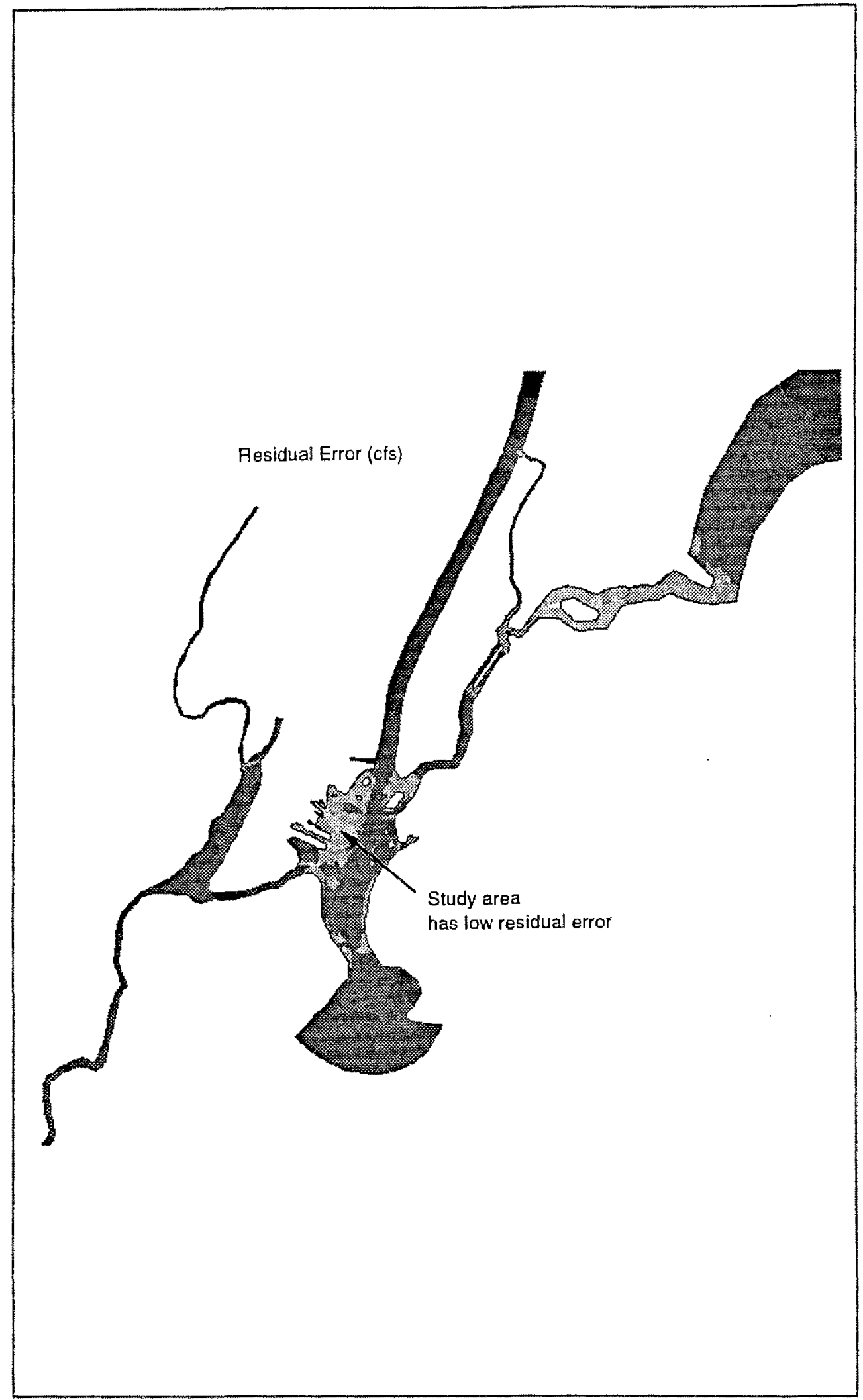

Figure A15. Residual error in the continuity equation of the hydrodynamic model, RMA2 


\begin{tabular}{|c|c|c|c|c|}
\hline \multicolumn{5}{|c|}{$\begin{array}{l}\text { Table A3 } \\
\text { Hydrodynamic Coefficient Assignments by zone }\end{array}$} \\
\hline Description & $\mathrm{Man}_{\mathrm{ft}^{1 / 6}}$ & $\begin{array}{l}\text { Eddy Viscosity } \\
\left(\mathrm{lb}-\mathrm{sec} / \mathrm{ft}^{2}\right)\end{array}$ & $\begin{array}{l}\text { Max Vel } \\
\text { fps }\end{array}$ & $\begin{array}{l}\text { Maximum } \\
\text { Peclet \# }\end{array}$ \\
\hline Shallows (less than $15 \mathrm{ft}$. deep) & 0.050 & 30 & 0.8 & 41 \\
\hline Perimeter of islands & 0.050 & 50 & 1.8 & 66 \\
\hline Dead end zones & 0.020 & 25 & 0.6 & 56 \\
\hline Ambrose and Anchorage Channel & 0.020 & 50 & 3.2 & 174 \\
\hline Piers along deep channels & 0.030 & 50 & 1.4 & 87 \\
\hline Red Hook and southern East River & 0.020 & 100 & 4.2 & 76 \\
\hline Eastern Kill van Kull approach & 0.020 & 50 & 2.5 & 92 \\
\hline Pier cross channel near Port Jersey & 0.020 & 15 & 2.0 & 106 \\
\hline Port Jersey & 0.020 & 15 & 0.7 & 54 \\
\hline Coney Island Atlantic Ocean Boundary & 0.020 & 200 & 1.8 & 70 \\
\hline Southern Hudson River & 0.020 & 200 & 2.6 & 93 \\
\hline Western Kill van Kull & 0.020 & 150 & 2.8 & 54 \\
\hline East River near Williamsburg Bridge & 0.020 & 300 & 4.3 & 31 \\
\hline Upper Hudson River to Troy & 0.022 & 500 & 1.9 & 37 \\
\hline Arthur Kill, Newark Bay, Passaic & 0.022 & 300 & 4.4 & 60 \\
\hline Harlem River & 0.022 & 300 & 3.3 & 23 \\
\hline Hellsgate and beginning Long IsI Sound & 0.022 & 1000 & 7.0 & 41 \\
\hline Eastern Long Island Sound & 0.020 & 1000 & 1.5 & 51 \\
\hline Claremont Ship Channel & 0.020 & 15 & 0.55 & 19 \\
\hline Intersection of Pier Channel \& Claremont & 0.020 & 15 & 0.55 & 16 \\
\hline Claremont Terminal general vicinity & 0.020 & 15 & 2.0 & 57 \\
\hline
\end{tabular}

resolution is the highest. As expected, the greatest error (shown in dark shades) is located in the expanded boundary condition regions where the resolution is course.

Compare Interior Stations with Tidal Harmonics. Tidal harmonic data are available from published sources (NOAA and TIDE1) for several stations throughout the study area. The data give phase and amplitude variations from station to station. Similar stations were observed in the RMA2 numerical model and compared to the TIDE1 defined relationships. Typical comparisons were made at Fort Hamilton (Figure A16a) which is located near the Narrows, and at the Battery (Figure A16b) which is located between the Hudson and East Rivers. The comparison of defined versus computed water surface elevation is within the accuracy limits required for ship simulation. 


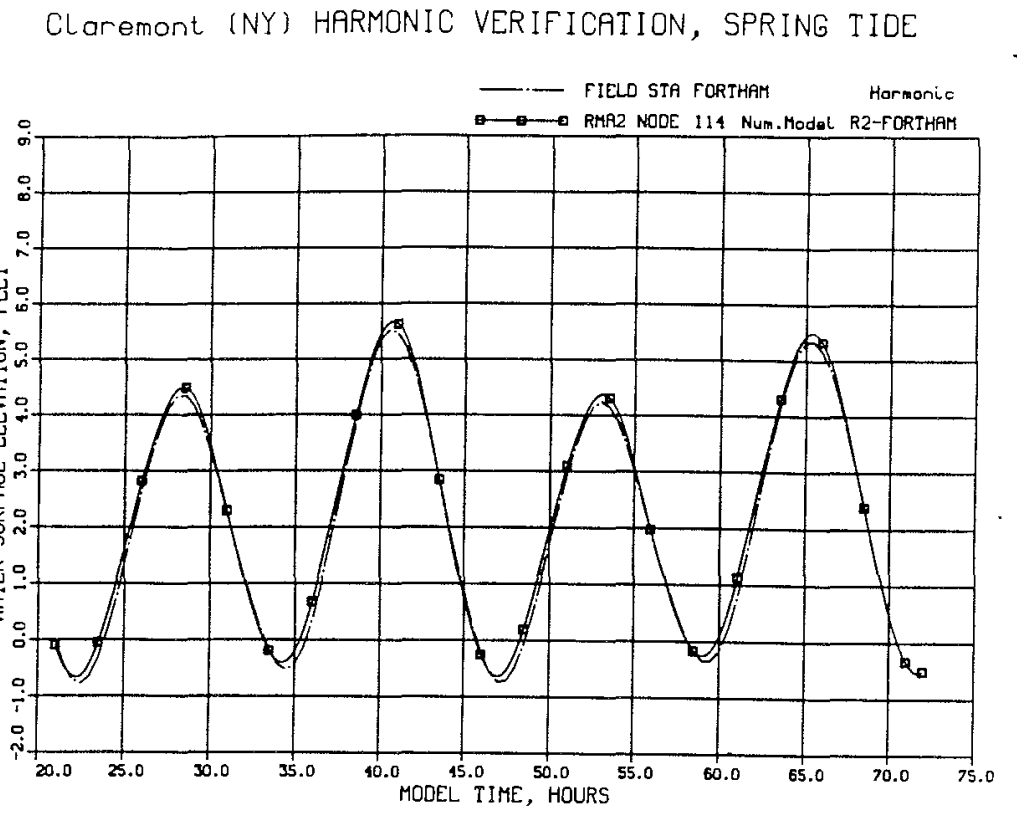

a. Fort Hamilton near the Narrows

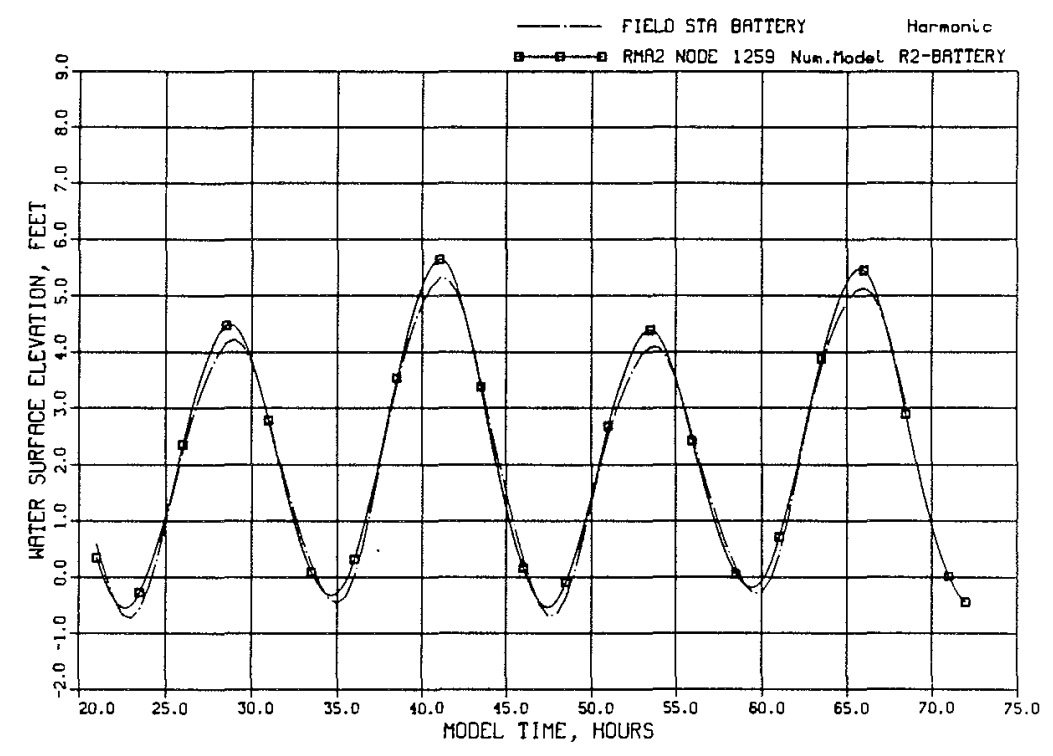

b. The Battery located between the Hudson and East Rivers

Figure A16. RMA2 versus harmonic predictions 
Maximum Ebb and Flood Velocities. For purposes of ship simulation, the criterion for selecting the time of maximum ebb and flood velocities was a navigable depth of $32 \mathrm{ft}$ or greater at the Claremont ship terminal. The depth averaged velocity results from the RMA2 model at the intersection of the Claremont channel and the Pier channel were compared with the water depth (see Figure A17) and hours 39.25 and 44.00 were selected as the highest velocities with the $32 \mathrm{ft}$ depth criterion. Note that the slight oscillation in velocity magnitude near hours $38.50,51.0$, and 63.0 are the result of cross channel effects. The base condition optimum flood (hour 39.25) and ebb (hour 44.00) velocities in the Claremont and Pier channel intersection are presented in Figures A18 and A19. For reference, Figure A20 illustrates the computed water surface elevation at the Narrows.

\section{Test of Base Versus Plan Channel Designs}

\section{Procedures}

The plan channel design simulations followed the same basic procedures as outlined for the hydrodynamic model validation. Results from the existing condition geometry with the summer of 1992 bathymetry were compared with the two proposed plan channel designs.

\section{Hydrodynamic Comparisons}

Recall that the Claremont channel Plan A design entailed deepening the channel from 30 to $34 \mathrm{ft}$. Plan B also has the channel deepened to $34 \mathrm{ft}$ but the width narrows from $300 \mathrm{ft}$ to $250 \mathrm{ft}$ wide at the tip of the pier. Since the changes are extremely localized, hydrodynamic changes were found to be confined to the study area.

There are no detectable changes in the water surface elevation between the base condition and either plan A or plan B, see Figure A21.

The changes in velocities within the Claremont and Pier channel intersection were relatively minor. Figures A22 through A24 compare the differences in the $\mathrm{x}$ - and $\mathrm{y}$-velocity components and the velocity magnitude between the Base and plans. The influences of the pier channcl on the Claremont channel velocities are apparent by the complicated signal. In general, the shallower existing channel had greater velocity extremes than either plan design.

Figures A25 and A26 are the Plan B llood and ebb velocity vector plots. These compare directly with the base Figures A18 and A19 presented earlier. The differences between the plans are not visually detectable. 


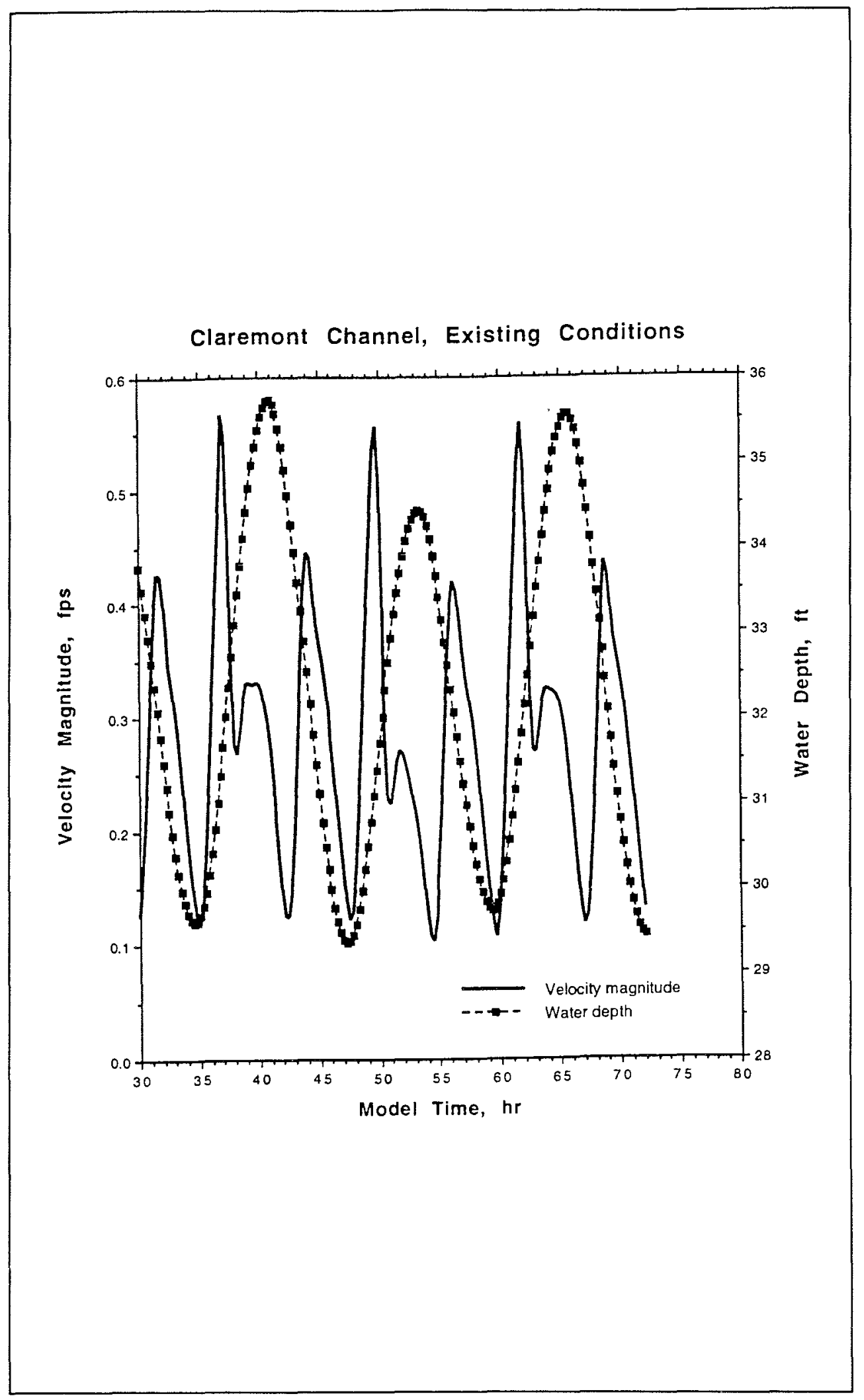

Figure A17. Velocity and depth for the existing (Base) condition at the Claremont and Pier Channel intersection 


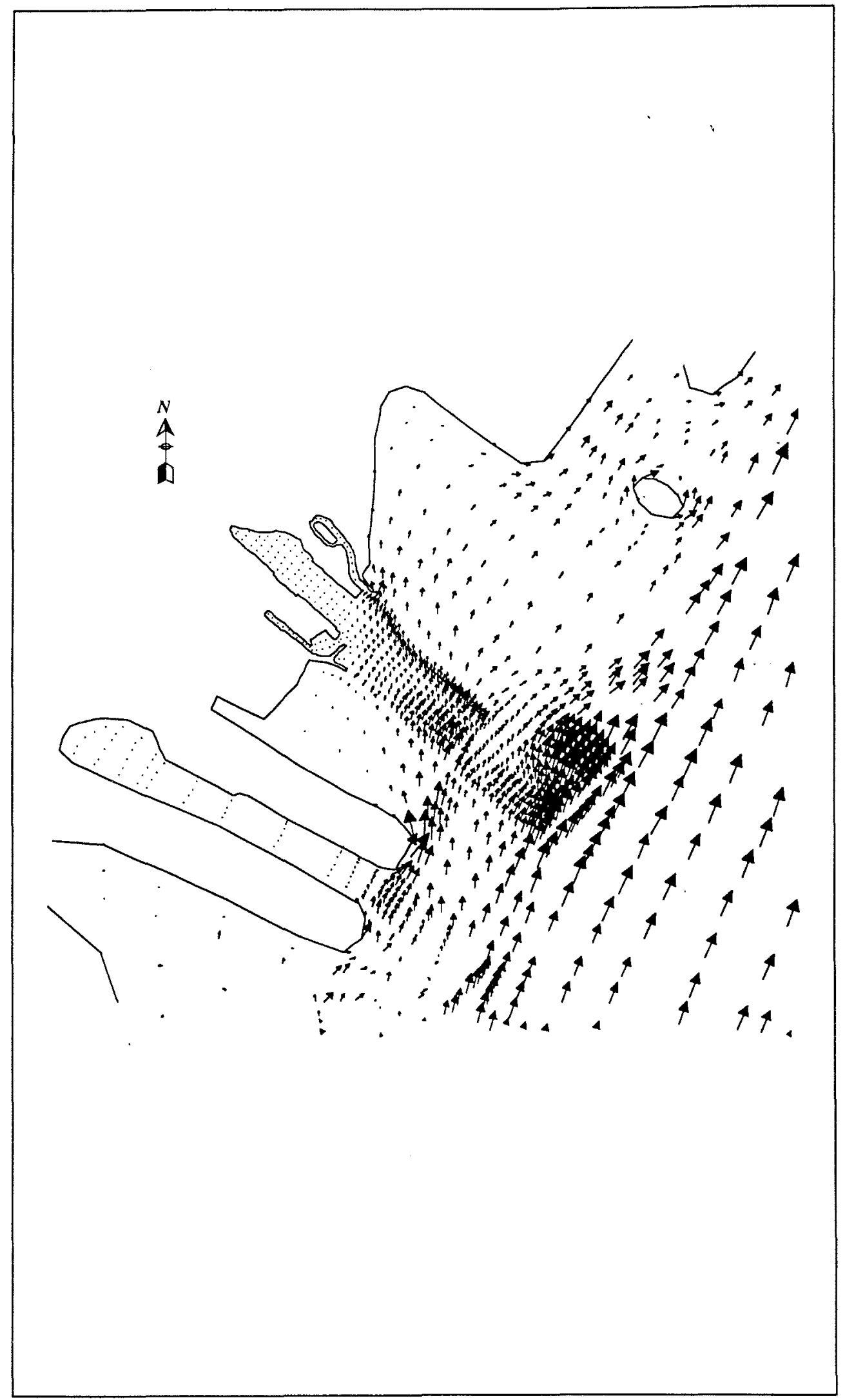

Figure A18. Velocity vectors for optimum flood (hour 39.25), existing condition 


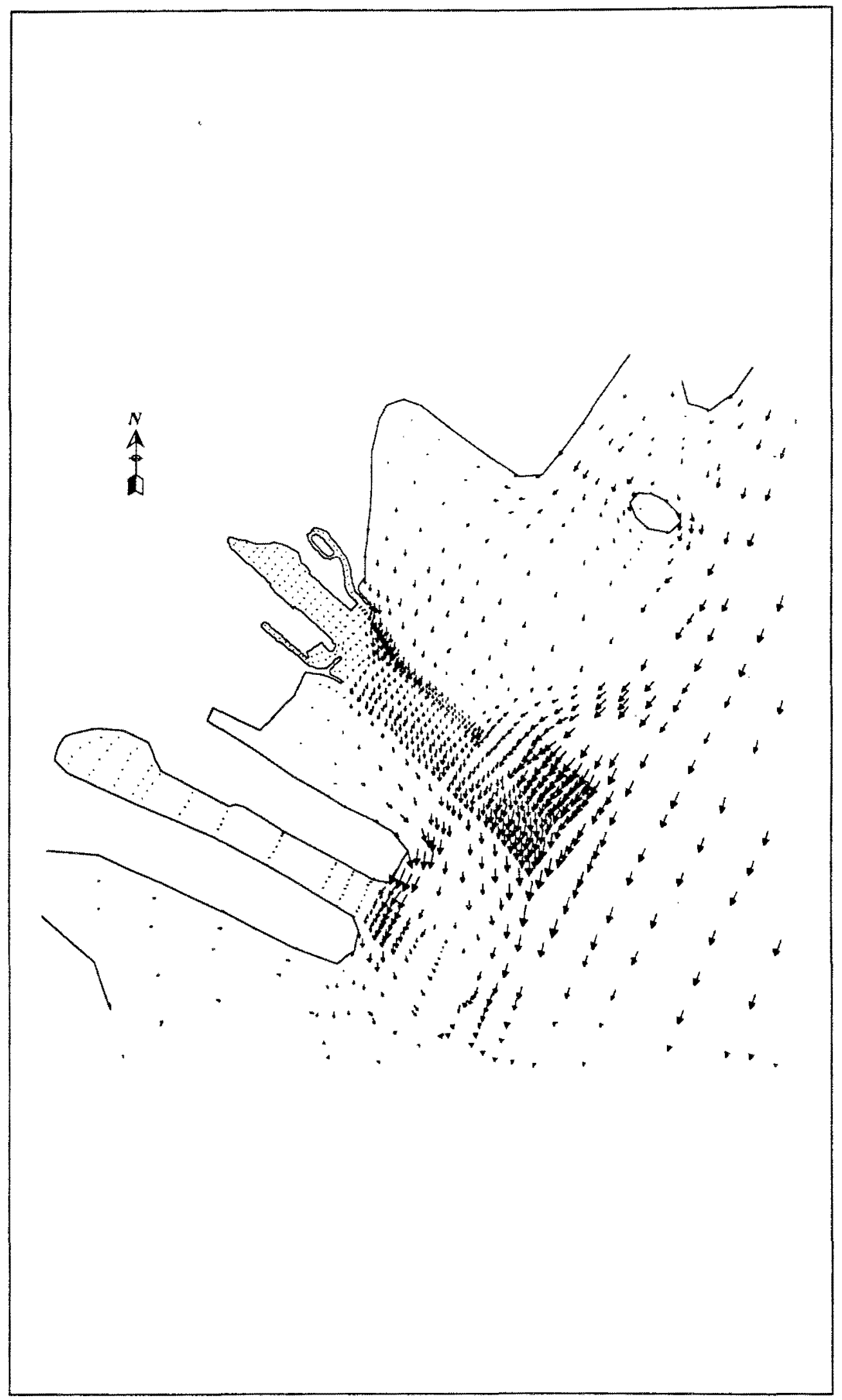

Figure A19. Velocity vectors for optimum ebb (hour 44.00 ), existing condition 


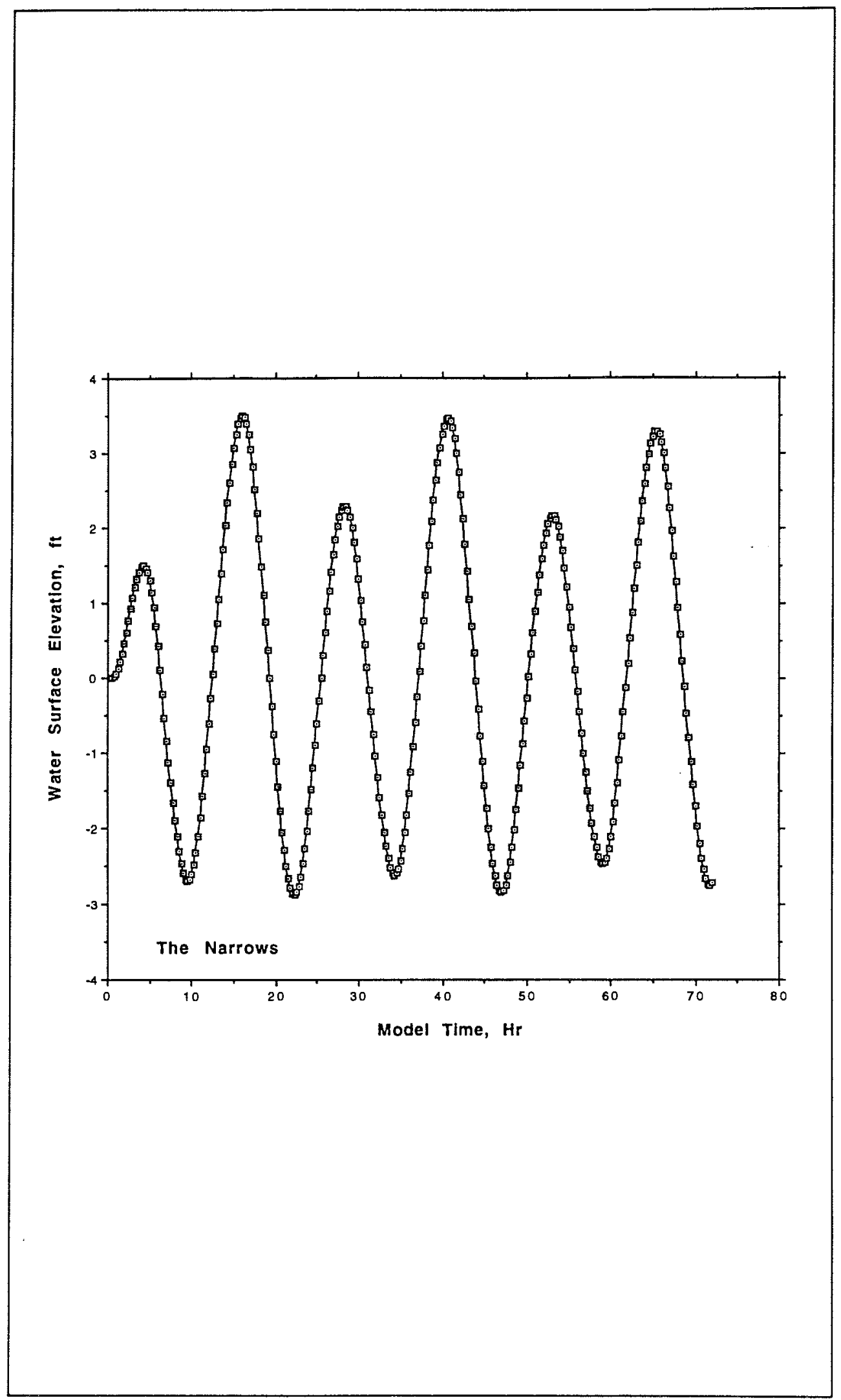

Figure A20. Water surface elevation at the Narrows, existing condition 


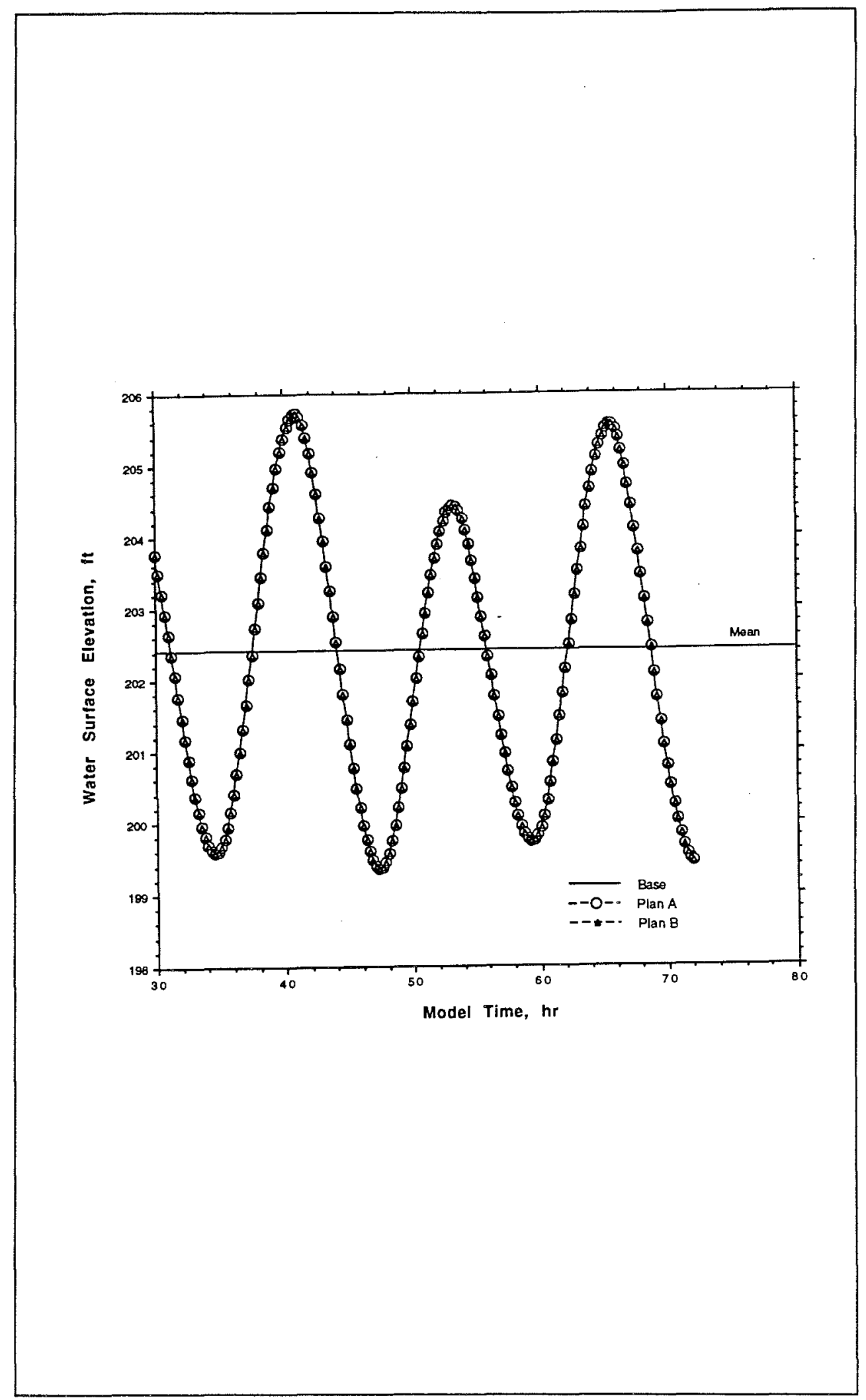

Figure A21. Water surface elevation at the Claremont and Pier Channel Intersection, Base versus Plan 


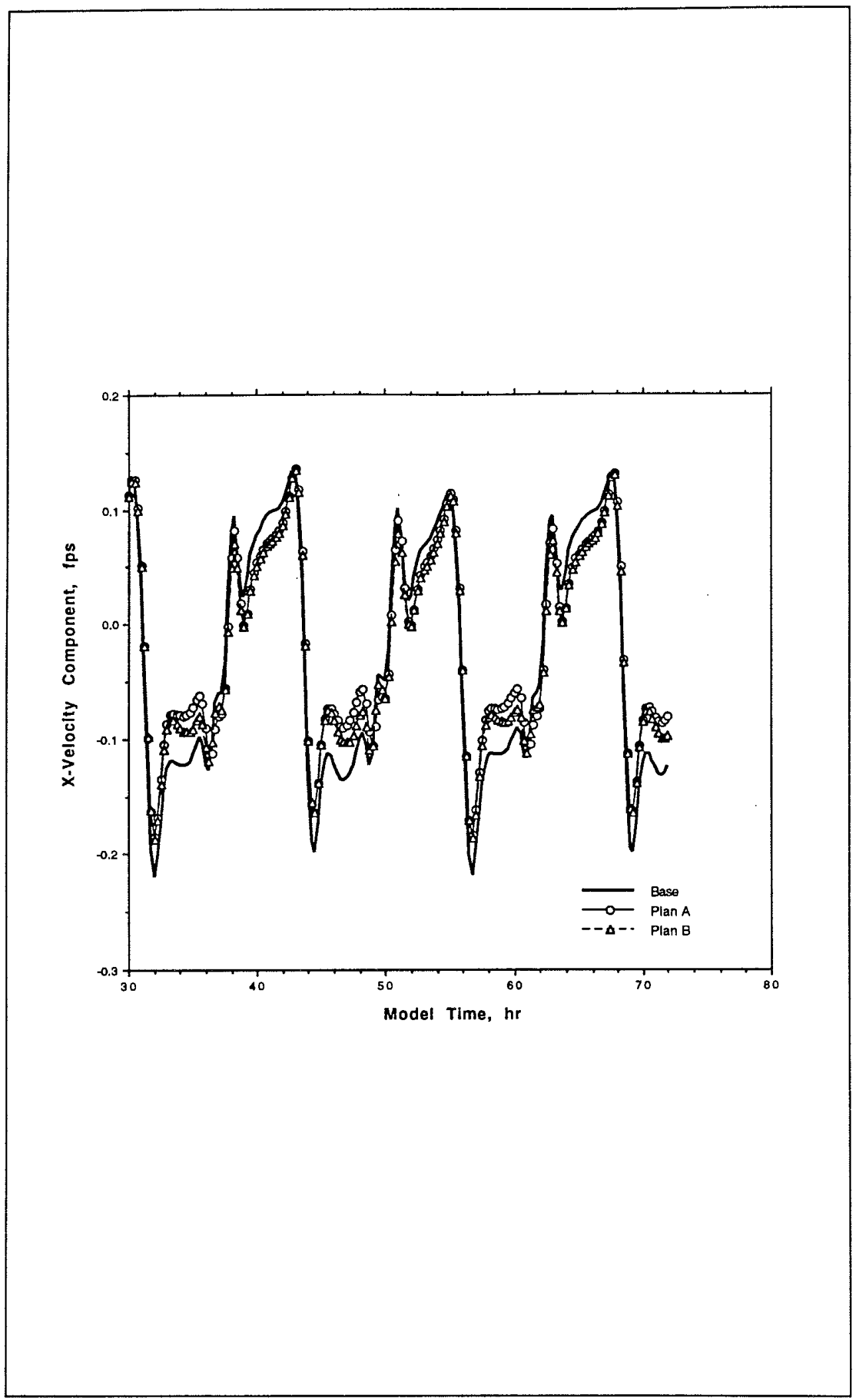

Figure A22. X-Component of velocity at the Claremont and Pier Channel Intersection, Base versus Plan 


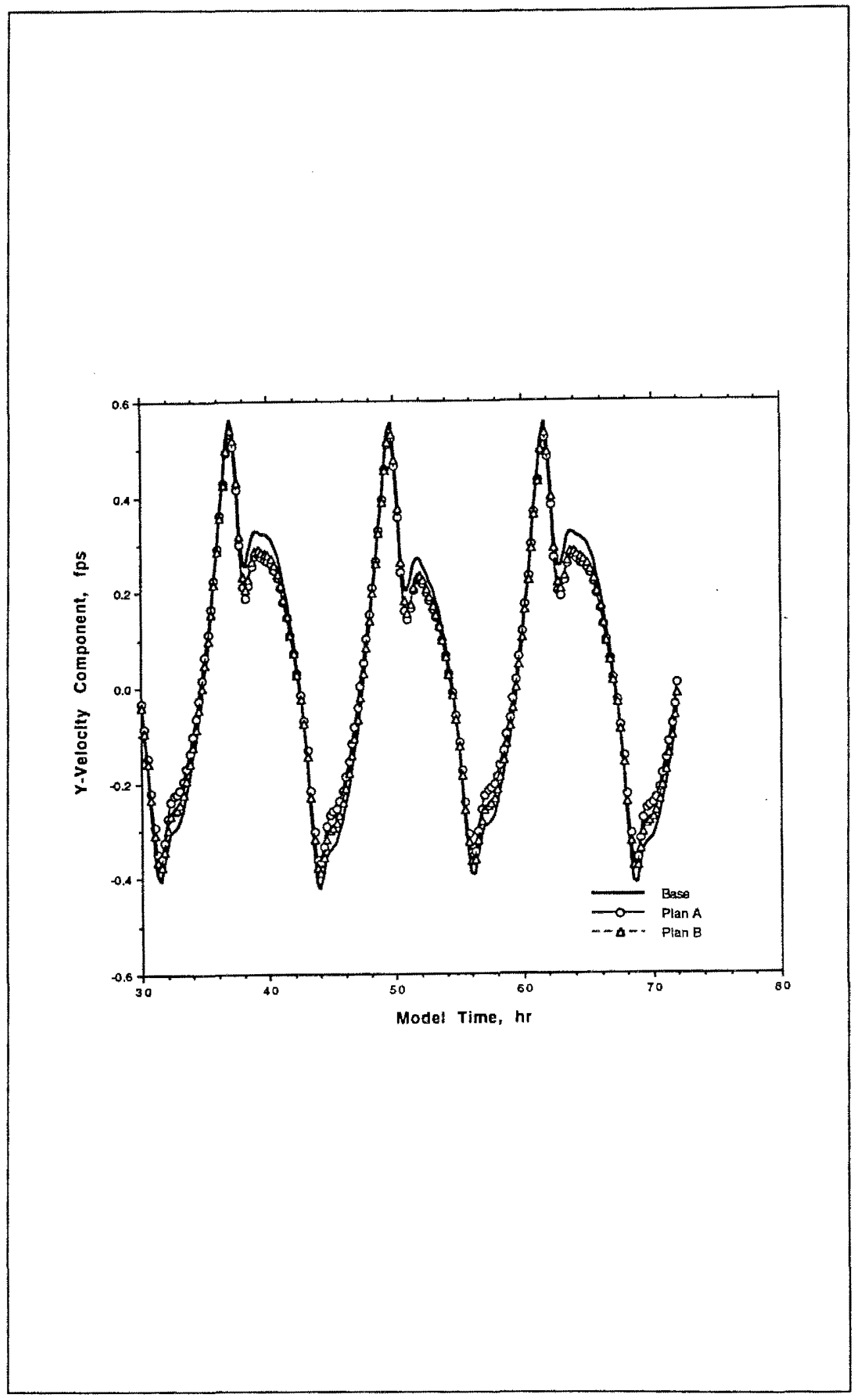

Figure A23. Y-Component of velocity at the Claremont and Pier Channel intersection, Base versus Plan 


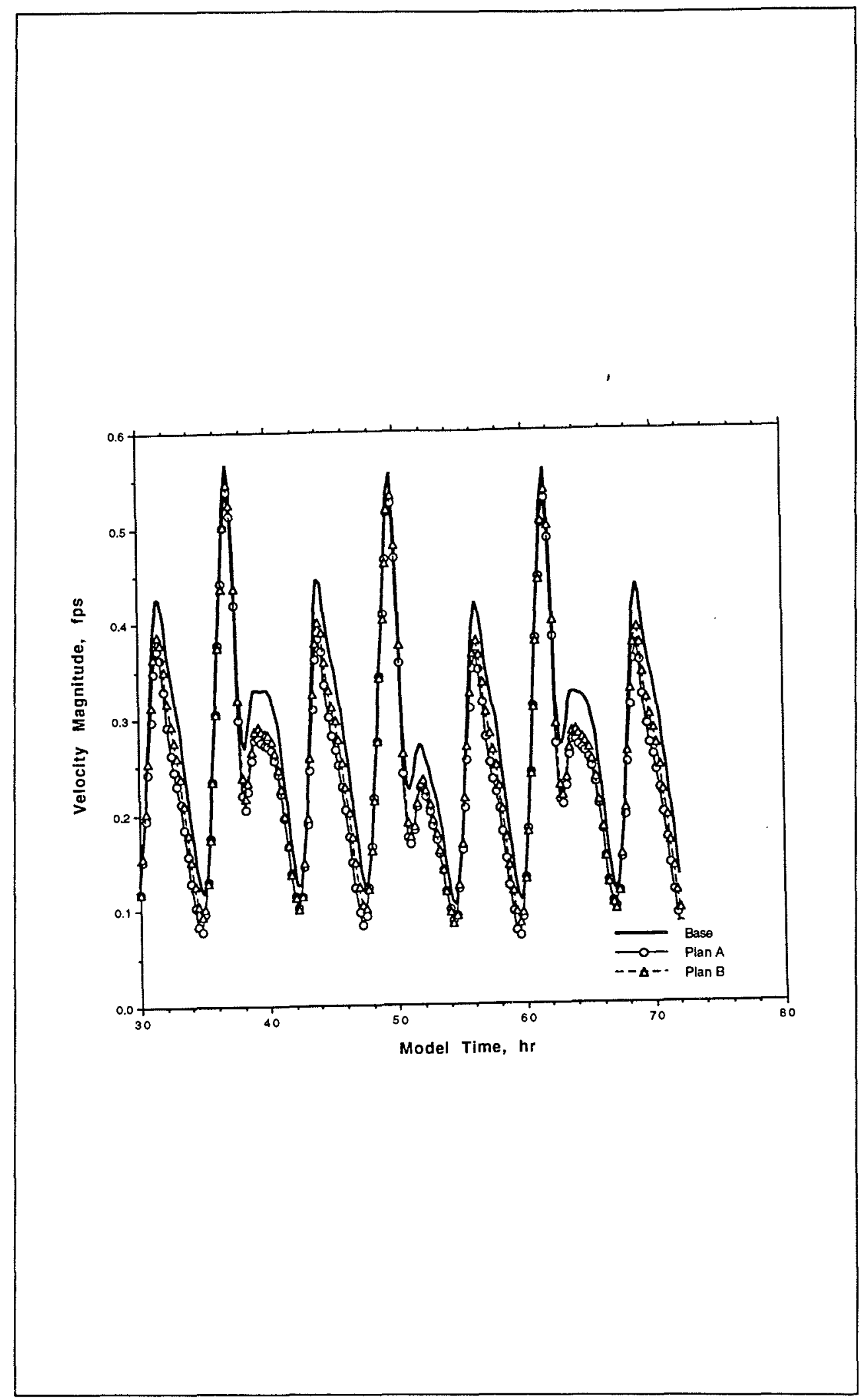

Figure A24. Magnitude of velocity at the Claremont and Pier Channel Intersection, Base versus Plan 


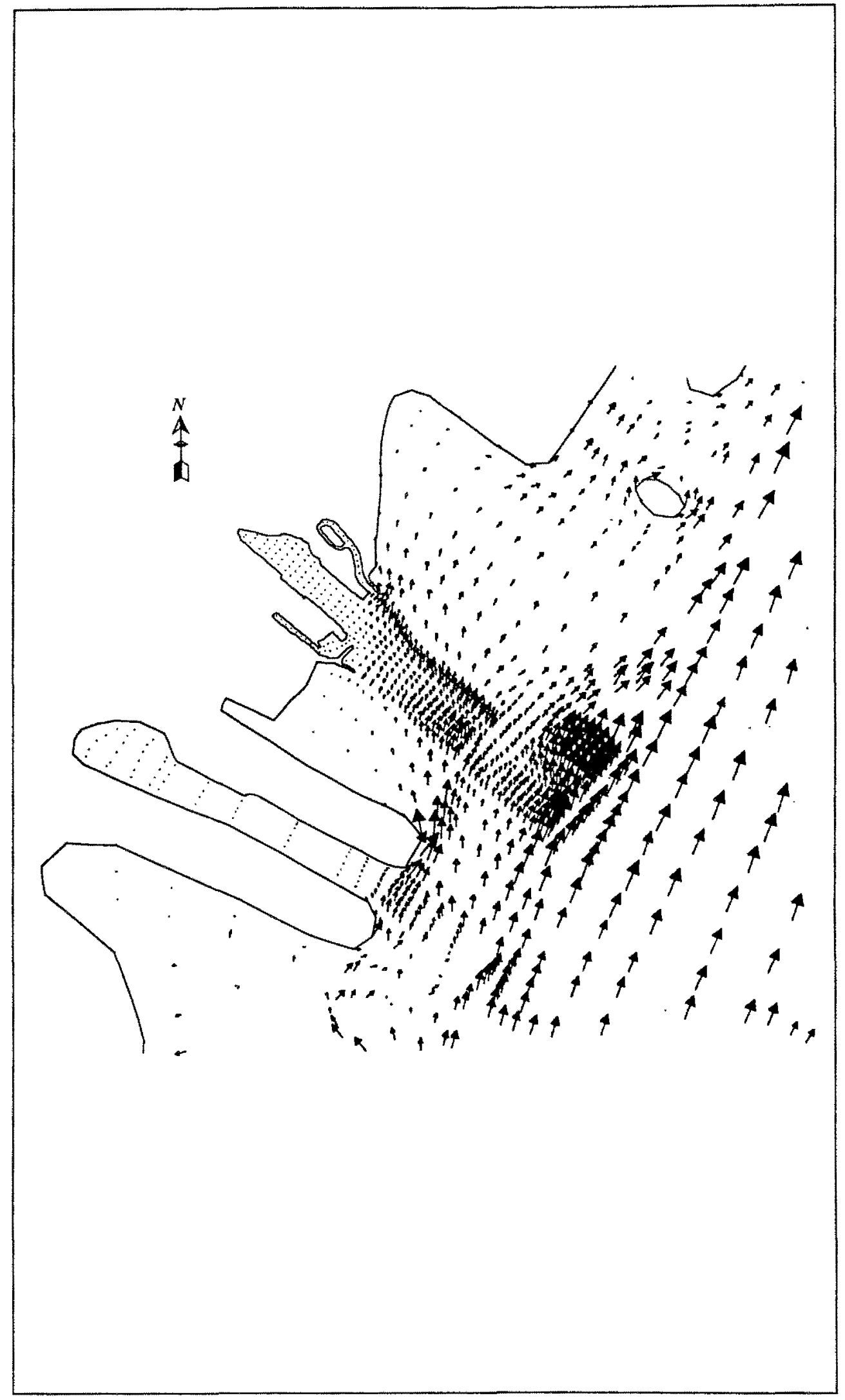

Figure A25. Velocity vectors for optimum flood (hour 39.25), Plan B 


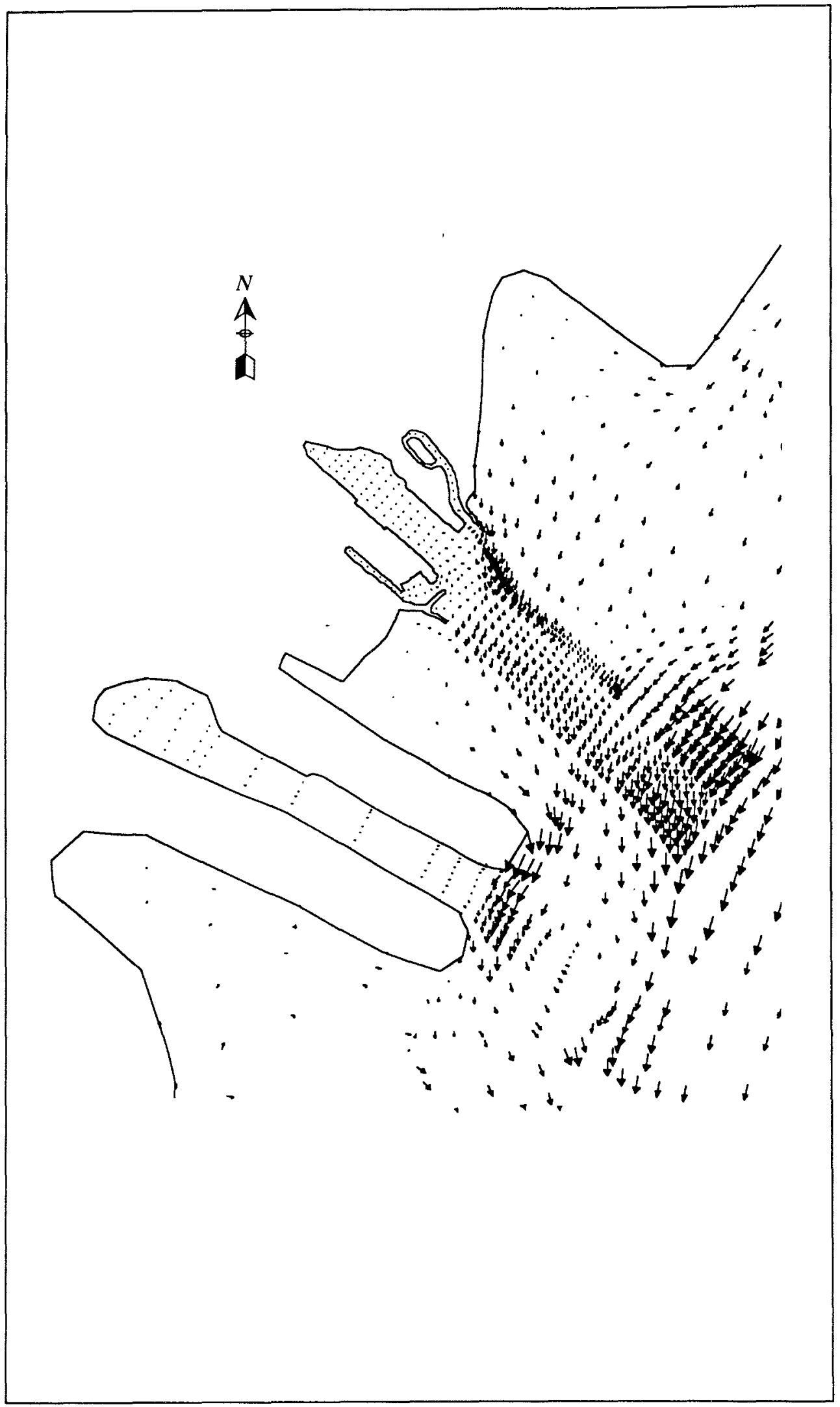

Figure A26. Velocity vectors for optimum ebb (hour 44.00), Plan B 


\section{Summary and Conclusions}

New insights in numerical model mesh design coupled with a prior knowledge base of the New York Harbor system set the stage for a successful hydrodynamic study to support the tasks of Claremont channel ship simulation. The significant factors are outlined below:

a. Increased resolution throughout the lower and upper New York Harbor to insure low residual errors within the study area.

b. Resolved the Claremont channel tracking area to allow for approximately two elements per ship length, and one element per ship width.

c. Extended the computational domain of the model to provide better boundary condition control points.

d. Eliminated tidal phasing sensitivity problems by using a 0.25 -hr time step and by not using the close boundary condition locations defined by New York Harbor physical model data.

e. Used tidal harmonic data for all of the boundary conditions except the Hudson River (which used the mean discharge).

f. Eliminated the problem of tidal reflection by extending the Hudson River to the head of tide at Troy.

g. Employed new insights and technology in mesh design.

(1) Decreased the boundary break angles and thereby increased the local accuracy in the conservation of mass.

(2) Used the FastTABS pre- and post-processing interactive graphical tool to check for severe depth gradients, element shape violations, and other errors.

Extending the refined computational domain and using harmonic boundary conditions to drive the two-dimensional vertically integrated RMA2 model proved to be the most critical factors.

Based upon the reactions of the six New York area pilots who used the hydrodynamic data provided by this study for simulation piloting, the study was successful. Furthermore, the project was completed without the added expense of synoptic ficld dati or surveys.

The hydrodynamic differenees between the existing conditions and the two plan designs were minor. 


\section{Appendix B \\ The TABS-MD System}

TABS-MD is a collection of generalized computer programs and utility codes integrated into a numerical modeling system. TABS-MD is capable of one-, two-, and/or three-dimensional computations; however, only the one- and two-dimensional vertically avcraged capability will be discussed in this summary. The system is used for studying hydrodynamics, sedimentation, and transport problems in rivers, reservoirs, bays, and estuaries. A schematic representation of the system is shown in Figure B1. It can be used either as a stand-alone solution technique or as a step in the hybrid modeling approach. The basic concept is to calculate water-surface elevations, current patterns, sediment erosion, transport and deposition, the resulting bed surface elevations, and the feedback to hydraulics. Existing and proposed geometry can be analyzed to determine the impact on sedimentation of project designs and to determine the impact of project designs on salinity and on the stream system. The system is described in detail by Thomas and McAnally (1985).

The three basic 2-D depth-averaged components of the system are as follows:

a. "A Two-Dimensional Model for Free Surface Flows," RMA2.

b. "Sediment Transport in Unsteady 2-Dimensional Flows, Horizontal Plane," STUDH.

c. "Two-Dimensional Finite Element Program for Water Quality," RMA4.

RMA2 is a finite elcment solution of the Reynolds form of the NavierStokes equations for turbulent flows. Friction is calculated with Manning's equation and eddy viscosity coefficients are used to define the turbulent exchanges. A velocity form of the basic equation is used with side boundaries treated as either slip or static. The model has a marsh porosity option as well as the ability to automatically perform wetting and drying. Boundary conditions may be water-surface elevations, velocities, discharges, or tidal radiation. 


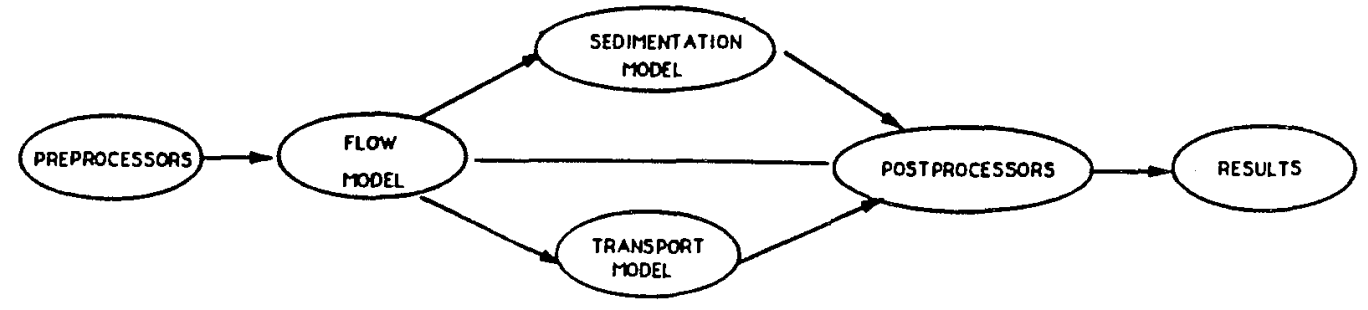

Figure B1. TABS-MD schematic

The sedimentation model, STUDH, solves the convection-diffusion equation with bed source-sink terms. These terms are structured for either sand or cohesive sediments. The Ackers-White (1973) procedure is used to calculate a sediment transport potential for the sands from which the actual transport is calculated based on availability. Clay crosion is based on work by Partheniades (1962) and Ariathurai and the deposition of clay utilizes Krone's equations (Ariathurai, MacArthur, and Krone 1977). Deposited material forms layers and bookkceping allows up to 10 layers at each node for maintaining separate material types, deposit thickness, and age. The code uses the same mesh as RMA2.

Salinity calculations, RMA4, are made with a form of the convective- diffusion equation which has gencral source-sink terms. Up to six conservative substances or substances requiring a decay term can be routed. The code uses the same mesh as RMA2. The model accomodates a mixing zone outside of the model boundaries for estimation of re-rntrainment.

Each of these gencralized computer codes can be used as a stand-alone program, but to facilitate the preparation of input data and to aid in analyzing results, a family of utility programs was developed for the following purposes:
a. Digitizing
b. Mesh generation
c. Spatial data management
d. Graphical output
e. Output analysis
f. File management
g. Interfaces
h. Job control language 


\section{Finite Element Modeling}

The TABS-MD numerical models used in this effort employ the finite element method to solve the governing equations. To help those who are unfamiliar with the method to better understand the system, a brief description of the method is given here.

The finite element method approximates a solution to governing equations by dividing the area of interest into smaller subareas, which are called elements. The dependent variables (e.g., water-surface elevations and sediment concentrations) are approximated over each elcment by continuous functions which interpolate based on unknown point (node) values of the variables. An error, defined as the deviation of the governing equations using the approximate solution from the equation using the correct solution, is minimized. Then, when boundary conditions are imposed, a set of solvable simultaneous equations is created. The solution is continuous over the area of interest.

In one-dimensional problems, elements are line segments. In twodimensional problems, the elements are polygons, usually either triangles or quadrilaterals. Nodes are located on the edges of elements and occasionally inside the elements. The interpolating functions may be linear or higher order polynomials. Figure B2 illustrates a quadrilateral element with eight nodes and a linear solution surface where $F$ is the interpolating function.

Most water resource applications of the finite element method use the Galerkin method of weighted residuals to minimize error. In this method the residual, the local error in the equations use of the approximate and solution, is weighted by a function that is identical to the interpolating function and then minimized. Minimization results in a set of simultaneous equations in terms of nodal values of the dependent variable (c.g. water- surlace elevations or sediment concentration). The time portion of time-dependent problems can be solved by the finite element method, but it is generally more efficient to express derivatives with respect to time in finite difference form.

\section{The Hydrodynamic Model, RMA2}

\section{Applications}

This program is designed for far-licld problems in which vertical accelerations are negligible and the velocity vectors at a node generally point in the same dircetions over the entire depth of the water column at any instant of time. It expects a vertically homogeneous fluid with a free surface. The model will deline the response to a specified horizontally inhomogeneous fluid. Both steady and unsteady state problems can be analyzed. A surface wind stress can be imposed and the eflects fo the earth's rotation can be included. 


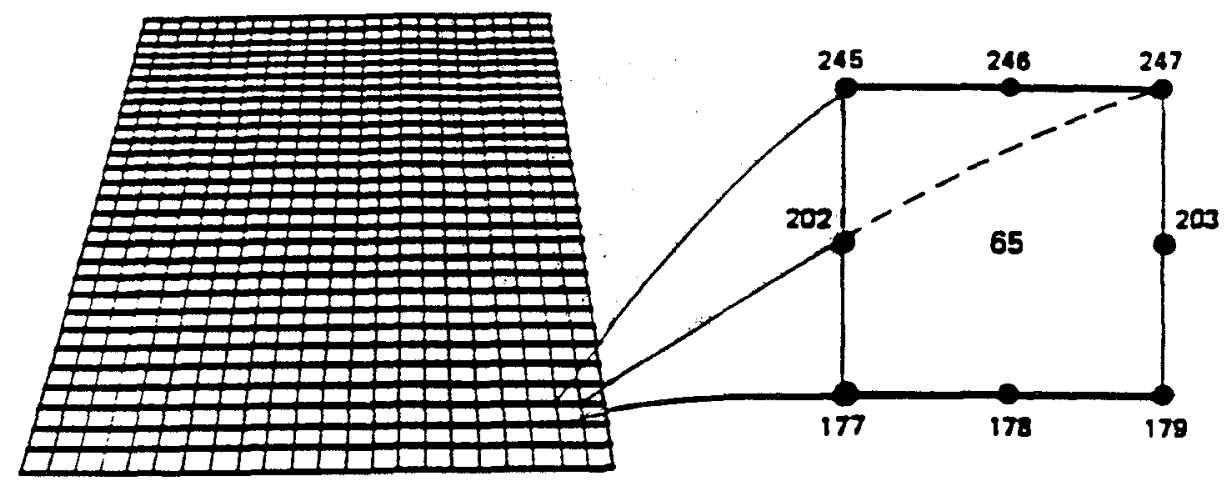

a. Eight nodes define each element
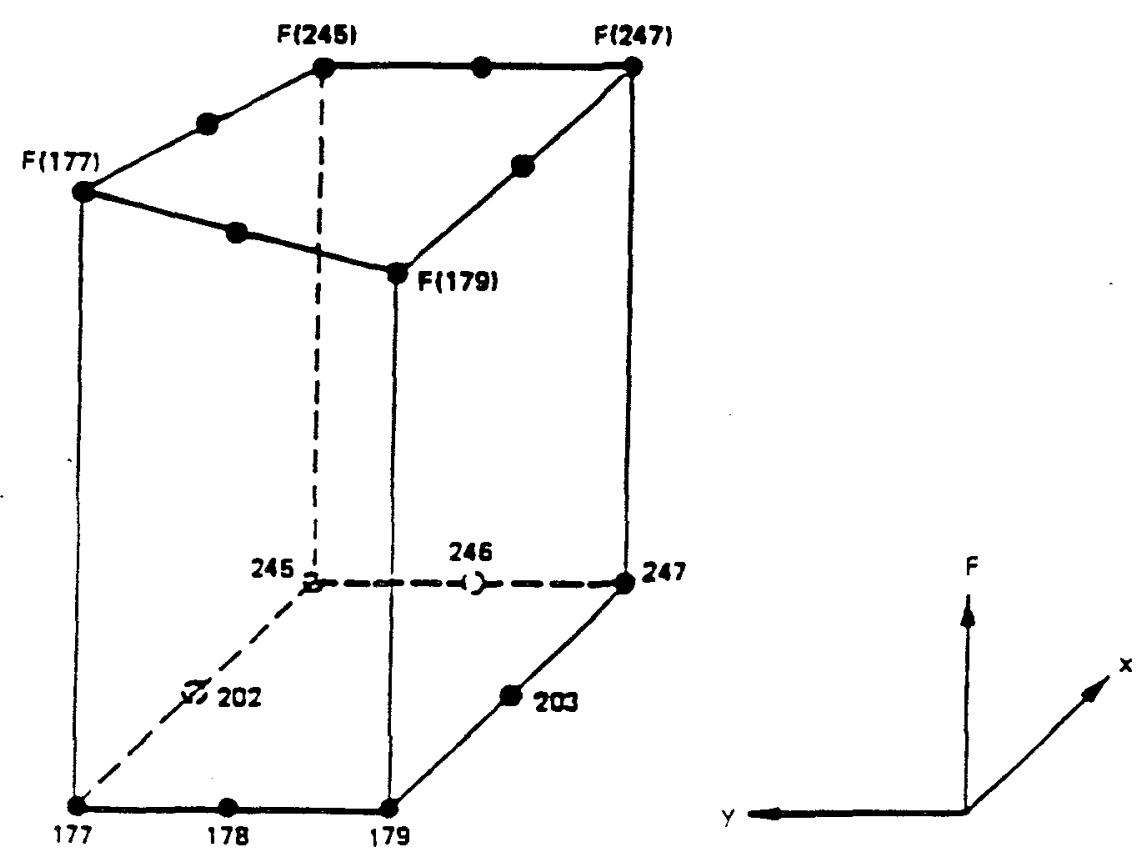

b. Linear interpolation function

Figure B2. Two-dimensional finite element mesh 
The program has been applied to calculate water levels and flow distribution around islands; flow at bridges having one or more relief openings, in contracting and expanding reaches, into and out of off-channel hydropower plants, at river junctions, and into and out of pumping plant channels; circulation and transport in waterbodies with wellands; and general water levels and flow patterns in rivers, reservoirs, and estuaries.

\section{Limitations}

This program is not designed for near-field problems where flowstructure interactions (such as vortices, vibrations, or vertical accelcrations) are of interest. Areas of vertically stratified flow are beyond this program's capability unless it is used in a hybrid modeling approach. It is two-dimensional in the horizontal plane, and zones where the bottom current is in a different direction from the surface current must be analyzed with considerable subjective judgment. It is a free-surface calculation for subcritical flow problems.

\section{Governing equations}

The generalized computer program RMA2 solves the depth-integrated equations of fluid mass and momentum conscrvation in two horizontal directions. The form of the solved equations is

$$
\begin{aligned}
& h \frac{\partial u}{\partial t}+h u \frac{\partial u}{\partial x}+h v \frac{\partial u}{\partial y}-\frac{h}{\rho}\left(\varepsilon_{x x} \frac{\partial^{2} u}{\partial x^{2}}+\varepsilon_{x y} \frac{\partial^{2} u}{\partial y^{2}}\right)\left(\frac{\partial a}{\partial x}+\frac{\partial h}{\partial x}\right)+\frac{g u n^{2}}{\left(1.486 h^{1 / 6}\right)^{2}}\left(u^{2}+v^{2}\right)^{1 / 2} \\
&+-\zeta V_{a}^{2} \cos \psi-2 h \omega v \sin \phi=0 \\
& h \frac{\partial v}{\partial t}+h u \frac{\partial v}{\partial x}+h v \frac{\partial v}{\partial y}-\frac{h}{\rho}\left(\varepsilon_{y x} \frac{\partial^{2} v}{\partial x^{2}}+\varepsilon_{y y} \frac{\partial^{2} v}{\partial y^{2}}\right) \\
&+g h\left(\frac{\partial a}{\partial y}+\frac{\partial h}{\partial y}\right)+\frac{g v h^{2}}{\left(1.486 h^{1 / 6}\right)^{2}}\left(u^{2}+v^{2}\right)^{1 / 2} \\
& \quad-\zeta V_{a}^{2} \sin \psi-2 \omega h u \sin \phi=0 \\
& \frac{\partial h}{\partial t}+h\left(\frac{\partial u}{\partial x}+\frac{\partial v}{\partial y}\right)+u \frac{\partial h}{\partial x}+v \frac{\partial h}{\partial y}=0
\end{aligned}
$$


where

$$
\begin{aligned}
h= & \text { depth } \\
u, v= & \text { velocities in the Cartesian dircctions } \\
x, y, t= & \text { Cartesian coordinates and time } \\
\rho= & \text { density of fluid } \\
\varepsilon= & \text { eddy viscosity coefficient, for } \mathrm{xx}=\text { normal direction on } \mathrm{x} \text {-axis } \\
& \quad \text { surfacc; } y \mathrm{y}=\text { normal dircction on } \mathrm{y} \text {-axis surface; } \mathrm{xy} \text { and } \\
& \quad \mathrm{yx}=\text { shcar direction on each surface } \\
g= & \text { acceleration due to gravity } \\
a= & \text { elevation of boltom } \\
n= & \text { Manning's } \mathrm{n} \text { valuc } \\
1.486= & \text { conversion from SI (metric) to non-SI units } \\
\zeta= & \text { empirical wind shear cocfficient } \\
V_{a}= & \text { wind spced } \\
\psi= & \text { wind direction } \\
\omega= & \text { rate of earth's angular rotation } \\
\phi= & \text { local latitude }
\end{aligned}
$$

Equations B1, B2, and B3 are solved by the finite element method using Galerkin weighted residuals. The elcments may be one-dimensional lines or two-dimensional quadrilaterals or triangles and may have curved (parabolic) sides. The shape functions are quadratic for velocity and linear for depth. Integration in space is performed by Gaussian integsation. Derivatives in time are replaced by a nonlinear finite difference approximation. Variables are assumed to vary over each time intcrval in the form

$$
f(t)=f(0)+a t+b t^{c} \quad t_{0} \leq t<t_{0}+\Delta t
$$

which is differentiated with respect to time, and cast in finitc difference form. Letters $a, b$, and $c$ are constants. It has becn found by experiment that the best value for $c$ is 1.5 (Norton and King 1977).

The solution is fully implicit and the set of simultaneous equations is solved by Newton-Raphson non linear itcration. The computer code executes the solution by means of a front-type solver that assembles a portion of the matrix and solves it beforc assembling the next portion of the matrix. The front solver's efficiency is largely independent of bandwidth and thus does not requirc as much care in formation of the computational mesh as do earlier traditional solvers.

The code RMA2 is based on the earlier versions (Norton and King 1977) but differs in several ways. It is formulated in terms of velocity (v) instead of unit discharge (vh), which improves some aspects of the code's behavior; it permits drying and wetting of areas within the grid; it permits specification of turbulent coefficients in directions other than along the $x$ - and $z$-axes; it accommodates the specifications of hydraulic control structures in the network; 
it permits wetlands to be simulated as either totally wet/dry or as gradually changing wetting and it permits input in either English or system international units. For a more complete description, see Appendix $F$ of Thomas and McAnally (1985).

\section{The Sediment Transport Model, STUDH}

\section{Applications}

STUDH can be applied to clay and/or sand bed sediments where flow velocities can be considered two-dimensional (i.e., the speed and direction can be satisfactorily represented as a depth-averaged velocity). It is useful for both deposition and erosion studies and, to a limited extent, for stream width studies. The program trcats two categories of sediment: noncohesive, which is referred to as sand here, and cohesive, which is referred to as clay.

\section{Limitations}

Both clay and sand may be analyzed, but the model considers a single, effective grain size for each and treats cach separatcly. Fall velocity must be prescribed along with the water-surface clevations, $x$-velocity, $y$-velocity, diffusion coefficients, bed density, critical shear stresses for erosion, erosion rate constants, and critical shear stress for deposition.

The program docs not compute water-surface elevations or velocities; therefore these data must be provided. For complicated gcometries, the numerical model for hydrodynamic computations, RMA2, is used. However, STUDH can only accept a two-dimensional network.

\section{Governing equations}

The generalized computer program STUDH solves the depth-integrated convection-dispersion equation in two horizontal dimensions for a single sediment constituent. For a more complete description, sce Appendix G of Thomas and McAnally (1985). The form of the solved equation is

$$
\begin{gathered}
\frac{\partial C}{\partial t}+u \frac{\partial C}{\partial x}+v \frac{\partial C}{\partial y}=\frac{\partial}{\partial x}\left(D_{x} \frac{\partial C}{\partial x}\right) \\
+\frac{\partial}{\partial y}\left(D_{y} \frac{\partial C}{\partial y}\right)+\alpha_{1} C+\alpha_{2}=0
\end{gathered}
$$

where

$$
C=\text { concentration of sediment }
$$


$u=$ depth-integrated vclocity in $\mathrm{x}$-direction

$v=$ depth-integrated velocity in y-direction

$D_{x}=$ dispersion coefficient in $x$-direction

$D_{y}=$ dispersion cocflicient in $y$-dircction

$\alpha_{1}=$ coefficient of concentration-dependent source/sink term

$\alpha_{2}=$ cocfficient of source/sink term

The source/sink terms in Equation B5 are computed in routines that treat the interaction of the flow and the bed. Separate sections of the code handle computations for clay bed and sand bed problems.

\section{Sand transport}

The source/sink terms are evaluated by first computing a potential sand transport capacity for the specilied flow conditions, comparing that capacity with the amount of sand actually being transported, and then eroding from or depositing to the bed at a rate that would approach the equilibrium value after sufficient elapsed time.

The potential sand transport capacity in the model is computed by the method of Ackers and White (1973), which uses a transport power (work rate) approach. It has been shown to provide superior results for transport under steady-flow conditions (Whitc, Milli, and Crabbe 1975) and for combined waves and currents (Swart 1976). Flume tests at the US Army Engineer Waterways Experiment Station have shown that the concept is valid for transport by estuarine currents.

The total load transport function of Ackers and White is based upon a dimensionless grain size

$$
D_{g r}=D\left[\frac{g(s-1)}{v^{2}}\right]^{1 / 3}
$$

where

$$
\begin{aligned}
& D=\text { sediment particle diameter } \\
& s=\text { specific gravity of the sediment } \\
& v=\text { kincmatic viscosity of the lluid }
\end{aligned}
$$

and a sediment mobility parameter 


$$
F_{g r}=\left[\frac{\tau^{, n_{\mathrm{r}}(1-n)}}{\rho g D(s-1)}\right]^{1 / 2}
$$

where

$$
\tau^{\prime}=\text { total boundary shear stress }=\rho g R S
$$

where

$$
\begin{aligned}
& R=\text { hydraulic radius } \\
& S=\text { slope of water surface } \\
& n=\text { a coefficient expressing the relative importance of bed-load and } \\
& \text { suspended-load transport, given in Equation B9 } \\
& \text { NOTE: } \\
& n=1 \text { for finc sediments } \\
& n=0 \text { for coarse sediments } \\
& \tau=\text { boundary surface shear stress }
\end{aligned}
$$

The surface shear stress is that part of the total shcar stress which is due to the rough surface of the bed only, i.e., not including that part due to bed forms and geometry. It thercfore corresponds to that shear stress that the flow would exert on a plane bed.

The tolal sediment transport is (in $\mathrm{kg} / \mathrm{m}^{3}$ ) expressed as an effective concentration

$$
G_{P}=C_{A}\left[\frac{F_{g r}}{A}-1\right]^{m} \frac{s D}{h} G\left[\frac{\rho}{\tau} U\right]^{n}
$$

where $U$ is the average flow specd, and for $1<\mathrm{D}_{\mathrm{gr}} \leq 60$

$$
\begin{aligned}
& n=1.00-0.56 \log D_{g r} \\
& A=\frac{0.23}{\sqrt{D_{g r}}}+0.14 \\
& \log C_{a}=2.86 \log D_{g r}-\left(\log D_{g r}\right)^{2}-3.53
\end{aligned}
$$




$$
m=\frac{9.66}{D_{g r}}+1.34
$$

For $D_{g r}<60$

$$
n=0.00
$$

$$
A=0.17
$$

$$
C_{a}=0.025
$$

$$
m=1.5
$$

Note the $C_{a}$ has units consistent with $G_{p}\left(\mathrm{~kg} / \mathrm{m}^{3}\right.$ for STUDH).

Equations B6-B16 result in a potential sediment concentration $G_{p}$. This value is the depth-averaged concentration of sediment that will occur if an equilibrium transport rate is reached with a nonlimited supply of sediment. The rate of sediment deposition (or crosion) is then compuled as

$$
R=\frac{G_{p}-C}{t_{c}}
$$

where

$$
\begin{aligned}
& C=\text { present sediment concentration } \\
& t_{c}=\text { time constant }
\end{aligned}
$$

For deposition, the time constant is

$$
t_{c}=\text { larger of }\left\{\begin{array}{c}
\Delta t \\
o r \\
\frac{C_{d} h}{v_{s}}
\end{array}\right.
$$

and for erosion it is 


$$
t_{c}=\text { larger of }\left\{\begin{array}{c}
\Delta t \\
o r \\
\frac{C_{e} h}{U}
\end{array}\right.
$$

where

$$
\begin{aligned}
& \Delta t=\text { computational time-step } \\
& C_{d}=\text { response time coefficient for deposition } \\
& V_{s}=\text { sediment sctlling velocity } \\
& C_{e}=\text { response time coefficient for erosion }
\end{aligned}
$$

The sand bed has a specified initial thickness which limits the amount of erosion to that thickness.

\section{Cohesive sediments transport}

Cohesive sediments (usually clays and some silts) are considered to be depositional if the bed shear stress cxerted by the flow is less than a critical value $\tau_{d}$. When that value occurs, the deposition rate is given by Krone's (1962) equation

$$
S=\left\{\begin{array}{l}
-\frac{2 V_{s}}{h} C\left(1-\frac{\tau}{\tau_{d}}\right) \text { for } C<C_{c} \\
-\frac{2 V_{s}}{h C_{c}^{2 / 3}} C^{5 / 3}\left(1-\frac{\tau}{\tau_{d}}\right) \text { for } C>C_{c}
\end{array}\right.
$$

where

$$
\begin{aligned}
S & =\text { source term } \\
V_{s} & =\text { fall velocity of a sediment particle } \\
h & =\text { nlow depth } \\
C & =\text { sediment concentration in water column } \\
\tau & =\text { bed shear stress } \\
\tau_{d} & =\text { critical shear stress for deposition } \\
C_{c} & =\text { critical concentration }=300 \mathrm{mg} / \ell
\end{aligned}
$$

If the bed shear stress is greater than the critical value for particle erosion $\tau_{e}$, matcrial is removed from the bed. The source term is then computed by Ariathurai's (Ariathurai, MacArthur, and Kronc 1977) adaptation of Partheniades' (1962) findings: 


$$
S=\frac{P}{h}\left(\frac{\tau}{\tau_{e}}-1\right) \text { for } \tau>\tau_{c}
$$

where $P$ is the crosion rate constant, unless the shear stress is also greater than the critical value for mass erosion. When this valuc is exceeded, mass failure of a sediment layer occurs and

$$
S=\frac{T_{L} \rho_{L}}{h \Delta t} \text { for } \tau>\tau_{s}
$$

where

$T_{L}=$ thickness of the failed layer

$\rho_{L}=$ density of the failed layer

$\Delta_{t}=$ time interval over which failure occurs

$\tau_{s}=$ bulk shear strength of the layer

The cohesive scdiment bed consists of 1 to 10 layers, each with a distinct density and erosion resistance. The layers consolidate with overburden and time.

\section{Bed shear stress}

Bed shear stresses are calculated from the llow speed according to one of four optional cquations: the smooth-wall log velocity profile or Manning equation for flows alone; and a smooth bed or rippled bed equation for combined currents and wind waves. Shear stresses are calculated using the shear velocity concept where

$$
\tau_{b}=\rho u_{*}^{2}
$$

where

$$
\begin{aligned}
& \tau_{b}=\text { hed shear stress } \\
& u_{*}=\text { shear velocity }
\end{aligned}
$$

and the shear velocity is calculated by one of four methods:

a. Smooth-wall log velocity profiles 


$$
\frac{\bar{u}}{u_{*}}=5.75 \log \left(3.32 \frac{u_{*} h}{v}\right)
$$

which is applicable to the lower 15 perent of the boundary layer when

$$
\frac{u_{*} h}{v}>30
$$

where $\bar{u}$ is the mean flow velocity (resultant of $u$ and $v$ components)

b. The Manning shear stress equation

$$
u_{*}=\frac{(\bar{u} n) \sqrt{g}}{C M E(h)^{1 / 6}}
$$

where CME is a coefficient of 1 for SI (metric) units and 1.486 for non-SI units of measurement.

c. A Jonsson-type equation for surface shear stress (plane beds) caused by waves and currents

$$
u_{*}=\sqrt{\frac{1}{2}\left(\frac{f_{w_{o m}}+f_{c} \bar{u}}{u_{o m}+\bar{u}}\right)}\left(\bar{u}+u_{o m}\right)^{2}
$$

where

$$
\begin{aligned}
f_{w} & =\text { shear stress coeflicient for waves } \\
u_{o m} & =\text { maximum orbital velocity of waves } \\
f_{c} & =\text { shear stress coefficient for currents }
\end{aligned}
$$

d. A Bijker-type equation for total shear stress caused by waves and current 


$$
U_{*}=\sqrt{\frac{1}{2} f_{c} \bar{u}^{2}+\frac{1}{4} f_{k} u_{o m}^{2}}
$$

\section{Solution method}

Equation B5 is solved by the finite element method using Galerkin weighted residuals. Like RMA2, which uses the same general solution technique, elements are quadrilateral and may have parabolic sides. Shape functions are quadratic. Integration in space is Gaussian. Time-stepping is performed by a Crank-Nicholson approach with a weighting factor $(\theta)$ of 0.66 . A front-type solver similar to that in RMA2 is used to solve the simultaneous equations.

\section{The Water Quality Transport Model, RMA4}

\section{Applications}

The water quality model, RMA4, is designed to simulate the depth-average advection-diffusion process in most water bodics with a free surface. The model is used for investigating the physical processes of migration and mixing of a soluble substance in rescrvoirs, rivers, bays, estuarines and coastal zones. The model is useful for evaluation of the basic processes or for defining the effectiveness of remedial measures. For complex gcometries the model utilizes the depth-averaged hydrodynamics lorm RMA2.

The water quality model has been applied to define the horizontal salinity distribution; to trace temperature effects from power plants; to calculate residence times of harbors or basins; to optimize the placement of outfalls; to identify potential critical areas for oil spills or other pollutants spread; to evaluate turbidity plume extent; and to monitor other water quality critcrion within game and fish habitats.

\section{Limitations}

The formulation of RMA4 is limited to one-dimensional (cross-scelionally averaged) and two-dimensional (depth-averaged) situations in which the concentration is fairly well-mixed in the vertical. It will not provide accurate concentrations for stratilfied situations in which the constituent concentration influences the density of the fluid. In addition, the accuracy of the transport model is dependent on the accuracy of the hydrodynamics (e.q. as supplied from RMA2). 


\section{Governing Equations}

The CEWES version of RMA4 is a revised version of RMA4 as developed by King (1989). The generalized computer program solves the depthintegrated equations of the transport and mixing process. The form of the equations solved is:

$$
\begin{gathered}
h\left(\frac{\partial c}{\partial t}+u \frac{\partial c}{\partial x}+v \frac{\partial c}{\partial y}-\frac{\partial}{\partial x} D_{x} \frac{\partial c}{\partial x}-\frac{\partial}{\partial y} D_{y} \frac{\partial}{\partial y}\right. \\
-\sigma+k c)=0
\end{gathered}
$$

where

$$
\begin{aligned}
h & =\text { water depth } \\
c & =\text { constituent concentration } \\
t & =\text { time } \\
u, v, & =\text { velocily components } \\
D_{x}, D_{y^{*}} & =\text { turbulent mixing coefficients } \\
k & =\text { first order decay } \\
\sigma & =\text { source/sink of constituent }
\end{aligned}
$$

Note that the basic governing equation for RMA4 is the same ad for the sediment transport model, STUDH. The differences between the two models lies in the source/sink terms.

Equation B29 is solved by the finite element method using Galerkin weighted residuals. As with the hydrodynamic model, RMA2, the transport model RMA4 handles one-dimensional segments or two-dimensional quadrilaterals or triangles with the option for curved sides. Spatial integration of the equations is performed by Gaussian techniques and the temporal variations are handled by nonlinear finite differences, consistent with the method described for RMA2. The frontal solution method is also used in RMA4, as with the other programs in the TABS-MD system, to provide an efficient solution algorithm.

The boundary conditions for RMA4 are specified in several optional ways. The boundary concentration may be specificd absolutcly at a certain level regardless of the llow direction; the concentration can be specified to be applied only when the water is leaving the model; or a mixing zone may be specified just beyond the model boundary to provide the possibility of reentertainment of constituent into the model that may have crossed the boundary carlicr. For a more detailed description of the constituent transport model, RMA4, see King and Rachicle, 1989.

Within the one-dimensional formulation of the model, there is a provision for defining the constituent concentration mixing and transport at control 
structures as they may have been specified in RMA2. These allow for either a flow through condition, as for example lor a wicr type flow, or for a mixing chamber type of flux, which would be appropriate for a navigation lock. 


\section{References}

Ackers, P., and White, W. R. 1973. (Nov). "Sediment Transport: New Approach and Analysis," Joumal, Hydraulics Division, American Society of Civil Engineers, Vol 99, No. HY-11, pp 2041-2060.

Ariathurai, R., MacArthur, R. D., and Krone, R. C. 1977 (Oct). "Mathematical Model of Estuarial Sediment Transport," Technical Report D-77-12, U.S. Army Engineer Waterways Experiment Station, Vicksburg, MS.

King, Ian P., and Richard Rachicle, 1989. "Program Documentation: RMA4 A Two Dimensional Water Quality Model; Version 3.0", Resource Management Associates, Laflayettc, CA.

Krone, R. B. 1962. "Flume Studies of Transport of Sediment in Estuarial Shoaling Processes," Final Report, Hydraulics Enginecring Research Laboratory, University of California, Berkeley, CA.

Norton, W. R., and King, I. P. 1977 (F(b). "Operating Instructions for the Computer Program RMA-2V," Resource Management Associates, Lafayette, CA.

Partheniades, E. 1962. "A Study of Erosion and Deposition of Cohesive Soils in Salt Water," Ph.D. Disscrtation, University of California, Berkeley, CA.

Swart, D. H. 1976 (Sep). "Coastal Sediment Transport, Computation of Longshore Transport," R968, Part 1, Delft Hydraulics Laboratory, The Nctherlands.

Thomas, W. A., and McAnally, W. H., Jr. 1985 (Aug). "Uscr's Manual for the Generalized Computer Program System; Open-Channel Flow and Sedimentation, TABS-2, Main Text and Appendices A through O," Instruction Report HL-85-1, U.S. Army Engineer Waterways Experiment Station, Vicksburg, MS.

White, W. R., Milli, H., and Crabbe, A. D. 1975. "Scdiment Transport Theories: An Appraisal of Available Mcthods," Report Int 119, Vols 1 and 2, Hydraulics Rescarch Station, Wallinglord, England. 
Public reporting burden for this collection of information is estimated to average I hour per response, including the time for reviewing instructions, searching existing data sources. gathering and maintaining the data needed, and completing and reviewing the collection of information. Send comments regarding his burden estimate or any other aspect of this Devis Highway, Suite 1204. Arlington, VA 22202-4302, and to the Office of Management and Budget, Paperwork Reduction Project (0704-0188), Washington, DC 20503.

\begin{tabular}{l|l|l} 
1. AGENCY USE ONLY (Leave blank) & $\begin{array}{l}\text { 2. REPORT DATE } \\
\text { September } 1994\end{array}$ & $\begin{array}{l}\text { 3. REPORT TYPE AND DATES COVERED } \\
\text { Final Report }\end{array}$
\end{tabular}

4. TITLE AND SUBTITLE

5. FUNDING NUMBERS

Claremont Terminal Channel, New York Harbor

6. AUTHOR(S)

Randy A. McCollum

Barbara P. Donnell

7. PERFORMING ORGANIZATION NAME(S) AND ADDRESS(ES)

8. PERFORMING ORGANIZATION REPORT NUMAER

U.S. Army Engineer Waterways Experiment Station

3909 Halls Ferry Road, Vicksburg, MS 39180-6199

Technical Report

HL-94-14

\section{SPONSORING/MONITORING AGENCY NAME(S) AND ADDRESS(ES)}

10. SPONSORING/MONITORING AGENCY REPORT NUMBER

U.S. Army Engineer District, New York

New York, NY 10278-0090

\section{SUPPLEMENTARY NOTES}

Available from National Technical Information Service, 5285 Port Royal Road, Springfield, VA 22161.

12a. DISTRIBUTION/AVALLABILITY STATEMENT

12b. DISTRIBUTION CODE

Approved for public release; distribution is unlimited.

\section{ABSTRACT (Maximum 200 words)}

A ship simulator investigation of Claremont Terminal Channel was performed to determine the effects on ship handling of the proposed widening and deepening of the existing channel from approximately $150 \mathrm{ft}$ to $300 \mathrm{ft}$ and $27 \mathrm{ft} \mathrm{mlw}$ to $34 \mathrm{ft} \mathrm{mlw}$, respectively. A hydrodynamic model study of the same area was conducted in support of the ship simulator investigation to supply current fields for the existing channel and proposed channel modifications. This report will describe the ship simulator investigation, it's conclusions, and recommendations. Appendix A will describe the hydrodynamic verification and numerical simulation of the existing Claremont Channel bathymetry and two proposed channel design plans. Appendix B describes the governing equations of the TABS-MD numerical modeling system.

\begin{tabular}{|c|c|c|c|}
\hline \multicolumn{3}{|l|}{ 14. SUBJECT TERMS } & $\begin{array}{l}\text { 15. NUMBER OF PAGES } \\
145\end{array}$ \\
\hline $\begin{array}{l}\text { Claremont Channel } \\
\text { Ship simulation }\end{array}$ & \multicolumn{2}{|c|}{$\begin{array}{l}\text { Numerical hydrodynamic modeling } \\
\text { TABS-MD }\end{array}$} & 16. PRICE CODE \\
\hline $\begin{array}{l}\text { 17. SECURITY CLASSIFICATION } \\
\text { OF REPORT } \\
\text { UNCLASSIFIED }\end{array}$ & $\begin{array}{l}\text { 18. SECURITY CLASSIFICATION } \\
\text { OF THIS PAGE } \\
\text { UNCLASSIFIED }\end{array}$ & $\begin{array}{l}\text { 19. SECURITY CLASSIFICATION } \\
\text { OF ABSTRACT }\end{array}$ & 20. LIMITATION OF ABSTRACT \\
\hline
\end{tabular}

